\title{
Rheological aspects of uteroplacental blood flow : a study in the awake late-pregnant guinea pig
}

Citation for published version (APA):

Verkeste, C. M. (1990). Rheological aspects of uteroplacental blood flow : a study in the awake latepregnant guinea pig. [Doctoral Thesis, Maastricht University]. Rijksuniversiteit Limburg. https://doi.org/10.26481/dis.19901206cv

Document status and date:

Published: 01/01/1990

DOI:

$10.26481 /$ dis. $19901206 \mathrm{cv}$

Document Version:

Publisher's PDF, also known as Version of record

\section{Please check the document version of this publication:}

- A submitted manuscript is the version of the article upon submission and before peer-review. There can be important differences between the submitted version and the official published version of record.

People interested in the research are advised to contact the author for the final version of the publication, or visit the DOI to the publisher's website.

- The final author version and the galley proof are versions of the publication after peer review.

- The final published version features the final layout of the paper including the volume, issue and page numbers.

Link to publication

\footnotetext{
General rights rights.

- You may freely distribute the URL identifying the publication in the public portal. please follow below link for the End User Agreement:

www.umlib.nl/taverne-license

Take down policy

If you believe that this document breaches copyright please contact us at:

repository@maastrichtuniversity.nl

providing details and we will investigate your claim.
}

Copyright and moral rights for the publications made accessible in the public portal are retained by the authors and/or other copyright owners and it is a condition of accessing publications that users recognise and abide by the legal requirements associated with these

- Users may download and print one copy of any publication from the public portal for the purpose of private study or research.

- You may not further distribute the material or use it for any profit-making activity or commercial gain

If the publication is distributed under the terms of Article $25 \mathrm{fa}$ of the Dutch Copyright Act, indicated by the "Taverne" license above, 


\section{RHEOLOGICAL ASPECTS OF}

\section{UTEROPLACENTAL BLOOD FLOW}

A study in the awake late-pregnant guinea pig 
The financial support by the Netherlands Heart foundation, Schering Nederland BV Glaxo BV. Ciba-Geigy BV. Talas BV and Organon Nederland BV for the publication of this thesis is greatfully acknowledged. 


\section{RHEOLOGICAL ASPECTS OF UTEROPLACENTAL BLOOD FLOW}

A study in the awake late-pregnant guinea pig

\section{PROEFSCHRIFT}

ter verkrijging van de graad van doctor aan de Rijksuniversiteit Limburg te Maastricht, op gezag van de Rector Magnificus, Prof.Dr F.I.M. Bonke, volgens het besluit van het College van Dekanen, in het openbaar: te verdedigen op donderdag, 6 december 1990 om 14.00 uur

door

Carla Marjon Verkeste

geboren op 6 december 1960 te Rotterdam 
Promotor: Prof.Dr J. de Haan

Co-promotor: Dr L.L.H. Peeters

Referenten: Prof. Dr H.A.J. Struyker Boudier, voorzitter Prof. Dr H. Schmid-Schönbein, Rheinisch Westfälische Technische Hochschule, Aken

Prof.Dr J.G. Aarnoudse, Rijksuniversiteit Groningen Prof.Dr G. Kootstra

Dr Ir. A.P.G. Hoeks

CIP-GEGEVENS KONINKIJJKE BIBLIOTHEEK, DEN HAAG

Verkeste, Carla Marjon

Rheological aspects of uteroplacental blood flow: a study in the awake late-pregnant guinea pig / Carla Marjon

Verkeste. - Maastricht : Datawyse. - III.

Proefschrift Maastricht. - Met lit. opg. - Met

samenvatting in het Nederlands.

ISBN 90-5291-040-5

SISO 605.5 UDC 612.1:612.63(043.3) NUGI 743

Trefw.: rheologie / bloedsomloop

Produktie en layout: Datawyse Maastricht, Ruud Leliveld Omslag ontwerp en illustraties: Raymond Ritzen Druk: Krips Repro Meppel 
Aan René 


\section{CONTENTS}

- Rheological aspects of blood flow . . . . . . . .99

1.1.a

1.1.b

$1.1 . \mathrm{c}$

1.1.c.1

1.1.c.2

$1.1 . \mathrm{d}$

1.1.d.1

1.1.d.2

1.1.d.3

1.1.d.4

1.1.d.5

1.1.d.6

1.2

$1.2 . \mathrm{a}$

$1.2 . \mathrm{b}$

$1.2 . \mathrm{c}$

1.2.c. 1

1.2.c. 2

1.2.c.3

1.2.c. 4

1.3

1.3. a

1.3.b

1.3.c

1.3.c. 1

1.3.c. 2

$1.3 . c .3$

1.3.c. 4

1.4

Vascular structure 9

Driving pressure 10

Viscosity:Basic principles and defenitions $\quad I I$

Newtonian fluids $\quad 1 l$

Non-Newtonian fluids $\quad 13$

Whole blood viscosity 13

Hematocrit 14

Erythrocyte deformability 14

Erythrocyte aggregation 16

Plasma viscosity 16

White blood cells $\quad 17$

Platelets 17

- Rheological aspects of uteroplacental blood flow in normal pregnancy

Placental structure 18

Driving pressure 18

Whole blood viscosity 20

Hematocrit 21

Erythrocyte deformability 22

Erythrocyte aggregation 22

Plasma viscosity 23

- Rheological aspects of uteroplacental blood flow in complicated pregnancy

Placental structure 23

Driving pressure 24

Whole blood viscosity 24

Hematocrit 25

Erythrocyte deformability 26

Erythrocyte aggregation 26

Plasma viscosity 26

. Aim of the study . . . . . . . . . . . . . 27 
2 Systemic leakage of $15 \mu \mathrm{m}$ radioactive microspheres over a period of 24 hours, in the awake late-pregnant guinea pig . 37

3 Relationship between maternal hemodynamics and hematocrit and hemodynamic effects of isovolemic hemodilution and hemoconcentration in the awake late-pregnant guinea pig . . 45

4 Nondeformable red cells do not interfere with uteroplacental blood flow in awake late-pregnant guinea pig . . . . . . 63

5 Increased red cell aggregation does not reduce uteroplacental blood flow in the awake hemoconcentrated late-pregnant guinea pig . . . . . . . . . . . . . . . . . 79

6 Uteroplacental blood flow appears to be autoregulated for hydrostatic pressure in the awake late-pregnant guinea pig . .89

7 Summary and conclusion . . . . . . . . . . . . . 101 Samenvatting en conclusies . . . . . . . . 105

Ter afsluiting . . . . . . . . . . . . . . . . 107 Curriculum vitae . . . . . . . . . . . . . . . . . 109 


\section{Introduction}

\begin{tabular}{|l} 
Abbreviations \\
Hct $=$ Hematocrit (vol\%) \\
IUGR $=$ Intra uterine growth retardation \\
PIH $=$ Pregnancy induced hypertension \\
PV $=$ Plasma viscosity $(\mathrm{Pa} \cdot \mathrm{s})$ \\
RBC $=$ Red blood cell \\
UBF $=$ Uteroplacental blood flow $\left(\mathrm{ml} \cdot \mathrm{min}^{-1}\right)$ \\
WBC $=$ White blood cell \\
WBV $=$ Whole blood viscosity $(\mathrm{Pa} \cdot \mathrm{s})$
\end{tabular}

\subsection{Rheological aspects of blood flow}

\section{1.a. Vascular structure}

Blood has a transport function, and as the metabolic rate varies with tissue function, local blood flow is adjusted accordingly. Several mechanisms are involved in the regulation of local blood flow (1). Long-term control, over a period of days, weeks or months, is established by an increase or decrease in the sizes and density of functional blood vessels. Rapid changes, in seconds to minutes, are predominantly regulated by the arterioles proximal to the precapillary sphincters. The pattern of opening and closure of the precapillary sphincters can be explained by the following 2 theories: a) The vasodilator theory: Vasodilating substances which are formed during the normal oxydative metabolism diffuse back to the area surrounding the precapillary sphincters, 
metarterioles, and arterioles where they induce relaxation and hence, dilatation. b) The oxygen demand theory: A lower oxygen availability for local oxidative metabolism diminishes the strength of contraction of the precapillary sphincter.

From the Hagen-Poiseuille equation the rate of volume flow can be calculated (equation 1):

$$
Q=\pi \cdot \frac{\Delta P}{l} \cdot \frac{r^{4}}{8 \eta} \quad\left[\mathrm{ml}_{.} \sec ^{-1}\right]
$$

Provided that fluid movement in a tubular system is laminar and non-pulsatile the Hagen-Poiseuille equation can be applied. This equation indicates that volume flow (Q) is determined by: 1) The pressure gradient $(\Delta \mathrm{P})$ along a tube, 2) the geometry length and radius of the tube ( 1 and $r$, respectively) and 3 ) the viscosity of the fluid $(\eta)$. The Hagen-Poiseuille equation is often used for estimation of organ blood flow. However, the organ blood flow calculated with this equation should be interpreted with caution, particularly since 2 parameters in the equation, geometry and whole blood viscosity (WBV), are related to one another in a complex and unpredictable fashion. In this chapter the literature regarding WBV and its interaction with the microcirculation is reviewed. On the basis of the available information the physiological impact of WBV on blood flow will be discussed.

\section{1.b. Driving pressure}

Most vascular beds have an intrinsic capacity to compensate for moderate changes in perfusion pressure. This phenomenon is uniformly termed "autoregulation", and is defined as the intrinsinc capacity of a tissue to modulate vascular resistance in response to changes in perfusion pressure in such a way, that volume flow and fluid exchange in the capillaries bed preserved. Autoregulation has been demonstrated in the kidney (2), brain (3), myocardium (4), pkeletal muscle (5) and intestines (6) Two hypotheses have been proposed to explain the mechanism of autoregulation: A) Myogenic theory: Blood vessels are distended in response to a rise in pressure. The resulting mechanical stretch of the tunica media triggers the smooth muscle fibers to contract. B) Metabolic theory: A decrease in perfusion pressure leads to a fall in tissue flow and, with it, accumulation of metabolites. The latter induces vessel dilatation and thus a fall in vascular resistance. The circle is closed by the subsequent wash-out of accumulated metabolites and restoration of the initial flow rate (1). Further details about the autoregulatory response are given in chapter 6 . 


\section{1.c. Viscosity: Basic principles and definitions}

\section{1.l.c.l. Newtonian fluids}

On the molecular level, a fluids' intrinsic resistance to flow represents the energy loss arising when molecules from different flow velocity layers slide (shear) along each other, when the fluid is brought into motion. Newton defined this measurable physical property as "viscosity". An understanding of the thin fluid layers moving along each other with different velocities, is illustrated in figure 1 by a deck of playing cards. If the upper card is tipped with the finger one can create a velocity gradient. Namely, the upper card is displaced over the greatest distance while the bottom card remains still. The cards are sheared along each other, the shear induced by the tip of the finger. The shear force per unit of area is called shear stress. The difference in velocity between two cards represents shear rate. A more physical understanding of the term viscosity is provided by figure 2 . The horizontal pushing force divided by the surface area (F/A) of the fluid layer is termed the shear stress $(\tau)$. Shear stress is expressed in Pascal $(\mathrm{Pa})$. The velocity gradient, or shear rate $(\gamma)$, is the difference in velocity between 2 fluid layers with respect to their in-between distance $(\mathrm{dv} / \mathrm{dx})$, expressed in reciprocal seconds $\left(\mathrm{s}^{-1}\right)$. The flow velocity is zero at the
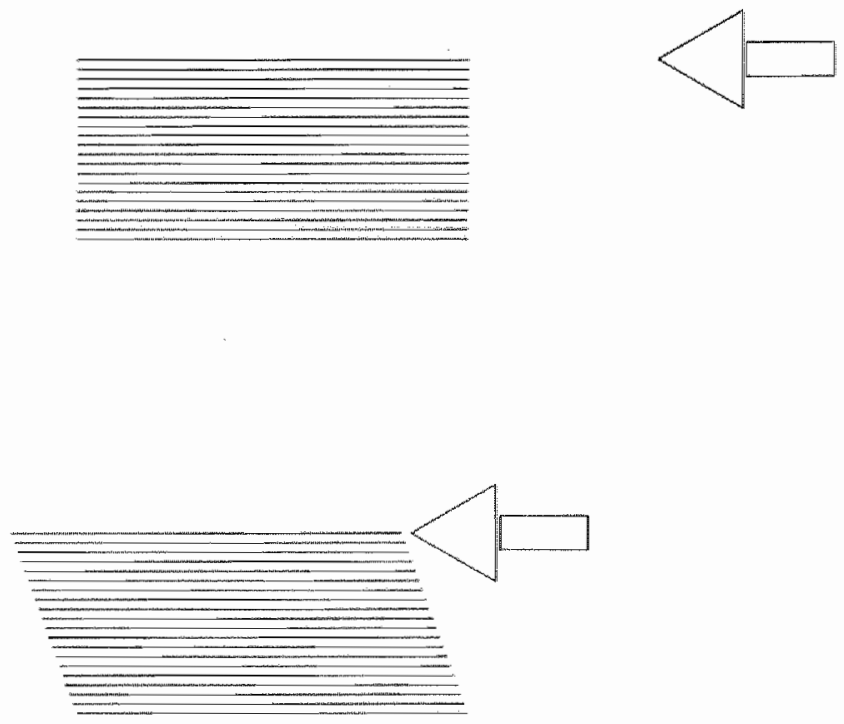

Figure 1

Schematical presentation of the concept shear 
wall and maximal in the axial portion of a tube. A larger force (driving pressure) will induce a larger displacement per unit time, of the fluid layers relative to one another. In a tubular representation the latter implies that the velocity gradient perpendicular to the direction of flow will be higher.

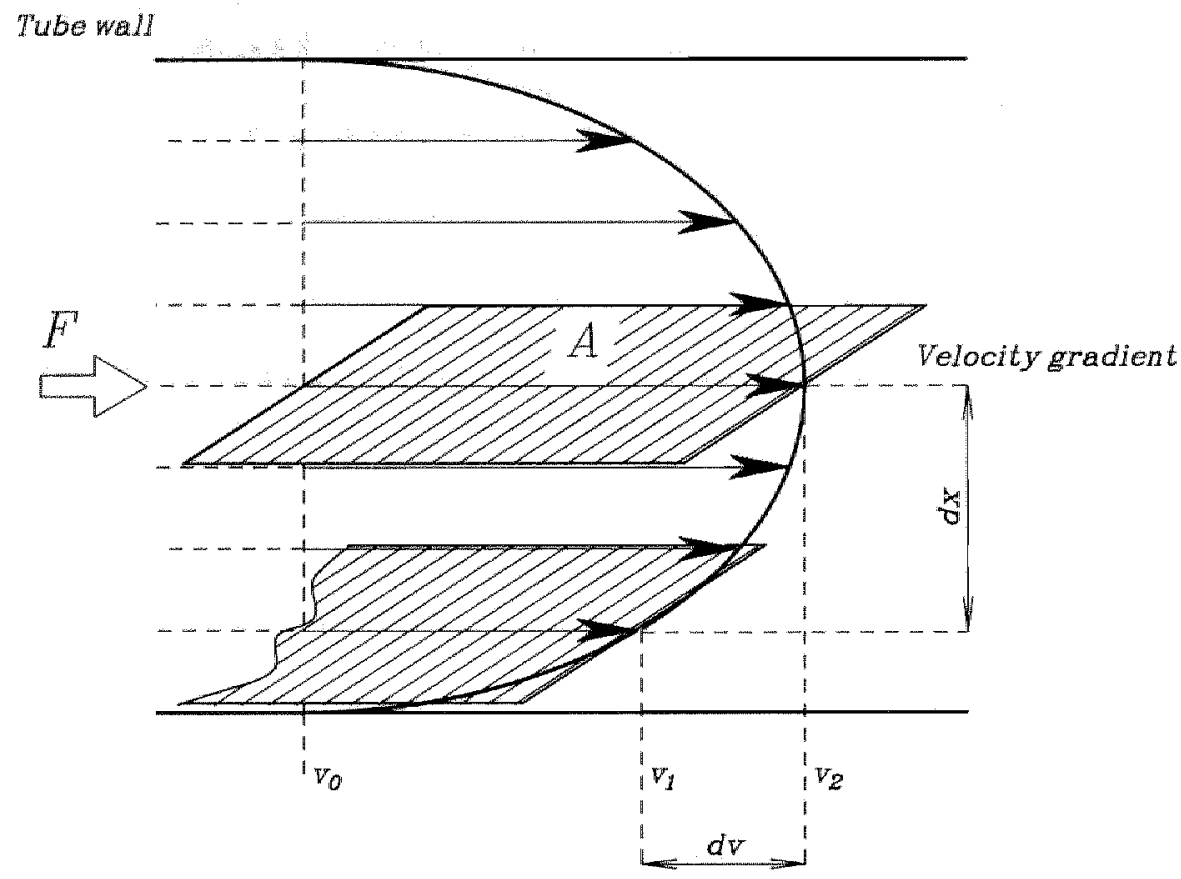

Figure 2

Cross section of a cylindrical tube showing the velocity profile in laminar flow

Viscosity $(\eta)$ is defined as the ratio between shear stress and shear rate $(\tau / \gamma)$ and can be expressed in centiPoise (cP) (equation 2). However, it is more common to express the viscosity in Pascal second $(\mathrm{Pa}, \mathrm{S})$. One Pascal second is the equivalent of 1000 centiPoise.

$$
\text { Viscosity }(\eta)=\text { Shear stress }(\tau) / \text { Shear rate }(\gamma)
$$

Water, oil and plasma are "Newtonian" fluids. This indicates that they show a linear relationship between shear stress and shear rate. That is to say, their viscosity varies independently of shear rate. 
Rheology is the science that is engaged in the study of the intrinsic (viscosity) and extrinsic (interaction with surrounding) flow properties of a fluid. In biology, rheology deals with the study of these flow properties in the macro and microcirculation.

\section{1.c.2. Non-Newtonian fluids}

Non-Newtonian fluids can be subdivided into: Pseudoplastic- (e.g. paint), Dilatant- (e.g. wet cement), Bingham- (e.g. toothpaste), Visco-elastic- (e.g. polymeres) and Casson fluids (e.g. blood). They all have in common that the relation between shear rate and shear stress is nonlinear, often a result of shear-stress dependent changes in the configuration of asymmetric molecules. Each type of non-Newtonian fluid has its own specific mathematical relationship between shear stress and shear rate, and thus between viscosity and shear rate.

\section{1.d. Whole blood viscosity}

Blood is a non-Newtonian Casson fluid as indicated by the increase in viscosity in low shear conditions, as opposed to a viscosity almost equal to that of plasma when the shear rate is high. The non-Newtonian behavior of blood as demonstrated in figure $3 a$ and $b$, is caused by the physical changes that occur in the suspended erythrocytes when the exerted shearing forces change. As a rule of thumb the internal resistance of any suspension of rigid particles increases with particle density. For blood this means that the viscosity increases as a function of the hematocrit (Hct, vol\%). Superimposed on this relationship is the
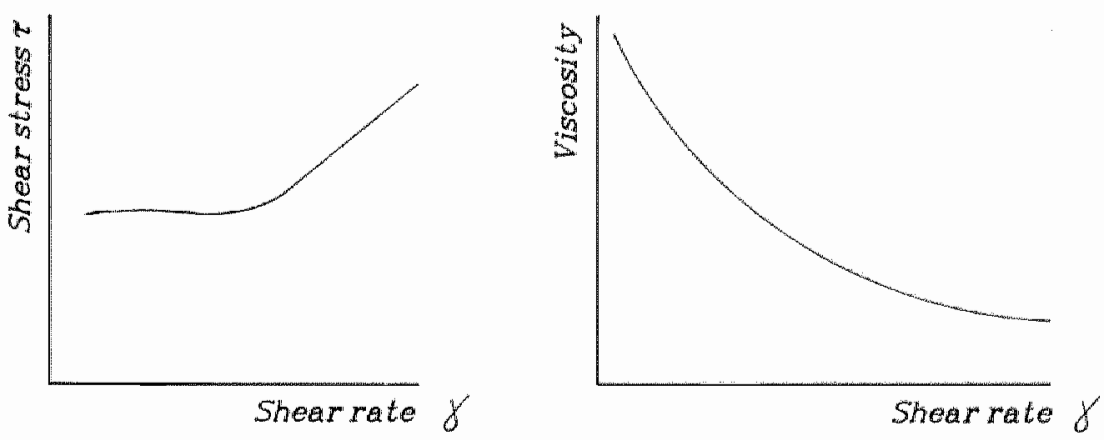

Figure $3 A$ and $B$

A. Relationship between shear stress and shear rate for normal blood.

$B$. Relationship between viscosity and shear rate for normal blood 
impact of the physical change in individual blood cells induced by different shearing conditions, more specifically, the impact of RBC deformability and aggregability, white cell density and properties, tendency of platelets to adhere and the concentration of certain proteins in the plasma such as fibrinogen and macroglobulines (7). As the viscosity of blood varies with shear condition it is important to emphasize that WBV in the macrocirculation may differ from that in the microcirculation in an unpredictable fashion. This makes it extremely difficult to speculate about the influence of local WBV upon tissue rheology. A practical consequence of the latter is that WBV should be measured at different shear rates which requires complex and expensive viscometers (8).

\section{1.d.1. Hematocrit}

Hct is not constant throughout the vascular system but rather falls with decreasing vessel diameter and increasing shear rate. This causes the so-called the Fahraeus-Lindqvist effect (9) which is defined as the decline in viscosity with decrease in vessel diameter. The Fahraeus-Lindqvist effect is related to the tendency of red blood cells (RBCs) to migrate towards the axial portion of a vessel which provokes a higher velocity of cells relative to that of the plasma. The velocity difference between cells and plasma indicates that RBCs pass a vessel more rapidly than plasma. This implies that at any given time, the fraction of cells in the vessel will be lower than that of plasma when compared to the no-flow state. This so-called "autodilution" is most important in arteries and arterioles with a diameter of less than $\approx 100 \mu \mathrm{m}$, reaching its largest effect in vessels with a diameter of $\approx 15-20 \mu \mathrm{m}(9)$. The viscosity-lowering effect of autodilution is potentiated by the lubricating effect of the plasma layer that forms between the rapidly moving cells and vessel wall.

\section{1.d.2. Erythrocyte deformability}

The biconcave discoid shape that the RBC adopts in conditions of zero shear force represents the form in which minimum bending energy is needed (10). It is however not clear how the RBC achieves its biconcave shape. It has been suggested that probably two membrane forces are involved (11). A force that tends to form the smallest surface for the enclosed volume on the one hand and a force that tends to form an extended, stretched surface on the other. The RBC membrane is a complex structure able to mold into a kaleidoscope of shapes without membrane fragmentation, depending on the magnitude and duration of applied stress exerted on its surface. This property is referred to as RBC deformability and represents a parameter which can be quantitated from the 
relationship between shear stress on the one hand, and the ratio between surface area and cell volume on the other. The flexibility of the RBC serves the following functional purposes:

1 It reduces the resistance of RBCs during their passage of the smallest vessels of the microcirculation.

2 It improves the cell-to-wall contact in the capillaries thus favoring gas exchange with the surrounding tissue.

3 It reduces friction among RBCs in flowing blood.

The overall effect of these characteristics is a lower blood viscosity, particularly in high shear conditions. The flexibility of the $\mathrm{RBC}$ is determined by the stiffness of the cell membrane and that of the cytoplasma. These 2 parameters are determined independently from each other by the membranes" phospholipid composition and the degree of packing of the intracellular hemoglobin, respectively (11-14). Other factors, such as intracellular $\mathrm{Ca}^{2+}$ and ATP content and aging of the cell, may also influence $\mathrm{RBC}$ deformability $(15,16)$. In vivo it is extremely rare that the RBC assumes its discoid shape since such a form occurs only when shear forces are close to zero. In capillaries the RBC folds along a longitudinal axis assuming an asymmetrical shape, which can only be maintained if the membrane continuously moves around its cytoplasm in a proces referred to as "tank treading". In addition, in high shear conditions the RBC alignes its axis along the direction of flow in order to obtain an "aerodynamic" shape, thereby reducing the friction between $\mathrm{RBCs}$ and with it, the bloods" internal resistance to flow. When RBCs are suspended in hypertonic salt solutions, the osmotic loss of intracellular water reduces cell volume and causes notching of the cell membrane (11). Both damaged cells $(13,14,17,18)$ and $\mathrm{RBCs}$ with a reduced deformability $(19-21)$ are removed from the circulation. The difference in size between these 2 types of cells suggests that their removal from the circulation is not accomplished by simple filtration but by some more sophisticated selection process (18).

The conflicting results reported with respect to $\mathrm{RBC}$ deformability in different conditions are in part related to its complex measurement technique which is hampered by a low reproducibility. However, this low reproducibility may be partly caused by the lack of standardization in Hct, plasma proteins and leucocyte count in these studies. The methods introduced so far, are based on quantitation of either 1 . the filterability through $5 \mu \mathrm{m}$ pores, or 2 . the elongation index by a) a cone-plate rheoscoop, b) a laser diffractometer, c) micropipette aspiration (12). 


\section{1.d.3. Erythrocyte aggregaition}

Another property of RBCs with an important impact on WBV is the tendency of RBCs to aggregate into long reversible aggregate complexes (Rouleaux formations) in conditions of low shear rate $\left(\gamma \leq 60 \mathrm{~s}^{-1}\right)(22,23)$. Rouleaux formation, is a result of bridging of cell surfaces by the plasma fibrinogen and globulins. The mechanisms that enable the reversable binding is still subject to discussion. It has been suggested that binding is accomplished by Brownian motion (24). However, the following explanation is more commonly supported. The RBC has negative electric charges mainly due to the presence of $\mathrm{N}$-acetylneuraminic acid. These charges represent the electric repulsive energy of the $\mathrm{RBC}$. These repulsive forces are counterbalanced by forces that promote adherence of RBCs. They are caused by the reversible interaction in low shear condition between RBCs and plasma proteins with a high molecular weight and a large assymmetrical spatial structure, such as fibrinogen and some macroglobulines, to link RBCs to one another by protein bridges. When two RBCs approximate and the aggregating force exceeds the one comprised in the electric repulsive energy, the $2 \mathrm{RBCs}$ will aggregate. In steady state most of the net aggregation energy is stored in the membrane as membrane strain energy. The release of this strain energy alters the shape of the $\mathrm{RBC}$ after incorporation in a rouleaux. Fibrinogen acts as the molecular bridge between two erythrocytes. Without fibrinogen the tendency of RBCs to aggregate is almost absent. Specific instruments have been developed to quantitate erythrocyte aggregability. Syllectometry, erythrocyte sedimentation rate (ESR) and zeta sedimentation rate (ZSR) are described as such. The principles, possibilities and limitations of these measurements are detailed elsewhere (25).

\section{1.d.4. Plasma viscosity}

Plasma viscosity (PV) and serum viscosity are mostly determined by the plasma protein composition and the temperature. Plasma and serum behave like Newtonian fluids except in case of some rare conditions in the presence of paraproteins $(8,26)$. The PV provides useful information in the screening for organic diseases and is a sensitive monitor of disease activity. Apart from its diagnostic uses, PV is an important, but neglected determinant of blood flow in vivo (27), and hence has physiological and pathophysiological relevance. Plasma is a suspension of proteins and smaller molecules in water. The suspended molecules disturb the fluid streamlines during flow, requiring increased dissipation of energy, and thus increasing viscosity. PV correlates with total plasma protein, but the correlation is poor, due to greatly differing effects of each type 
of protein $(28,29)$. The influence of a particular protein on PV increases with its concentration, size and asymmetry (ratio between length and diameter). PV is quantitated by standard capillary viscometry (30).

\section{1.d.5. White blood cells}

Although the concentration of white blood cells (WBCs) is low, they are likely to play an important role in the rheologic properties of blood, especially in the microcirculation (31). A better understanding of the impact of WBCs on the bloods' flowing properties can be obtained when their geometric features and viscoelastic properties are considered. The $\mathrm{WBC}$ has an overall spherical shape, is larger and less deformable than RBCs (32). Due to the presence of membrane foldings the WBC has is a larger membrane-to-volume ratio as compared to the RBC. The differences in physical characteristics between red and white blood cells have an important effect on the hemorheological properties in the microcirculation: In high flow states, when the RBC are dispersed, the larger WBCs are allowed to migrate to the axial portion of the vessel, thus increasing WBC velocity and reducing intravascular WBC concentration. Contrarily, in low flow states; the WBCs are pushed towards the vessell wall by the RBC aggregates which tend to occupy the axial portion of the vessel. These rheological events in low flow states favor WBCs to adhere or roll along the vessel wall. WBCs can even actively move in the opposite direction to the flow along the vessel wall. The WBCs are especially prone to make contact with the endothelium in the venular system where they respond to chemotactic agents released by the endothelial cells. The interaction of WBCs with the vessel wall could be the most important cause of the abnormally high vascular resistance observed in inflammation, shock and other low flow states $(33,34)$.

\section{1.d.6. Platelets}

A circulating platelet has a discoid (plate-like) shape. Due to their relatively small diameter $(2-3 \mu \mathrm{m})$ and low concentration in the blood it is not surprising that platelets play a negligible role in hemorheology. Platelets may become critical for the flow properties of blood in vessels with a diameter as small as that of the platelet. However, unlike RBCs, platelets have several distinct characteristics which permit them to alter flow in larger vessels as well. An example is the ability of the platelets to attach to various surfaces, particularly of damaged vessel walls. In addition, in response to certain stimuli they will dramatically increase their tendency to stick to each other to form clusters of particles (microthrombi) or even thrombi, which may occlude the vascular lumen (35). 


\subsection{Rheological aspects of uteroplacental blood flow in normal pregnancy}

\section{2.a. Placental structure}

The placental microcirculation is divided into two parts, the maternal and the fetal circulation. The fetal circulation is a capillary system and therefore the flow properties within this circulation can be expected to resemble those described for other capillary beds. In contrast, the maternal (intervillous) circulation is a porous system (36), in which the Fahraeus-Lindqvist effect is generally assumed not to be operative. In addition, this structure is considered to be deprived of autoregulation $(37,38)$. Recently, the following hypothesis has been proposed to describe the flow properties of blood in this peculiar intervillous microvasculature (36). In such an exchange system optimal diffusion conditions are reached at the expense of external low mechanical energy dissipation. The mechanical energy requirement of any circulation amounts to the product of driving pressure and flow rate. It is known from chromatographic columns how little power is needed to maximize an exchange area when a fluid passes through the voids between small spheres, a typical example of a porous material (39). This implies that the unique structure of the uteroplacental vascular bed is optimal for gas exchange with a minimum of power. The shear forces in the intervillous space have been estimated (40). The villi behave like small obstacles in current blood causing intermittent condensation of the flowing fluid laminae (figure 4). This flowing pattern leads to frequent accelerations and decelerations of associated convergent and divergent fluid laminae, respectively. As a consequence, such a conduit system couples a somewhat higher shear stress to a lower shear rate, in contrast to a capillary system where probably comparable shear stress is coupled to a much higher shear rate (41). The lower shear rate at maintained shear stress in the intervillous space serves to optimize gas exchange by extending the exposure time of maternal RBCs to the exchange membrane while maintaining the closest possible contact (40).

\section{2.b. Driving pressure}

Various attempts have been made to assess the autoregulatory response of the uteroplacental circulation. So far, the results of these studies have been conflicting. In sheep the uteroplacental circulation seems to behave passive as the blood flow changes in proportion to the changes in perfusion pressure 


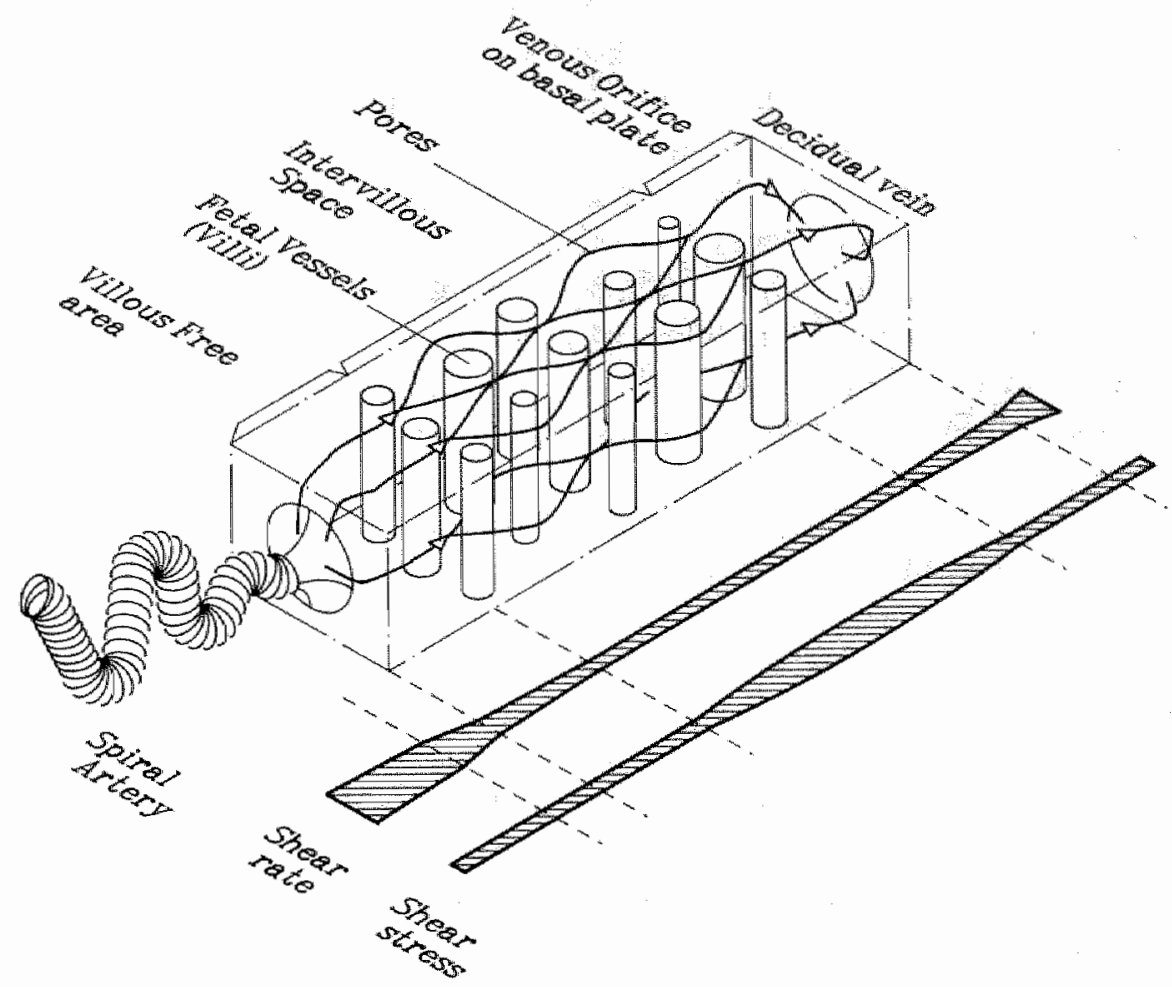

Figure 4

Hypothetical presentation of the perfusion through the intervillous space

without significant alterations in the vascular resistance (42-44). This has also been demonstrated in the anesthetized guinea pig (45). Contrarily, the placentas of both anesthetized and awake rabbits appear to exhibit some form of autoregulation $(46,47)$. The problem of the flow-pressure interrelationship in the pregnant uterus is difficult to investigate. However, it is generally assumed that the uteroplacental vascular bed not only lacks autoregulation but also lacks active mechanisms to regulate its own blood supply. A lack of autoregulation implies that uteroplacental blood flow (UBF) varies as a function of the uteroplacental pressure gradient $(46,47)$. However, in most studies a possible relationship between UBF and arterial blood pressure may have been blurred by side effects of anesthesia and the pharmacological agents used to induce blood pressure changes. Therefore, conclusive data on the shape of the flow-pressure curve and thus on the autoregulatory response of the hemochorial placenta is still lacking. Theoretically, the placenta should have some form of autoregulation since instability of the hydrostatic pressure gradient over the intervillous space will 
also affect the fluid exchange across the villous surface (1). It is conceivable that the latter is unfavorable for the placentas' exchange function e.g. through the development of villous edema or dehydration. If the placenta is assumed to be autoregulated the anatomical difference between a porous and capillary microarchitecture can be considered trivial with respect to function. In that case the regulation of vascular resistance only differs by the site of resistance vessels. In fact, in species with a hemochorial placenta $80 \%$ of the uteroplacental resistance is located in the radial arteries and the proximal portion of the spiral arteries while the pressure in the spiral artery is comparable to the one in the proximal portion of a capillary $(45,48,49)$.

\section{2.c. Whole blood viscosity}

According to Poiseulles' law the perfusion of tissue varies as a function of driving pressure, vascular geometry and the reciprocal of blood viscosity. The resistance vessels proximal to any microcirculation are responsible for most of the resistance to flow. Superimposed on the latter is the effect of the actual bloods' viscosity, which may vary widely between different sites depending on local shear forces, vascular geometry and blood composition. The impact of WBV upon local blood flow depends on the local shearing forces exerted on the blood. The importance of blood rheology seems largest in conditions of "slow flow" when blood can be treated as a continuum exposed to relatively low shear stress. In contrast blood rheology seems to play a modest role in arteries and arterioles as the flow velocity is generally so high that blood behaves like a Newtonian fluid with a viscosity approaching that of plasma $(7,50)$. However, when shearing forces are not modulated by vasomotor control, autoregulation, and/or when the Fahraeus-Lindqvist phenomenon is absent, as may be the case in the porous placenta (see paragraph 1.2.a), the impact of WBV on blood flow may become important, more so when also blood supply is marginal (27). While the resistance to flow proximal to the intervillous space is mainly of vascular origin, the resistance to flow within the intervillous space is probably predominantly determined by hemorheological factors. Particularly in these conditions improvement of the bloods' fluidity could ameliorate impaired tissue perfusion (36). On the basis of ex-vivo measurements, it has been demonstrated that in the first and second trimester of pregnancy the WBV declines to reach a nadir at 28-30 weeks. In the last 2 months of pregnancy WBV increases again $(51,52)$. The most important cause of the observed early changes is probably the fall in maternal Hct associated with the physiologic hemodilution $(52,53)$. However, the understanding of the in-vivo impact of hemorheology specially on UBF is 
limited. For instance, it is still obscure whether the pathologically increased WBV in complicated pregnancy is a cause or an effect of the compromized UBF.

\section{2.c.l. Hematocrit}

As mentioned above in the first and second trimester of pregnancy WBV follows closely the gradual decrease in Hct (53-55). Although it is still obscure why the plasma volume compartment expands in the course of pregnancy, a possible reason for this physiological hemodilution may be that the oxygen transport in microcirculations with low flow such as the placenta, improves when Hct is lower (figure 5). To our knowledge, it is still unclear whether an imposed reduction in Hct leads to a rise in UBF as the role of WBV on placental resistance is still unsettled.

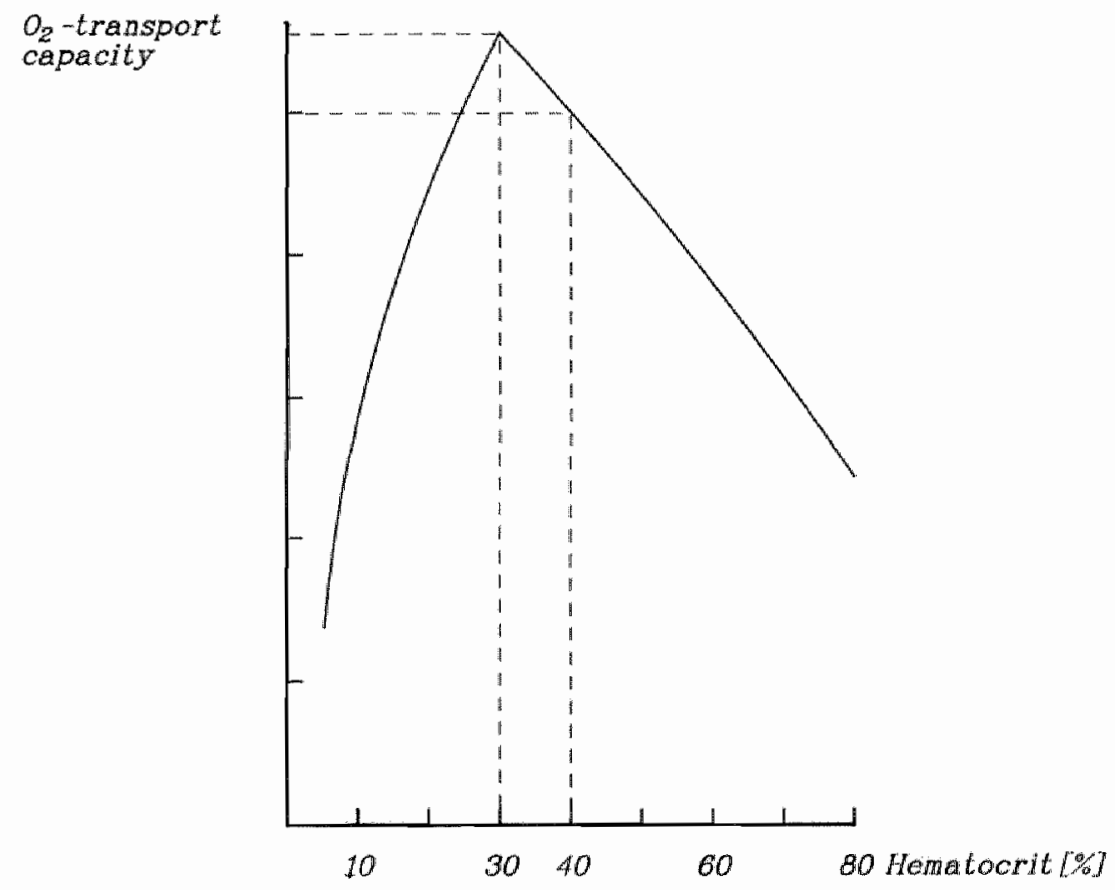

Figure 5

Relationship between $\mathrm{O}_{2}$-transport capacity and hematocrit 


\section{2.c.2. Erythrocyte deformability}

The question as to how (human) pregnancy affects erythrocyte deformability is still unsettled, as indicated by reports claiming an unchanged (56-59), an increased $(51,59-62)$ or a decreased RBC deformability $(63,64)$ in the course of pregnancy. The controversy with respect to $\mathrm{RBC}$ deformability in normal pregnancy may be purely technical, associated with its complex measurement and modest reproducibility. It has been suggested that the following accompanying phenomena may diminish $\mathrm{RBC}$ deformability in pregnancy.

1 A direct effect of placental steroids on the cell membrane $(63,65)$.

2 The larger RBC volume in pregnancy $(66,67)$.

The more spherical shape of the $\operatorname{RBC}(67,68)$ as well as its higher resistance to hemolysis as compared to the nonpregnant state (69) comply with these structural changes in the RBC. However, the increase in osmotic fragility of the $\mathrm{RBC}(70)$ cannot be explained by this latter hypothesis. Some authors reported that RBC deformability increased as a function of plasma fibrinogen levels (59), an observation which could not be substantiated by others (57). Also with respect to a possible correlation between $\mathrm{RBC}$ deformability and fetal outcome conflicting data have been reported $(57,64)$.

The conflicting data reported on $\mathrm{RBC}$ deformability in pregnancy are at least in part related to the technical complexity of the techniques to measure $R B C$ deformability (see also section 1.1.d.2.). Therefore, data on RBC deformability in pregnancy and their consequences for hemodynamics, particularly UBF, should be interpreted with caution.

\section{2.c.3. Erythrocyte aggregation}

The blood in the intervillous space has been described as a creeping flow through a porous medium in which shear forces are thought to be exceptionally low thus favoring the formation of RBC aggregates $(40,59,71)$. Particularly in the $2^{\text {nd }}$ half of pregnancy plasma fibrinogen increases $(55,72-74)$, which facilitates the formation of $\mathrm{RBC}$ aggregates. If indeed RBC aggregates are easily formed, acceleration in their formation in response to some unknown trigger is likely to induce a rise in the vascular resistance within the intervillous space. However, the probably non-laminar flow pattern in the intervillous space and frequent acceleration and decelerations of RBCs in this microstructure suggests that the rheological conditions in this microcirculation are less favorable for the formation of RBC aggregates than e.g. in capillary microcirculations. The latter implies that a rise in aggregability of RBCs may have a much more modest impact on the UBF in nomal pregnancy than previously suggested (36). 


\section{2.c.4. Plasma viscosity}

In normal human pregnancy the changes in plasma proteins appear to be carefully regulated. There is a gradual fall in total protein due to a decrease in the albumin concentration which in the first 6 months of pregnancy is partially compensated by small increases in both globulins and fibrinogen. The effect of the changes in protein levels on the PV is small and variable (53). Only in the last trimester there appears to be a modest increase (75) which has been attributed to the rise in the plasma levels of fibrinogen and large plasma proteins $(51,55,61)$. Whether the PV influences the perfusion of the intervillous space is unknown. The opposite changes in plasma and WBV in the first and second trimester of pregnancy suggest that the UBF changes little in response to variations in $\mathrm{PV}$.

\subsection{Rheological aspects of uteroplacental blood flow in complicated pregnancies.}

\section{3.a. Placental structure}

Fetal compromise is often a result of inadequate transplacental oxygen uptake due to uterine vascular insufficiency. Unfortunately, fetal compromise becomes only manifest after that fetal compensatory mechanisms have become exhausted and the demand of the fetus for $\mathrm{O}_{2}$ and nutrients begins to exceed the supply. It is not clear whether the origin of this insufficiency dates back to the events initiated by malimplantation of the blastocyst in the endometrium, or whether it develops secondary to inadequate maternal metabolic and hemodynamic adaptation in early pregnancy. It has been suggested that the lack of a trumpet-shape widening of the spiral arteries towards the outlet into the cotelydon predisposes for later development of preeclampsia and/or intra uterine growth retardation (IUGR) (76,77). This morphological feature may be a prerequisite for optimal expansion of the uteroplacental vascular bed. The absence of an internal elastic layer, caused by erosion of the vessel wall in early pregnancy, appears to be specific for the spiral artery in the pregnant uterus and serves the purpose to dampen the variations in perfusion pressure across the placental microcirculation (78). It is not clear to what extent these unique changes in the spiral arteries contribute to the pathogenesis of the central hemodynamic disturbances as seen in pregnancy induced hypertension (PIH) and preeclampsia. The poor understanding of the pathogenesis of these syn- 
dromes is caused by the late development of the typical clinical signs (79). E.g. terminal villi show enhanced proliferation in these patients (80). However, the description of these histological changes contribute little to the understanding of the etiology of the disease as they are likely to be induced by the disease process itself.

\section{3.b. Driving pressure}

The hypertensive response in PIH which is possibly triggered by renal hypoperfusion and stress-related release of catecholamine, is considered to be a compensatory mechanism which protects the marginal UBF against a further decrease $(76,81)$. Therefore, the hypertension in PIH and preeclampsia is believed to be beneficial for the growing fetus. However, on the basis of section 1.2.b. it can be derived that an increase in driving pressure would disturb the hydrostatic pressure in the intervillous space with adverse consequences for the fluid flux across the trophoblastic membrane (see also section 1.2.b.). Therefore, the hypertension in PIH/preeclampsia is likely to be a symptom of this disease with yet obscure effects on the UBF.

\section{3.c. Whole blood viscosity}

It has been suggested that local platelet activation within the uteroplacental microvasculature, rather than rheological abnormalities, causes the disturbed uteroplacental microcirculation in complicated pregnancies (56). Nevertheless it has been demonstrated that maternal hemorheology is impaired in PIH and preeclampsia many weeks before clinical symptoms become manifest (82). There is also a direct relationship between changes in the flow properties and secondary morphological findings in the placenta. Amelioration of the flow properties of blood in the intervillous space may improve gas exchange at unchanged total volume flow (83). It is not clear whether structural alterations precede those in hemorheological parameters in the pathogenesis of IUGR/preeclampsia. The experimental data on WBV in the studies reported so far are based on measurements in blood ex vivo, which means that they provide no information on the role of unfavorable hemorheology in its relation to local microvascular changes. On the basis of the available information, hemorheological alterations do not seem to be the cause of complicated pregnancies, but are likely to develop in concert with other factors such as platelet activation (56) and atherosclerotic vascular lesions $(77,84)$. At any rate preeclampsia and 
IUGR have often been described as being associated with an increased WBV $(61,74,85-89)$. However, it is still obscure whether the latter aggravates the disease or is merely an insignificant side effect.

\section{3.c.l. Hematocrit}

In complicated pregnancies the $\mathrm{RBC}$ density is significantly elevated $(69,87$, $88,90,91$ ). In these pregnancies the magnitude by which the Hct is elevated correlates closely with BP and peripheral vascular resistance (69). The cause of the rise in Hct in complicated pregnancies appears to be either hemoconcentration secondary to extravasion of plasma in the systemic microcirculation or inadequate plasma volume expansion (92). The absence of the viscosity-lowering effect of the Fåhraeus-Lindqvist phenomenon suggests that a rise in maternal systemic Hct is particularly unfavorable for the intervillous perfusion. In chronic obstructive vascular diseases in which WBV is elevated, isovolemic hemodilution has been demonstrated to ameliorate microcirculatory hypoperfusion. Preeclampsia and IUGR resemble these diseases since the overall systemic flow rate is reduced while WBV is increased as evidenced by the rise in Hot, enhanced RBC aggregation and reduced RBC deformability. Hemodilution can be beneficial in these complicated pregnancies since it lowers WBV by: 1 a lowering effect on plasma fibrinogen,

2 a lowering effect on the Hct, and

3 an overall increasing effect on shear rate.

Figure 6 shows the relationship between the maximum $\mathrm{O}_{2}$-transport capacity and Hct. It follows that in conditions characterized by low systemic flow and hemoconcentration, isovolemic hemodilution may lead to a better circulatory

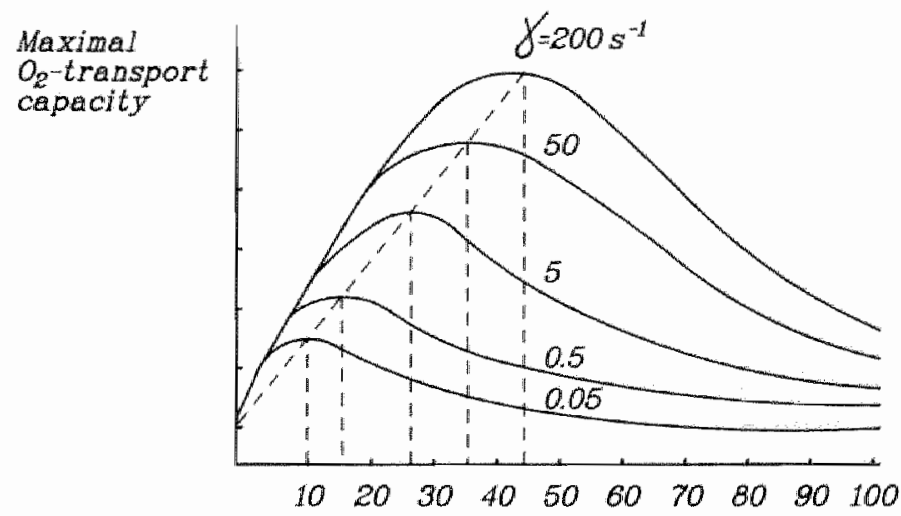

Henatocrit [\%]

Figure 6

The relationship between a maximal $\mathrm{O}_{2}$ - transport capacity and hematocrit at five different shear rates 
function as tissue perfusion and $\mathrm{O}_{2}$-supply are improved (93). However, in preeclampsia the hemoconcentration is often paralleled by a markedly reduced plasma volume. In this condition treatment by plasma volume expansion prewails over isovolemic hemodilution. Such a management requires careful hemodynamic monitoring of the blood volume, e.g. end-diastolic filling pressure to prevent overfilling.

\section{3.c.2. Erythrocyte deformability}

The impact of preeclamptic pregnancy or IUGR, on deformability is still unsettled $(56,61,69,87,88,94,95)$. The complexity of the measurement technique for RBC deformability is likely to have contributed to this controversy (see also section 1.1.d.2.). However, to our knowledge the in-vivo effect of reduced $\mathrm{RBC}$ deformability on UBF has not been investigated. Theoretically, one could speculate that a lower RBC deformability facilitates entrapment of the $\mathrm{RBCs}$ in the smaller pores of the intervillous microarchitecture. The lower overall density of open pores implies an increased resistance to flow. This hypothesis can only be tested experimentally by demonstrating that a higher placental entrapment of less deformable RBCs relative to normal RBCs is paralleled by a reduced UBF.

\section{3.c.3. Erythrocyte aggregation}

In normal pregnancy there is an increased blood level of fibrinogen. In preeclampsia and IUGR fibrinogen concentrations have increased to levels above those of normal pregnancy $(86,92,96)$. This effect not only may increase PV $(69,74)$ but is also likely to contribute to the increased aggregability of the RBCs. The latter could lead to formation of large solid aggregates of erythrocytes, which act as emboli and thus provide a possible explanation for the fundamental vascular disturbances in preeclampsia (92). Fibrin deposition observed in the uteroplacental blood stream $(97,98)$ supports the theory for an increased RBC aggregability in the intervillous space.

\section{3.c.4. Plasma viscosity}

In complicated pregnancies PV has been described to be both higher $(74,87$, 99-101) and unchanged $(56,61,88)$. It is not clear whether a possible increase in PV can be entirely attributed to a rise in fibrinogen levels since some studies were unable to demonstrate a rise in complicated pregnancies $(59,102,103)$. Therefore, it is likely that serum globulins play an as important role in these pregnancies as fibrinogen. Since the uteroplacental blood stream appears to be a preferential site for fibrin(ogen) deposition $(97,98)$, it is possible that local PV 
differs from the PV in the central portion of the circulation. This would complicate the interpretation of changes in fibrinogen levels with respect to their impact on uteroplacental perfusion.

\subsection{Aim of the study}

In any circulation the vessels proximall to the microcirculation are responsible for the flow resistance. The impact of WBV upon local blood flow depends on the local shearing forces exerted on the blood. Blood rheology is likely to play a modest role in those sites of the circulation where the shear rate is high and vessel diameter is clearly larger than the size of the blood cells. The resistance in the arteries supplying the placenta is mainly determined by vascular geometry. However, the resistance in the intervillous space and in the veins draining the placenta is probably determined by hemorheological factors, as the uteroplacental vascular bed is assumed to lack the characteristic to regulate the arterio-venous pressure gradient and volume flow by opening or closing capillaries. In addition the shear rate is low and the placenta does not benefit from the Fashraeus-Lindquist phenomenon. In the blood withdrawn from normal pregnant individuals, hemorheological parameters such as Hct, RBC deformability and aggregability have been found to change in the course of gestation. However, the magnitude and direction of those changes vary widely among different investigators. Nevertheless, it is evident that high risk pregnancies are associated with abnormal maternal hemorheology. The latter suggests that disturbed hemorheology and UBF may either be causally related or represent only concomitant symptoms of a similar disease. As mentioned above, most studies are based on ex vivo macrocirculatory blood measurements. Therefore, solid experimental proof about the precise consequences of impaired ex vivo hemorheology at the level of the intervillous space is lacking.

The present studies were designed to evaluate the effect of maternal hemorheology on UBF by selectively manipulating the most important determinants of hemorheology: systemic Hct, RBC deformability and aggregability. UBF was determined by $15 \mu \mathrm{m}$ radioactive microspheres. The reliability of this technique was evaluated in a separate study.

We hypothesized that UBF can be manipulated by rheological parameters and mean arterial pressure (figure 7). All studies were performed in awake late-pregnant guinea pigs because of its discoid hemomonochoriall placentas. The rheological characteristics of blood flow within the lacuneous labyrinthine 


\section{HYPOTHESIS}

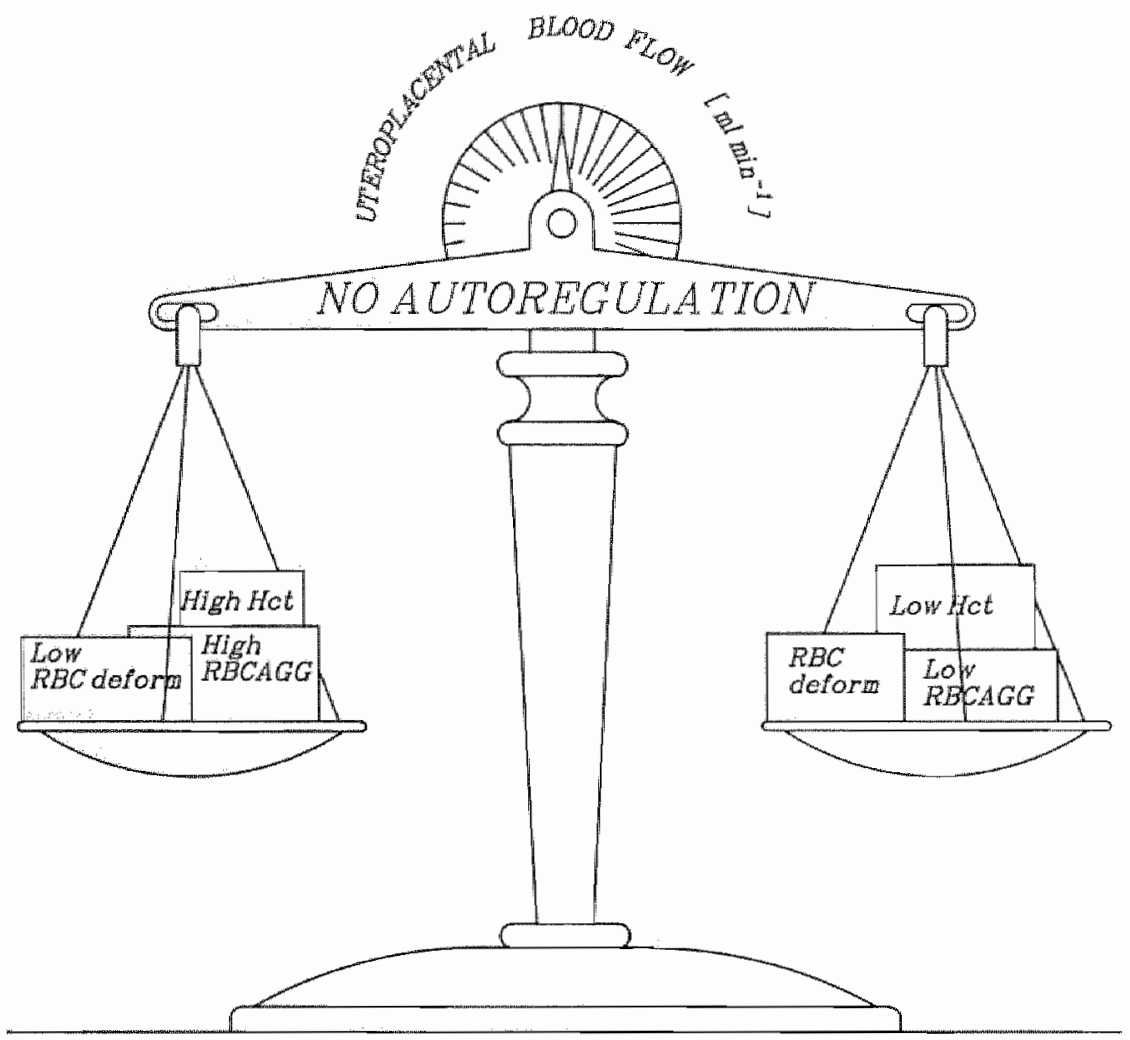

Figure 7

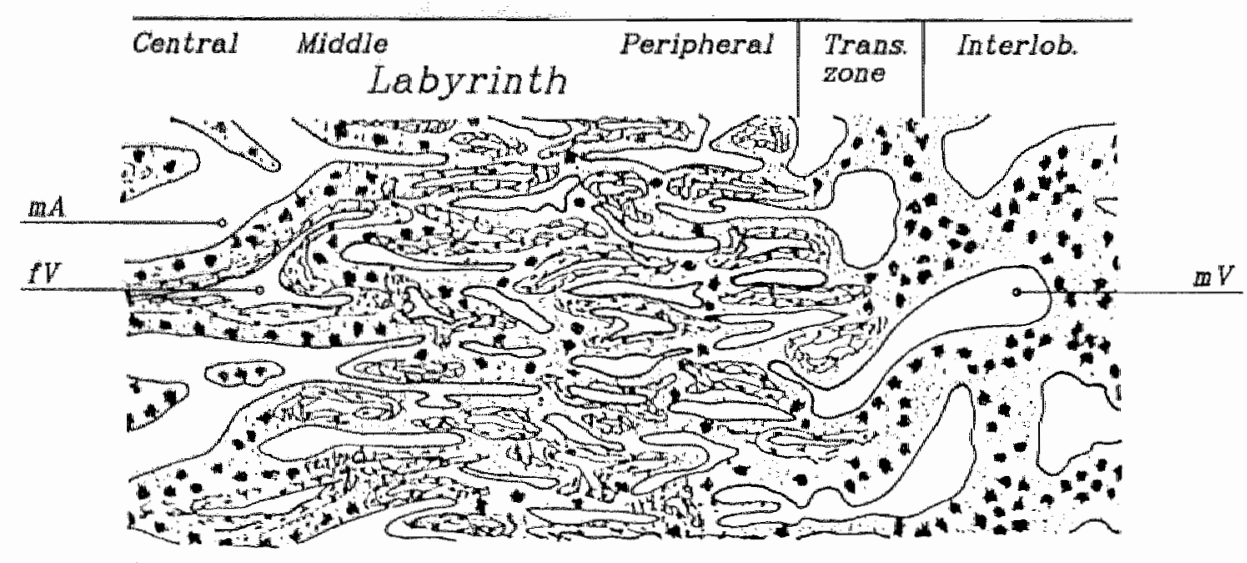

Figure 8

Microacrchitecture within the guinea pig placenta 
microarchitecture of the guinea pig placenta (figure 8) were assumed to resemble those in the intervillous space of the human placenta. Particularly since capillaries, and thus the Fahraeus-Lindqvist phenomenon, are lacking in both types of placental microarchitecture. 


\section{References}

1. Guyton AC 1986 Textbook of medical physiology $7^{\text {th }}$ ed. W.B. Saunders, New York pp. 230-241.

2. Aukland K, Oein AH 1987 Renal autoregulation: modeis combining tubuloglomerular feedback and myogenic response. Am J Physiol 252:F768-F783.

3. Faraci FM, Baumbach GL, Heistad DD 1989 Myogenic mechanisms in the cerebral circulation. J Hypertension 7 (Suppl 4):S61-\$64.

4. Feigl EO 1989 Coronary autoregulation. J Hypertension 7 (Suppl 4):S55-S58.

5. Jonison PC 1964 (ed) Autoregulation of blood flow. New York, Am Heart Assoc Monograph 8.

6. Lundgren O 1989 Autoregulation of intestinal blood flow: Physiology and pathophysiology. J Hypertension 7 (Suppl 4):S79-S84.

7. Merrill EW 1969 Rheology of blood. Physiol Rev 49(4): 863-888.

8. Lowe GDO, Barbenel JC 1988 Plasma and blood viscosity. In: Clinical blood rheology (Lowe GDO ed.), CRC Press, Boca Raton, pp 11-44.

9. Geahtgens P 1980 Flow of blood through narrow capillaries: Rheological mechanisms determining capillary hematocrit and apparent viscosity. Biorheology 17:183-189.

10. Canham PB 1970 The minimum energy of bending and shear stabilizing the shape of the red blood cell. J Theor Biol 26:61-81.

11. Braasch D 1971 Red cell deformability and capillary blood flow. Physiol Reviews 51(4):679-701.

12. Chien $S 1977$ Principles and techniques for assessing erythrocyte deformability. Blood Cells 3:71-99.

13. LaCelle PL 1970 Alteration of membrane deformabiltiy in hemolytic anemias. Semin Hematol 7:355-371.

14. Mohandas N, Philips WM, Bessis M 1979 Red blood cell deformability and hemolytic anemias. Semin Hematol 16:95-114.

15. Thao Chan M, Garnier F, George C 1984 The role of erythrocyte deformability in the rheological behaviour of the blood. Folia Haematol Leipzig 111(6):788-796.

16. Sutera BSP, Gardner RA, Boylan CW, Carroll GL, Chang KC, Marvel JS, Kilo C, Gonen B, Williamson JR 1985 Age-related changes in deformability of human erythrocytes. Blood 65(2):275-282.

17. Weed RI 1970 The importance of erythrocyte deformability. Am J Med 49(2):147-150.

18. Haest WM, Driessen GK, Kamp D, Heidtmann H, Fischer TM, Stöhr-Liesen M 1980 Is "deformability" a parameter for the rate of elimination of erythrocytes from the circulation?. Pfluggers Archiv 388:69-73.

19. Clark MR, Mohandas NS, Shohet SB 1983 Osmotic gradient ektacytometrie: Comprehensive characterization of red cell volume and surface maintainance. Blood 61(5):899-910. 
20. Linderkamp O, Meiselman HJ 1982 Geometric, osmotic and membrane mechanical properties of density-separated human red cells. Blood 59:1121-1127.

21. Simchon S, Jan KM, CHien S 1987 Influence of reduced red cell deformability on regional blood flow. Am I Physiol 253:H898-903.

22. Chien S, Jan KM 1973 Ultrastructural basis of the mechanism of rouleaux formation. Microvasc Res 5:155-166.

23. Chien S, Sung LA, Simchon S, Lee MML, Jan KM, Skalak R 1983 Energy balance in red cell interactions. Ann NY Ac Sci 416:190-206.

24. Jansonius NJ $1959 \mathrm{Kw}$ antitatieve bestudering der rouleaux-vorming van erythrocyten door reflectie meting ("Syllectometrie"). Thesis, Groningen.

25. Rampling MW Red cell aggregation and yield stress. In: Clinical blood rheology (Lowe, G.D.O. ed), CRC Press, Boca Raton, pp 45-64.

26. Lowe GDO 1988 Rheology of paraproteinemias and leukemias. In: Clinical blood rheology (Lowe GDO ed. ), CRC Press, Boca Raton, pp 67-87.

27. Schmid-Schönbein H 1988 Fluid dynamics and hemorheology in Vivo. In: Clinical blood rheology (Lowe, G.D.O. ed), CRC Press, Boca Raton, pp 129-219.

28. Mayer GA, Friedrich J, Newell $J$ "Szivek J 1976 Plasma components and blood viscosity. Biorheology 3:177-182.

29. Rand PW, Barken RJ, Lacombe E 1970 Effects of plasma viscosity and aggregation on whole-blood viscosity. Am J Physiol 218:681-688.

30. International comittee for standardisation in haematology 1984 Recommendation for a selected emthod for the measurement of plasma viscosity. J Clin Pathol 37:1147-1152.

31. Skalak R, Schmid-Schönbein H, Chien S 1982 Analysis of white cell deformability. In Bagge U, Born GVR, Geahtgens P (eds): "White Blood Cells, Morphology and Rheology as Related to Function." The Hague: Nyhoff, pp 110.

32. Chien S 1988 White cell rheology. In. Clinical blood rheology (Lowe GDO ed.) CRC press, Boka Raton, 87-109.

33. Bagge U, Branemark PI, Karlsson K, Skalak R 1980 Three-dimensionall observations of red blood cell deformation in capillaries. Blood Cells 6:231-237.

34. Lipowsky HH, Kovalcheck $S$, Zweifach BW 1978 The distribution of blood rheological parameters in the microvasculature of cat mesentery. Circ Res 43:738-749.

35. Turitto VT 1988 Platelet rheology. In: Clinical blood rheology (Lowe, G.D.O. ed.), CRC Press, Boka Raton, pp 111-128.

36. Schmid-Schönbein H 1988 Conceptional proposition for a specific microcirculatory problem: maternal blood flow in hemochorial multivillous placentae as percolation of a "porous medium". In: Trophoblast research, Vol 3. (eds. Kaufmann, P., and Miller, R.K.) Plenum Publishing Corporation pp 17-38.

37. Meschia G 1973 Circulation to femalle reproductive organs. In: Handbook of physiology the cardiovascular system III pp. 241-269.

38. Assali NS 1989 Dynamics of the uteroplacental circulation in heal th and disease. Am $J$ Perinatol 6(2): 105-109. 
39. Nowak I 1984 Principles and theory of chromatography. In: New comprehensive Biochemistry wol8 Separation methods. Deyl Z (ed) Amsterdam, New York, Oxford Elsevier pp 1-27.

40. Peeters LLH, Buchan PC, 1989 Blood viscosity in perinatology. Rev Perinat Med 6.53-89.

41. Dullien FAL 1979 Porous media. Flluid transport and pore structure. New York, London, Toronto, Sydney, San Francisco, Academic Press.

42. Greiss jr F 1966 Pressure-flow relationship in the gravid uterine vascular bed. Am $\mathrm{J}$ Obst Gynecol 96:41-47.

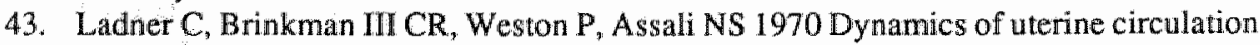
in pregnant and nompregnant sheep. Am J Physiol 218(1):257-263.

44. Berman W, Goodlin RC, Heymann MA, Rudolph AM 1976 Relationships between pressure and flow in the umbilical and uterine circulations of the sheep. Circ Res $38(4): 262-266$

45. Herberger $J$, Moll $W 1976$ The flow resistance of the maternal placental vascular bed of anesthetized guinea pigs. Z Geburtsh Perinat 180:61-66.

46. Bruce NS, Abdul-Karim RW 1974 Mechanisms controlling maternal placental circulation. Clin Obstet Gynecol 17(3):135-151.

47. Venuto RC, Cox JW, Stein JH, Ferris T 1976 The effect of changes in perfusion pressure on uteroplacental blood flow in the pregnant rabbit. J Clin Invest 57:938-944.

48. Moll W, Kunzel W 1973 The blood pressue in arteries entering the placentae of guinea pigs, rats, rabbits and sheep. Pflugers Arch 338:125-131.

49. Moll W, Künzel W, Stolte LAM, Kleinhout J, de Jong PA, Veth AFL 1974 The blood pressure in the decidual part of the uteroplacental arteries (Spiral arteries) of the rhesus monkey. Pflügers Arch 346:291-297.

50. Schmid-Schönbein H 1981 Interaction of vasomotion and blood rheology in haemodynamics. In: Clinical aspects of blood viscosity and cell deformability. Lowe GDO, Barbenel JC, Forbes JC (eds), Berlin Springer pp 49-66.

51. Buchan PC 1984 Maternal and fetal blood viscosity throughout normal pregnancy. J Obsiet Gynecol 4:143-150.

52. Kabara M, Marumoto Y, Taniguchi I, Kobayashi T 1982 Blood viscosity at low shear rate in normal and abnormal pregnancies. Clin Haenorheol 2:209:217.

53. Huisnan A, Aarnoudse JG, Heuvelmans JHA Goslinga $H$, Fidler $V$, Huisjes HJ, Zijlstra WG 1987 Whole blood viscosity during normal pregnancy. Br J Obstet Gynaecol 94:1143-1149.

54. Hytten FE, Paintin DB 1963 Increase in plasma volume during normal pregnacy. J Obstet Gynaecol Br Commonw 70:402-407.

55. Dintenfass L 1982 On changes in aggregation of red cells blood viscosity and plasma viscosity during normal gestation. Clin Haemorheol 2:175-188.

56. Inglis TCM, Stuart J, George AJ, Davies AJ 1982 Haemostatic and rheological changes in normal pregnancy and pre-eclampsia. Br J Haematol 50:461-465. 
57. Rodgers BD, Hreshchyshyn MM, Lee RV, Rodgers D, Ambrus CM 1988 Erythrocyte filterability in normal and high risk pregnancy. Obstet Gynecol 71(2):192-197.

58. Murphy JR 1968 Hemoglobin CC disease rheological properties of erythrocytes and abnormalities in cell water. J Clin Invest 47:1483-1495.

59. Buchan PC, McDonald HN 1981 Rheological studies in obstetrics and gynaecology. In: Lowe GDO, Barbenel JC, Forbes CD (eds) Clinical aspects of blood viscosity and cell deformability. Springer Verlag, Berlin, Heidelberg, New York, pp. 175192.

60. Buchan PC 1980 Evaluation and modification of whole blood filtration in the measurement of erythrocyte deformability in pregnancy and the newborm. $\mathrm{Br} J$ Haematol. 45:97-105.

61. Thomburn J, Drummond MM, Whigham KA, Lowe GDO, Forbes CD, Prentice CRM, Whitfield CR 1982 Blood viscosity and haemostatic factors in late pregnancy, preeclampsia and fetal growth retardation. Br J Obster Gynaecol 89:117-122.

62. Mandelli B, Polatti F, Bolis PF 1985 Study of erythrocyte deformability in physiological pregnancy. Clin Exp Obstet Gynecol 12:16-20.

63. Durocher JR, Weir MS, Lundblad EG, Patow WE, Conrad ME 1975 Effect or oral contraceptives and pregnancy on erythrocyte deformabillity and surface charge (39037). Proc Soc Exp Biol Med 150:368-370.

64. Kaibara M, Marumoto $\mathrm{Y}$, Kobayashi T 1985 a Erythrocyte filterability and fetal development in normal pregnancy. Am J Obstet Gynecol 152:719-720.

65. Kaibara M, Marumoto Y, Taniguchi I, Kigasawa K, Kobayashi T 1985 b Erythrocyte filterability and adenosine triphosphate levels in normal pregnancy and puetperium. Int J Microcirc Clin Exp 4:55-62.

66. Taylor DJ, Lind $\mathrm{T} 1976$ Haemoatological changes during normal pregnancy. Br J Obstet Gynaecol 83:760-767.

67. Bolton $\mathrm{FG}$, Street MJ 1982 Changes in erythrocyte wolume and shape in pregnancy. $\mathrm{Br}$ J Obstet Gynaecol 89:1018-1020

68. Friedberg V, Rathgen GH 1980 Physiologie der schwangerschaft. Thieme, Stutgart.

69. Heilmann L, Siekmann U, Schmid-Schönbein H, Ludwig H 1981 Hemoconcentration and pre-eclampsia. Arch Gynecol 231:7-21.

70. Robertsen EG 1968 Increased erythrocyte fragility in association with osmotic changes in pregnancy serum. J Reprod Fertil 16:323-324.

71. Schmid-Schönbein H 1984 Preface. In: Haemorheological disorders in obstetrics and neonatology. Heilmann L. Buchan PC (eds). Schattauer Verlag Gmbh, Stuttgart, New York, pp VI-VIII

72. Huisman A, Aarnoudse JG, Krans $M_{*}$ Huisjes $H J$, Fidler V, Zijlstra WG 1988 Red cell aggregation during normal pregnancy. Br J Haematol 68:121-124.

73. Ozanne P. Linderkamp O, Miller FC, Meiselman HJ 1983 Erythrocyte aggregation during normal pregnancy. Am J Obstet Gynecol 147:567-583.

74. Heilmann L, Mattheck C, Kurz E 1977 Rheological changes in the blood in nomal and pathological pregnancies. Arch Gynaekol 223:283-298. 
75. Harkness I 1971 The viscosity of human blood plasma" its measurement in health and disease. Biorheology 8:171-193.

76. Gerretsen G, Huisjes HJ, Elema ID 1981 Morphological changes of the spiral arteries in the placental bed in relation to pre-eclampsia and fetal growth retardation. Brit J Obstet Gynaecol 88:876-881.

77. Brosens IA 1977 Morphological changes in the uteroplacental bed in pregnancy hypertension. Clin Obstet Gynaecol 4(3):573-593.

78. Sheppard BL, Bonnar J 1974 The ultrastructure of the arterial supply of the human placenta in early and late pregnancy. J Obstet Gynaecol Brit Cwlth 81(7):497-511.

79. Fox H 1981 Placental malfunction as a factor in intra-uterine growth retardation. In: Fetal growth retardation wan Assche FA, Robertson WB (eds) Churchill Livingstone. Edinburgh, London, Melbourne, New York. pp.117-125.

80. Kaufmann P 1982 Development and differentiation of the human placental villous tree. Biblthca Anat 22:29-39.

81. Greiss FC 1963 The uterine vascular bed: Effect of adrenergic stimulation. Obstet Gynecol 21(3):295-301.

82. Eijzenbach V, Schoute E, van der Werf AJM, Goslinga H, 1989 Changes in blood viscosity during normal and hypertensive pregnancy. Clin Haemorheol 9(3):463.

83. Heilmann L, Ludwig H 1980 Die gestörte Mikrozirkulation bei der Gestose. Z Geburtsh Perinat 184:187-194.

84. Sheppard BL, Bonnar J 1976 The ultrastructure of the arterial supply of the human placenta in pregnancy complicated by fetal growth retardation. Br J Obstet Gynaecol 83:948-959.

85. Kaibara M, Marumoto Y, Taniguchi I, Kobayashi T 1981 Blood viscosity at a low shear rate in normal and abnormal pregnancies. Clin Hemorheol vol2:209-217.

86. Hobbs JB, Oats IN, Palmer AA, Mitchell G, Lou A, Mclver MA 1982 Whole blood viscosity in preeclampsia. Am J Obstet Gynecol 142:288-292

87. Buchan PC 1982 Preeclampsia a hyperviscosity syndrome. Am J Obstet Gynecol 142(1):111-112.

88. Lang GD, Lowe GDO, Walker JJ, Forbes CD, Prentice CRM, Calder AA 1984 Blood rheology in pre-eclampsia and intrauterine growth retardation: Effects of blood pressure reduction with labetolol. Br J Obstet Gynaecol 91:438-443.

89. Zondervan HA, Voorhorst FJ, Robertson EA, Kurver PH, Massen C 1985 Is maternal whole blood viscosity a factor in fetal growth? Eur J Obstet Gynecol Reprod Biol 20:1145-151.

90. Pickart LR, Greasy RK, Thaler MM 1976 Hyperfibrinogenemia and polycythemia with intrauterine growth retardation in fetal lambs. Am J Obstet Gynecol 124:268-271.

91. Sagen N, Koller P, Haram K 1982 Haemoconcentration in severe pre-eclampsia. Br J Obstet Gynaecol 89:802-805.

92. Făhraeus R 1962 Eclampsia- A diseases of the checked microcirculation. Acta Obstet Gynecol Scand 41:101-114. 
93. Goslinga H 1982 The viscosity of blood. An experimental study into the effect of alterations in blood viscosity during shock. Thesis." State University Utrecht.

94 Gresele P, Guerciolini $R$, Nenci GG 1982 Erythrocyte deformability changes in normal pregnancy and pre-eclampsia. Br J Haematol 52:340-342.

95. Stuart J, Kenny W, Inglis TCM NA 1983 Erythrocyte filterability in nomal pregnancy and pre-eclampsia. Br J Haematol 53(2):353-355.

96. Dumlop W, Furness C, Hill LM 1978 Maternal hemoglobin concentration haenatocrit and renal handling of urate in pregnancies ending in the births of small-for-dates infants. Br J Obstet Gynaecol 85:938-940.

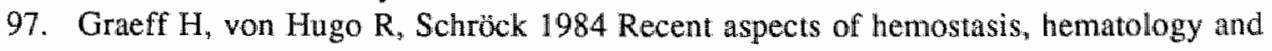
hemorheology in preeclampsia-eclampsia. Europ J Obstet Gynecol Reprod Biol 17:91102.

98. Bonnar J McNicol GP, Douglas AS 1971 Coagulation and fibrinolytic systems in pre-eclampsia and eclampsia. Br Med J ii:12-16.

99. Mathews JD, Mason TW 1974 Plasma viscosity and pre-eclampsia. Lancet ii:409.

100. Eastham RD 1965 Plasma viscosity estimation in the improved haematological screening of antenatal patients. J Obstet Gynaecol Br Commonw 72:763-764.

101. Buchan PC 1984 Fetal intra uterine growth retardation and hyperwiscosity. In: Heilmann L, Buchan PC (eds) Hemorheological disorders in obstetrics and neonatology. Stuttgart, New York, Schattauer Verlag pp. 7-20.

102. Condie RG, Ogston D 1976 Sequential studies on components of the haemostatic mechanism in pregnancy with particular reference to the development of pre-eclampsia. Br J Obstet Gynaecol 83:938-942.

103. Bonnar J, McNicol GP, Douglas AS 1969 Fibrinolytic enzyme system and pregnancy. Br Med J iii:387-389. 


\section{Systemic leakage of $15 \mu \mathrm{m}$ radioactive microspheres over a period of 24 hours, in awake late-pregnant guinea pig}

Carla M Verkeste and Louis LH Peeters

Journal of Developmental. Physiology 13(1):37-39,1990

\section{Abstract}

The present study was designed to determine the reliability of regional blood flow measurements with $15 \mu \mathrm{m}$ radioactive microspheres, when $24 \mathrm{~h}$ have elapsed between reference sampling and sacrifice. The study was performed in 12 chronically instrumented late-pregnant guinea pigs. The fraction of microspheres recovered from the lungs was consistently higher, by about $2 \%$ of the cardiac output after such a 24 h period, as compared to microsphere experiments performed immediately prior to sacrifice. This finding suggests dislodgement of radioactive particles from the systemic circulation between the time of completion of reference sampling and the subsequent $24 \mathrm{~h}$. No correlation could be demonstrated between the change in lung fraction and the change in any organ fraction in particular. Therefore, it is highly unlikely that the microspheres accumulated in the lungs over this period originate from the placenta or any other specific organ. It is concluded that in the awake late-pregnant guinea pig, the $2 \%$ loss of microspheres from the systemic circulation during the $24 \mathrm{~h}$ following reference sampling, does not invalidate the cardiac output distribution derived. 


\section{Introduction}

In order to obtain reliable information on cardiac output distribution with the microsphere technique, the injection of the radioactive microspheres should result in a homogeneous distribution of the microspheres in the blood. All microspheres should be distributed over the peripheral circulation in proportion to blood flow and be entrapped during the first passage of the microcirculation without disturbing the perfusion (1). It is generally accepted that the smallest microspheres which may be associated with minor systemic shunting have a diameter of $15 \mu \mathrm{m}$. The loss of non-deformable radioactive particles from the systemic circulation may occur either directly, via arterio-venous anastomoses, or indirectly by secondary dislodgement of entrapped microspheres. The absence of $15 \mu \mathrm{m}$ microsphere dislodgement from individual organs has been demonstrated for the myocardium (2) and the gut (3). The pores within the labyrinthine microstructure of the guinea pig placenta appear to be considerably larger than the average diameter in the rest of the microcirculation (4). Therefore, this placenta is a potential source of microsphere leakage. A number of studies have been performed to test the validity of the radioactive microsphere method in pregnant animals having a hemochorial placenta (5-10). The results generated by these studies are conflicting. Some authors report similar shunting of microspheres in non-pregnant and pregnant animals whereas others note a significantly higher shunting in the pregnant state. The present study was designed to determine, in the awake late-pregnant guinea pig, the magnitude and possible origin of microsphere shunting, in a 24 -h period following completion of reference sampling.

\section{Materials and methods}

The study was performed in 12 pregnant albino guinea pigs bred in our own laboratory facility. Details on animal breeding, housing and handling are described in a previous report ( 11$)$. Around the $50^{\text {th }}$ day of pregnancy, the animals were anesthetized and polyethylene catheters (outer diameter/inner diameter= $0.96 / 0.58 \mathrm{~mm}$, Talas, Ommen, Holland) were inserted into the left ventricle and the abdominal aorta. Details of the anesthesia and surgery are also described previously (1.1). After surgery the animals were allowed to recover for 6 days. Data of the experiments were collected under steady-state conditions, defined 
as the state reached after at least $20 \mathrm{~min}$ of stable readings for heart rate and blood pressure. Hematocrit was determined in duplicate by the microcapillary method. In order to determine cardiac output distribution and organ blood flows, $15 \mu \mathrm{m}$ radioactive microspheres were injected into the left ventricle while a reference sample was withdrawn, for a period of 1 minute, from the abdominal aorta at a rate of $0.6 \mathrm{ml} \cdot \mathrm{min}^{-1}$ (9). Since the amount of blood removed (ca. $1 \mathrm{ml}$ ) corresponds to about $1.5 \%$ of the total blood volume, it was not deemed necessary to replace it by transfusion from another animal. The microsphere experiment was followed by a $24 \mathrm{~h}$ period without experimentation and with minimal manipulation. The measurements were then repeated using a microsphere with a different radioactive label. About $15 \mathrm{~min}$ after the last microsphere injection the animals were sacrificed with an overdose of pentobarbital. All organs were dissected and radioactivity determined with a sodium crystal scintillation counter (Packard, Delft, Holland). The data were analyzed with a set of computer programs (12). All organs and the reference samples contained at least 700 microspheres. Differences between the $15 \mathrm{~min}$ (Control) and $24 \mathrm{~h}$ (Experiment) observations were evaluated using the Wilcoxon rank sign test. A p $<0.05$ (two-sided) was considered significant. Data are presented as means \pm standard deviation (SD).

\section{Results}

The experiment was performed at a mean gestational age of $57 \pm 2$ days. The litter consisted of $2.8 \pm 1.1$ fetuses with a total litter weight of $158 \pm 66 \mathrm{~g}$. Paired measurements of heart rate, blood pressure, hematocrit, cardiac output and cardiac output distribution, determined $15 \mathrm{~min}$ (Control) and $24 \mathrm{~h}$ (Experiment) before sacrifice of the animals are listed in table 1 . Heart rate and blood pressure were comparable on the 2 consecutive days. The hematocrit and cardiac output were both higher in the experimental condition. The lung fraction of cardiac output was $4.2 \%$ in the control condition and $6.3 \%$ in the experimental condition. Between the 12 individual animals the accumulation of firstly injected microspheres in the lungs over the study period varied between $0.5 \%$ and $6 \%$ of the cardiac output. The consistently lower lung fraction in the control condition was paralleled by higher skin and brain fractions. The magnitude of the change in lung fraction did not correlate with the change in skin or brain fractions (Spearman non-parametric correlation test). The change in placental fraction, ranging between $-4 \%$ and $+5 \%$ of the cardiac output, was inconsistent. In two 
Table 1

Heart rate (Beats minn $\left.^{2}\right)$, blood pressure ( $m m H g$ ), hematocrix (vol\%), cardiac output $\left(\mathrm{mlmin} \mathrm{n}^{-1}\right)$ and cardiac output distribution (\%) in late pregnant guinea pigs $(n=12), 15$ min (Control) and 24 h (Experiment) before sacrifice.

\begin{tabular}{lrc}
\hline Mean \pm SD & Control & Experiment \\
\hline Heart rate & $266 \pm 29$ & $271 \pm 31$ \\
Blood pressure & $52 \pm 5$ & $54 \pm 9$ \\
Haematocrit & $32 \pm 3$ & $33 \pm 3^{*}$ \\
Cardiac output & $205 \pm 40$ & $224 \pm 34^{*}$ \\
& & \\
Lungs & $4.2 \pm 2.1$ & $6.3 \pm 2.6^{*}$ \\
Heart & $3.6 \pm 0.6$ & $3.6 \pm 1.1$ \\
Liver & $0.3 \pm 0.2$ & $0.4 \pm 0.3$ \\
Gut & $17.2 \pm 1.5$ & $17.4 \pm 2.4$ \\
Spleen & $2.0 \pm 0.6$ & $2.1 \pm 0.9$ \\
Kidneys & $9.4 \pm 2.9$ & $9.8 \pm 2.0$ \\
Brain & $2.5 \pm 0.5$ & $2.2 \pm 0.3^{*}$ \\
Skin & $7.2 \pm 2.1$ & $5.8 \pm 1.3^{*}$ \\
Carcass & $38.2 \pm 6.1$ & $37.5 \pm 6.2$ \\
Placentas & $10.0 \pm 4.2$ & $9.7 \pm 5.3$ \\
Myometrium & $1.2 \pm 0.4$ & $1.5 \pm 0.5$ \\
& & \\
\hline
\end{tabular}

* p<0.05 versus control walue.

animals the accumulation of microspheres in the lungs changed from $3 \%$ to $7 \%$ and from $4 \%$ to $10 \%$ of the cardiac output, respectively. Also in these animals no systematic change in any particular organ fraction could be demonstrated.

\section{Discussion}

The objective of this study was to identify the possible origin of systemic shunting over a $24-\mathrm{h}$ period following a microsphere experiment. In the present study, as in our previous studies (13), an about $2 \%$ higher lung fraction was 
observed when the experimental animal was sacrificed $24 \mathrm{~h}$ instead of $15 \mathrm{~min}$ after the microsphere experiment. This phenomenon suggests secondary dislodgement of trapped microspheres from the systemic circulation, the placenta with its large pores being the most likelly source. In the present study this secondary accumulation of spheres in the lungs was paralleled by virtually no change in placental fraction, but significant decreases in the cardiac output fractions to brain and skin. The magnitude of the latter changes did not correlate with the increase in lung fraction. Therefore, it seems unlikely that the alterations in these fractions represent a consistent loss of microspheres from these organs. The change in brain fraction can be attributed to a compensation for the slight but consistent decrease in hematocrit and thus arterial $\mathrm{O}_{2}$ content (13), associated with the blood sampling. The alteration in skin fraction could reflect a difference in maternal sympathetic tone between the 2 experimental days. The skin contains many arteriovenous anastomoses. It is conceivable that these channels in the skin show a secondary loss of firstly injected microspheres, thus accounting for part of the systemic shunting (14). It is particularly important to emphasize the similarity of the placental fractions in the 2 conditions. The following observations provide further support for the absence of systematic secondary dislodgement of microspheres from the placentas in the late-pregnant guinea pig, a) The lung fractions of pregnant and non-pregnant animals are comparable (9), b) The lung fraction changes little over a $6 \mathrm{~h}$ interval between microsphere experiments $(10)$, c) The placental leakage of $15 \mu \mathrm{m}$ and $25 \mu \mathrm{m}$ microspheres, injected as a cocktail in the left ventricle of the guinea pig, is virtually the same (8). The present observations are probably only valid for the awake late-pregnant guinea pig. In the mid-pregnant guinea pig (personal observation) and in the anesthetized animal (5) both short-term and long-term leakage, seem to be markedly elevated. The significant change in lung fraction observed in our study implies secondary dislodgement of microspheres. However, no particular organ or tissue could be identified as a potential source for this microsphere leakage. Therefore, we conclude that various organs, including the placenta, show a consistent loss of microspheres up to a total loss of $2 \%$ of cardiac output over the $24 \mathrm{~h}$ prior to sacrifice. However, the magnitude of this systemic leakage is so small, that this phenomenon does not seem to invalidate the derived blood flow measurements. 


\section{References}

1. Buckberg GD, Luck JC, Payne DB, Hoffman JE, Archie JP, Fixler DE 1971 Some sources of emor in measuring regional blood flow with radioactive microspheres. J Appl Physio $31(4): 598-604$.

2. Consigny PM, Verrier ED, Payne BD, Edelist $G$, Jester $J$, Baer RW, Vlahakes Gi, Hoffman JE 1982 Acute and chronic microsphere loss from canine left ventricular myocardium. Am J Physiol 242:H392-H404.

3. Maxwell LC , Shepherd AP, Riedell GL 1982 Vasodilation or altered perfusion pressure moves $15 \mu \mathrm{m}$ spheres trapped in the gut wall. Am J Physiol 243:H123-H127.

4. Kaufmann $P_{*}$ Davidoff MS 1977 The guinea-pig placenta. In: Brodal $A_{\|}$Hild W, van Limborgh J, Ortmann R, Schiebler TH, Töndury G, Wolff E (eds), Advances In Anatomy, Embryology and Cell Biology wol53 fasc2. Springer-Verlag, Berlin, pp2629.

5. Bjellin L, Sjöquist POB, Mårtensson L, Carter AM 1979 Regional blood flow measurements with $15 \mu \mathrm{m}$ and $50 \mu \mathrm{m}$ microspheres in pregnant guinea-pigs. J Reprod Fertil $57: 415-418$.

6. Creasy RK, Kahanpää KV, de Swiet M 1974 Trapping of radioactive microspheres in the pregnant and non-pregnant rabbit. Acta Physiol Scand 90:252-260.

7. Johnson RL, Gilbert $M$, Meschia $G_{*}$ Battaglia FC 1985 Cardiac output distribution and uteroplacental bllood flow in the pregnant rabbit: A comparative study. Am J Obstet Gynecol 151:682-686.

8. Myers S, Sparks JW, Makowski EL 1986 Factors affecting radioactive microsphere measurement of blood flow in pregnant guinea pigs. Lab Anim Sci 36(5):522-526.

9. Peeters LLH, Grutters G, Martin CB 1980 The distribution of cardiac output in the unstressed pregnant guinea pig. Am J Obstet Gynecol 138:1177-1184.

10. van de Walle $A F G M$, Martin CB 1986 Effect of prolonged infusion of ritodrine on uteroplacental blood flow and cardiac output distribution in unanesthetized pregnant guinea pigs. Eur J Obstet Gynecol Reprod Biol 21:253-260.

11. Peeters LLH, Martensson L, van Kreel BK, Wallenburg HCS 1984 Uterine arterial and venous concentration of glucose, lactate, ketones, free fatty acids, and oxygen in the awake pregnant guinea pig. Pediatr Res 18:1172-1175.

12. Saxena PR, Schamhardt HC, Forsyth RP, Loeve J 1980 Computer programs for the radioactive microsphere technique Determination of regional blood flow and other hemodynamic variables in different conditions. Comp Prog Biomed 12:63-84.

13. Peeters LLH, Verkeste CM, Saxena PR, Wallenburg HCS 1987 Relationship between maternal hemodynamics and hematocrit and hemodynamic effects of isovolemic hemodilution and hemoconcentration in the awake late pregnant guinea pig. Pediatr Res 21:584-589. 
14. Saxena PR, Verdouw PD 1985 Tissue blood flow and localization of arteriovenous anastomoses in pigs with microspheres of four different sizes. Pflug Archiv 403:128135. 


\section{Relationship between maternal hemodynamics and hematocrit and hemodynamic effects of isovolemic hemodilution and hemoconcentration in the awake late-pregnant guinea pig}

Louis L Peeters, Carla M Verkeste, Pramod R Saxena and Henk CS Wallenburg

Pediatric Research 21(6):584-589,1987

\section{Abstract}

The relationship between the spontaneous hematocrit (Hct) and maternal hemodynamics and the hemodynamic effects of experimentally induced changes in this Hct were studied in the awake late-pregnant guinea pig. In animals with a relatively low Hct, cardiac output fractions and blood flows to brain and heart determined with microspheres were higher and those to kidneys lower than in animals with a relatively high Hct. The $\mathrm{O}_{2}$ flows to the kidneys and skin in the former animals were also lower. Cardiac output, heart rate, systemic blood pressure, and blood flows to the other organs, including the placenta, were not related to the Hct. Placental blood flow was found to vary in proportion to cardiac output. Both hemodilution and hemoconcentration induced changes in the cardiac output distribution and organ flow which resembled those observed in the spontaneous relation with Hct. In addition, hemodilution decreased systemic blood pressure. Both hemodilution and hemoconcentration increased placental blood flow; the magnitude of this flow in- 
crease was twice as high after hemodilution. The changes in oxygen flows after experimentally induced hemodilution and hemoconcentration appears to be directly related to the concomitant change in whole blood oxygen capacity. It is concluded that in the awake late-pregnant guinea pig, only brain, heart and kidney perfusion vary in relation to the arterial Hct. The higher placental blood flow after isovolemic hemodilution may be a result of better blood rheology in the porous-like intervillous space of the placentas in a state of reduced systemic blood pressure. The modest rise in placental blood flow after isovolemic hemoconcentration appears to be mostly related to the methodology employed.

\begin{tabular}{|l|}
\hline \multicolumn{2}{|l|}{ Abbreviations } \\
$\mathrm{Hct}=$ Hematocrit $($ vollo) \\
$\mathrm{Hb} \quad=$ Hemoglobin $\left(\mathrm{g} . \mathrm{l}^{-1}\right)$ \\
$\mathrm{Resp}=$ Respiration
\end{tabular}

\section{Introduction}

The Hct affects both the viscosity and the oxygen-carrying capacity of circulating blood. To allow optimal $\mathrm{O}_{2}$ transport, the Hct must be such that adequate $\mathrm{O}_{2}$-carrying capacity is combined with optimal fluidity of the blood in the microcirculation. In pregnant women, the Hct shows a fall of $15 \%$ in midgestation, mainly due to a gradual rise in plasma volume, to about $40 \%$ above nonpregnant levels (1). Pregnancies complicated by preeclampsia or intrauterine growth retardation show a certain degree of hemoconcentration which causes a relative rise in Hct and various plasma proteins. These alterations affect whole blood viscosity at different levels: elevated concentrations of proteins increase plasma viscosity and plasma osmolality (2). Increased plasma osmolality, in turn, diminishes red cell deformability (3). Elevated plasma concentrations of fibrinogen and certain macroglobulines enhance red cell aggregability (4). The relative contribution of these factors to the rheologic properties of blood is mainly determined by the behavior of the sheared erythrocytes within each specific microvasculature. The reduced total blood volume in preeclampsia may explain the relatively low cardiac output (5) and reduced uteroplacental blood flow (6) in this condition. The additional effect of an elevated whole blood viscosity on an already compromised uteroplacental blood flow is unknown. 
In order to quantitate the relative effect on the maternal circulation of each individual blood viscosity parameter, these parameters should be manipulated selectively in an appropriate, in vivo experimental model. Previous studies involved exchange transfusions in the anesthetized animal with Hot changes beyond the normal limits of the physiological range $(7,8)$. From data generated by these studies, it is difficult to differentiate between Hct and non-Hct related effects of isovolemic exchange transfusions within the physiologic range of Hct.

The present study was designed to evaluate the relationship between maternal cardiovascular dynamics and Hct and the effects on the maternal circulation of acute changes in Hct induced by means of isovolemic hemodilution or isovolemic hemoconcentration in the awake late-pregnant guinea pig. Inherent to this experimental design is the fact that changes in $\mathrm{O}_{2}$ content and blood viscosity will remain linked together. Consequently, Hct-related changes could either be caused by a change in $\mathrm{O}_{2}$ or by a change in blood viscosity. The guinea pig was chosen for this study because of its hemochorial placenta which may allow extrapolation to human pregnancy.

\section{Materials and methods}

Thirty-six albino guinea pigs with known postconceptional dates were used in this study. The animals were bred in our own laboratory facility. Details about breeding, housing, and handling are described in a previous report (9). Between day 48 and 52 of pregnancy, polyethylene catheters were inserted into the left ventricle and abdominal aorta using aseptic techniques $(9,10)$. Both catheters were tunneled subcutaneously and exteriorized between the shoulder blades. They were flushed once weekly with saline. Experiments were performed at least 5 days after surgery at a gestational age between 55 and 60 days. At the time of the experiment all animals had adequatelly recovered from surgery, as reflected in a retum to the presurgical weight gain.

Experimental protocol. In all animals the cardiac output, cardiac output distribution, and regional blood flows were determined in duplicate on 2 consecutive days. On the 1 st day these variables were measured without preceding manipulation. After these so-called "control" measurements the animals were subjected to either an isovolemic hemodilution, a "sham" procedure, or an isovolemic hemoconcentration. On the next day, $24 \mathrm{~h}$ later, the second set of so-called "posttransfusion" measurements were obtained. Arterial blood pres- 
sure and heart rate were monitored troughout both periods of experimentation. The flow measurements with $15 \mu \mathrm{m}$ microspheres (NEN, Dreieich, West Germany) were performed using the reference sampling technique (10). Each blood flow measurement was based on the results of two separate microsphere injections under the same experimental condition as described in detail in a previous report (11). At the time of the injections of microspheres a reference sample of blood was withdrawn from the abdominal aorta at a constant rate of 0.65 $\mathrm{ml} / \mathrm{min}$. Prior to each microsphere experiment, an arterial blood sample was abtained $(0.3 \mathrm{ml}$ ) for the measurement of blood gases ( $A B L 3$, Radiometer, Copenhagen, Denmark), $\mathrm{O}_{2}$ saturation, Hb concentration (OSM2, Radiometer), and Hct (microcapillary technique). Fifteen min after the last injection of microspheres the animals were killed with an overdose of a barbiturate. The catheter positions were checked at autopsy and all organs were dissected. In all animals, the tip of the catheter used for injection of microspheres appeared to be in satisfactory position in the left ventricle. The tip of the abdominal catheter was located between the kidneys and the aortic bifurcation.

Radioactivity in each tissue aliquot and in the reference sample was determined with a well scintillation counter adapted with a 3 -inch crystal (Autogamma Scintillation Counter 5220, Packard, Delft, Holland). The data were analyzed with a set of computer programs developed for processing data generated during microsphere experiments (12). All organs and reference samples contained at least 700 microspheres.

Isovolemic exchange transfusion. After the first set of blood flow measurements the animals were divided into three groups. In a hemodilution group of 13 animals, $8 \mathrm{ml}$ of blood were exchanged for $8 \mathrm{ml}$ of plasma, obtained from a nonpregnant guinea pig and stored at $-20^{\circ} \mathrm{C}$ for a period of $1-4$ months. In a sham group of 8 animals, $8 \mathrm{ml}$ of blood were withdrawn in a heparinized syringe, gently stirred for $30 \mathrm{~min}$ at $38^{\circ} \mathrm{C}$, and reinfused into the animals. The blood removed at the time of reference sampling (approximately $5 \mathrm{ml}$ ) was not replaced to avoid possible unpredictable side-effects associated with the administration of donor blood. In a hemoconcentration group of 12 animals, $8 \mathrm{ml}$ of whole blood were exchanged for $8 \mathrm{ml}$ of washed red cells. The preparations of red cells was based on the procedure described for human blood (13). Briefly, heparinized blood of a nonpregnant guinea pig was centrifuged at $1378 \mathrm{x} \mathrm{g}$ for $10 \mathrm{~min}$. The supematant was removed and the erythrocytes were gently mixed with saline ( $3: 2$ dilution) and recentrifuged. This procedure was repeated three times. Then $8 \mathrm{ml}$ of red cells were resuspended in $1 \mathrm{ml}$ of saline at $38^{\circ} \mathrm{C}$ and exchanged. An 8-ml exchange transfusion corresponds with a total volume exchange of approximately $12 \%$. Exchange transfusion did not affect the animals' food intake and weight gain. 
Data presentation and statistics. The correlations between organ flows and Hct, and between placental blood flow and systemic blood pressure, heart rate and cardiac output, were evaluated using Spearman's nonparametric correlation test. The change in lung fraction after any manipulation is indicative for systemic shunting (14). This variable was evaluated with Spearman's nonparametric correlation in its relation to fetal weight, placental weight, Hct, and all circulatory parameters determined on the 1 st day of experimentation. The paired observations on cardiac output, cardiac output fractions, organ blood flows, and organ oxygen flows within each group were evaluated with Wilcoxon's signed rank test. The organ blood and oxygen flows after hemodilution, after sham procedure, and after hemoconcentration were compared with those calculated for animals with a relatively low, intermediated, and relatively high baseline Hct, respectively (Wilcoxon's rank sum test). In Tables 1 to 4, data are expressed as mean $\pm \mathrm{SD}$. Changes in various parameters induced by exchange transfusion were not normally distributed. Therefore, where appropriate in the text, median values for these changes are given in parentheses. 


\section{Results}

Baseline characteristics. Some general characteristics and baseline hemodynamic parameters of the three groups of experimental animals are listed in Table 1. Only heart rate was significantly higher in the hemodilution group. In most animals the cardiac output fraction to the lungs was about $1-2 \%$ lower on the 2nd day of experimentation (Table 2 ), most likely primarily related to systemic shunting of 1 st day microspheres during the period between the two experiments. No correlation was found between the fraction of cardiac output shunted overnight and fetal weight, placental weight, gestational age, and any of the other parameters measured at the time of the first set of microspheres injections. The amount of shunting was not influenced by the type of subsequent manipulation. Part of this delayed shunting may have taken place across the placentas. If all microspheres shunted in the period between the two experiments would originate from the placentas, the value calculated for the first day placental blood flow would be underestimated by a median of $17 \%$. In three animals in each group, the amount of 1 st day microspheres shunted across the systemic circulation overnight amounted to $30 \%$ or more of the amount of 1 st day

Table I

General characteristics and baseline hemodynamic variables of the three groups of latepregnant guinea pigs (means $\pm S D$ )

\begin{tabular}{lccc}
\hline & $\begin{array}{c}\text { Hemodilution } \\
(\mathrm{n}=13)\end{array}$ & $\begin{array}{c}\text { Sham } \\
(\mathrm{n}=11)\end{array}$ & $\begin{array}{c}\text { Hemoconcentration } \\
(\mathrm{n}=12)\end{array}$ \\
\hline $\begin{array}{l}\text { Gestational age (days } \\
\text { postconception) }\end{array}$ & $55 \pm 3$ & $57 \pm 2$ & $57 \pm 2$ \\
Maternal wt (g) & $922 \pm 94$ & $888 \pm 146$ & $971 \pm 117$ \\
Litter size & $3.4 \pm 1.0$ & $2.7 \pm 1.1$ & $3.3 \pm 0.8$ \\
Mean fetal wt (g) & $54 \pm 14$ & $57 \pm 9$ & $55 \pm 9$ \\
Mean arterial pressure & $49 \pm 10$ & $53 \pm 10$ & $55 \pm 5$ \\
$\quad$ (mmHg) & $327 \pm 29^{*}$ & $269 \pm 31$ & $259 \pm 34$ \\
Heart rate (bpm) & $34 \pm 4$ & $33 \pm 4$ & $32 \pm 4$ \\
Hematocrit (xol\%) & & & \\
\hline
\end{tabular}

* $p<0.05$ (hemodilution versus two other groups, Wilcoxon rank sum test). 
Table 2

Cardiac output (mllmin), heart rate (bpm), systemic blood pressure (mmHg), systemic vascular resistance ( $\mathrm{mmHg} . \mathrm{g} . \mathrm{min} / \mathrm{ml}$ ), and cardiac output distribution (\%), before and $20 \mathrm{~h}$ after hemodilution, sham procedure (control), and hemoconcentration in the awake late-pregnant guinea pig

\begin{tabular}{|c|c|c|c|c|c|c|}
\hline & \multicolumn{2}{|c|}{$\begin{array}{l}\text { Hemodilution } \\
(n=13)\end{array}$} & \multicolumn{2}{|l|}{$\begin{array}{l}\text { Sham } \\
(\mathrm{n}=11)\end{array}$} & \multicolumn{2}{|c|}{$\begin{array}{l}\text { Hemoconcentration } \\
(\mathrm{n}=1,2)\end{array}$} \\
\hline & Before & After & Before & After & Before & After \\
\hline Hematocrit & $34 \pm 4$ & $28 \pm 4^{*}$ & $33 \pm 4$ & $32 \pm 3^{*}$ & $32 \pm 4$ & $38 \pm 3^{*}$ \\
\hline Cardiac output & $232 \pm 54$ & $222 \pm 42$ & $225 \pm 36$ & $209 \pm 40^{*}$ & $225 \pm 38$ & $223 \pm 22$ \\
\hline Heart rate & $327 \pm 29$ & $310 \pm 46^{*}$ & $269 \pm 31$ & $265 \pm 32$ & $259 \pm 34$ & $264 \pm 37$ \\
\hline Blood pressure & $49 \pm 10$ & $43 \pm 8^{*}$ & $53 \pm 10$ & $52 \pm 5$ & $55 \pm 5$ & $56 \pm 5$ \\
\hline \multicolumn{7}{|c|}{ Systemic vascular resistance $\stackrel{\ddagger}{\ddagger}$} \\
\hline Nonplacental & $133 \pm 28$ & $120 \pm 24$ & $137 \pm 20$ & $135 \pm 13$ & $153 \pm 22$ & $162 \pm 18$ \\
\hline placental & $30 \pm 12$ & $22 \pm 7$ & $27 \pm 10$ & $29 \pm 7$ & $40 \pm 7$ & $40 \pm 12$ \\
\hline \multicolumn{7}{|c|}{ Cardiac output fractions } \\
\hline Lungs & $4.9 \pm 2.0$ & $3.7 \pm 1.6^{*}$ & $5.1 \pm 1.6$ & $3.6 \pm 1.8^{*}$ & $5.1 \pm 1.7$ & $3.8 \pm 1.1^{*}$ \\
\hline Myocardium & $3.5 \pm 0.9$ & $4.1 \pm 1.2^{*}$ & $3.6 \pm 1.1$ & $3.6 \pm 0.6$ & $2.9 \pm 0.6$ & $2.9 \pm 0.7$ \\
\hline Brain & $1.9 \pm 0.5$ & $2.3 \pm 0.5^{*}$ & $2.2 \pm 0.2$ & $2.4 \pm 0.5^{*}$ & $2.1 \pm 0.5$ & $1.9 \pm 0.5$ \\
\hline Kidney & $10.3 \pm 1.7$ & $9.2 \pm 1.4^{*}$ & $9.9 \pm 2.0$ & $9.3 \# 3.0$ & $9.8 \pm 1.8$ & $10.9 \pm 2.5$ \\
\hline G.l.tract & $16.6 \pm 2.6$ & $16.7 \pm 2.1$ & $17.8 \pm 2.2$ & $17.4 \pm 1.4$ & $17.9 \pm 4.8$ & $16.9 \pm 4.6$ \\
\hline Skin & $5.8 \pm 2.0$ & $5.9 \pm 1.8$ & $5.8 \pm 1.4$ & $6.9 \pm 1.7$ & $4.9 \pm 1.3$ & $6.0+4.2$ \\
\hline Carcass & $37.6 \pm 7.6$ & $37.6 \pm 5.8$ & $37.3 \pm 6.4$ & $38.4 \pm 6.3$ & $40.0 \pm 8.7$ & $38.0 \div 9.1$ \\
\hline Placenta $^{\#}$ & $4.9 \pm 1.3$ & $7.0 \pm 1.3^{*}$ & $5.4 \pm 1.2$ & $6.3 \pm 1.4$ & $4.6 \pm 1.3$ & $6.0 \pm 1.8^{*}$ \\
\hline Placenta & $0.7 \pm 0.2$ & $0.9 \pm 0.3^{*}$ & $0.7 \pm 0.2$ & $0.8 \pm 0.2$ & $0.5 \pm 0.2$ & $0.7 \pm 0.2^{*}$ \\
\hline
\end{tabular}

† Placental vascular resistance per g fetal mass; nonplacental vascular resistance per g maternal minus fetoplacental weight.

* p $\quad 0.05$ (Wilcoxons' signed rank test).

\#, Placental fraction per $100 \mathrm{~g}$ fetus and per g placenta, respectively. 
microspheres recovered from the placentas. The placental blood flows of these animals were considered unreliable and therefore excluded from the subsequent analysis.

In order to evaluate the chronic relationship between various hemodynamic parameters and baseline Hct, the baseline data of all experimental animals were used. The baseline Hct ranged from $26 \%$ to 42 vol\%. Total cardiac output, systemic blood pressure, heart rate, and nonplacental vascular resistance in baseline condition did not correlate with the Hct. The cardiac output fractions and weight-specific blood flow to brain (Rsp=-0.35, $\mathrm{p}<0.05)$ and myocard (Rsp=-0.34, $\mathrm{p}<0.05$ ) correlated negatively, and those to the kidneys ( $\mathrm{Rsp}=$ $+0.36, \mathrm{p}<0.05$ ) correlated positively with the baseline Hct. Placental blood flow which varied independently of the spontaneous Hct, did correlate with total cardiac output ( $R s p=+0.49, n=27, p<0.01$ ). The oxygen flows, defined as the product of arterial oxygen content and blood flow, to the kidneys (Rsp=+0.56, $\mathrm{p}<0.001)$ and skin $(\mathrm{Rsp}=+0.32, \mathrm{p}<0.05)$ correlated positively with the baseline Het.

Effect of isovolemic hemodilution and hemoconcentration. A number of cardiovascular variables, before and $20 \mathrm{~h}$ after the isovolemic hemodilution, the sham procedure, and the isovolemic hemoconcentration are listen in Table 2 . Isovolemic hemodilution and hemoconcentration change the Hct by $6.3 \pm 3.0$ and $5.0 \pm 3.1 \mathrm{vol} \%$, respectively. Cardiac output did not change consistently after either exchange transfusion, but dropped significantly $(-6 \%)$ in the sham group. Hemodilution induced a significant decrease in blood pressure (-15\%), heart rate $(-6 \%)$, and the cardiac output fraction to the kidneys $(-9 \%)$. The cardiac output fractions to myocardium $(+16 \%)$, brain $(+13 \%)$, and placentas $(+45 \%)$ increased significantly. The percentage change in the flows to these four organs was comparable to the ones in the fractions. The sham procedure led to a small but consistent increase in the cardiac output fraction to the brain $(+4 \%)$. Hemoconcentration induced only a significant increase in the placental fraction of cardiac output $(+23 \%)$.

The weight-specific organ oxygen flow, before and $20 \mathrm{~h}$ after the isovolemic hemodilution, the sham procedure, and the isovolemic hemoconcentration are listen in Table 3. After hemodilution the total oxygen flow (product of cardiac output and arterial oxygen content) $(-23 \%)$ and the weight-specific oxygen flows to the kidneys $(-17 \%)$, the gastrointestinal tract $(-17 \%)$, and the carcass $(-15 \%)$ have decreased significantly. The oxygen flows to the placentas remained essentially unchanged. The sham procedure induced a significant decrease in total oxygen flow $(-11 \%)$ and the oxygen flow to the carcass $(-11 \%)$. After hemoconcentration, total oxygen flow $(+27 \%)$ and all organ oxygen 


\section{Table 3}

Total oxygen flow (in $\mu$ mollml) and regional axygen flows (in $\mu$ mollmin/100g) befor and 20 h after hemodilution, sham procedure (control), and hemoconcentration in the awake late-pregnant guinea pig.

\begin{tabular}{|c|c|c|c|c|c|c|}
\hline & \multicolumn{2}{|c|}{$\begin{array}{l}\text { Hemodilution } \\
(n=9)\end{array}$} & \multicolumn{2}{|l|}{$\begin{array}{l}\text { Sham } \\
(\mathrm{n}=10)\end{array}$} & \multicolumn{2}{|c|}{$\begin{array}{l}\text { Hemoconcentration } \\
(\mathrm{n}=12)\end{array}$} \\
\hline & Before & After & Before & After & Before & After \\
\hline Total O2 flow & $1678 \pm 380$ & $1155 \pm 299^{*}$ & $1561 \pm 337$ & $1321 \pm 253^{*}$ & $1384 \pm 384$ & $1644 \pm 246^{*}$ \\
\hline Myocardium & $2068 \pm 326$ & $1951 \pm 600$ & $2248 \pm 579$ & $2040 \pm 433$ & $1582 \pm 399$ & $1936 \pm 466^{*}$ \\
\hline Brain & $676 \pm 203$ & $641 \pm 191$ & $818 \pm 142$ & $788 \pm 157$ & $675 \pm 212$ & $731 \pm 183$ \\
\hline Kidneys & $2595 \pm 959$ & $1825 \pm 568^{*}$ & $2376 \pm 414$ & $2014 \pm 219$ & $1945 \pm 492$ & $2655 \pm 990^{*}$ \\
\hline G.1.tract & $971 \pm 278$ & $842 \pm 365^{*}$ & $1017 \pm 183$ & $906 \pm 82$ & $851 \pm 229$ & $998 \pm 230^{*}$ \\
\hline Skin & $69 \pm 30$ & $57 \pm 27$ & $84 \pm \| 1$ & $83 \pm 19$ & $60 \pm 22$ & $72 \pm 13^{*}$ \\
\hline Carcass & $172 \pm 25$ & $109 \pm 25^{*}$ & $172 \pm 42$ & $153 \pm 35^{*}$ & $145 \pm 48$ & $163 \pm 48^{*}$ \\
\hline Placenta & $899+299$ & $831 \pm 325$ & $815 \pm 206$ & $843 \pm 128$ & $641 \pm 223$ & $1033 \pm 233^{*}$ \\
\hline
\end{tabular}

$p<0.05$ (Wilcoxons' sigmed rank test).

\# Per kg fetal weight.

flows, except that to the brain, had increased significantly with a median value between 20 and $30 \%$. Placental oxygen flow had increased with a median value of $55 \%$.

A number of cardiovascular parameters together with the distribution of oxygen over various organs after hemodilution, sham, and hemoconcentration were compared with these parameters at corresponding spontaneous Hct. To this end, all baseline observations on oxygen flows and nonplacental vascular resistance were divided over three reference groups: an anemic group ( Hct $<31$ vol\%), a normal Hct group ( $31<\mathrm{Hct}<36$ vol\%), and a polycythemic group ( $\mathrm{Hct}$ $>36$ vol $\%$ ) (Table 4). The placental flow and vascular resistance after hemodilution was significantly lower than in the anemic reference group. Total and renal oxygen flow were significantly lower after the sham procedure as compared to the values observed in the normal Hct reference group. Placental $\mathrm{O}_{2}$ flow was significantlly higher in both the hemodilution and hemoconcentration group as compared to the anemic and polycythemic group, respectively. All other oxygen flows after hemodilution and hemoconcentration did not differ significantly from those in the anemic and polycythemic reference group, respectively. 


\section{Trable 4}

Blood pressure (mmHg), Vascular resistance $(\mathrm{mmHg} \cdot \mathrm{g} \cdot \mathrm{min} / \mathrm{ml})$, total oxygen flow (umollmin), oxygen flows to individual organs (umol/min/loog) in a condition of chronic anemia $(n=12)$, normal Hb $(n=12)$, and polycythemia $(n=11)$ as compared to the state after hemodilution $(n=9)$, after the sham procedwe $(n=10)$, and after hemoconcentration $(n=12)$, respectively.

$\begin{array}{llll}\frac{\text { Low Hat }}{\mathrm{In}} & \text { After } & \text { Normal Hct } & \\ & \text { At } & \text { After } \\ \text { anemiat } & \text { hemodilution } & \text { normal Hct } & \text { sham }\end{array}$

\begin{tabular}{ll}
\multicolumn{2}{l}{ Elevated Hct } \\
\hline In & After \\
polycy- & hemo- \\
themia & concentration
\end{tabular}

\begin{tabular}{lllllll}
\hline Helt (volio) & $28.6 \pm 1.7$ & $28.1 \pm 3.6$ & $32.6 \pm 1.5$ & $31.8 \pm 3.1$ & $38.1 \pm 2.0$ & $38.1 \pm 3.5$ \\
Blood pressure & $54.9 \pm 2.3$ & $43.5 \pm 8.9^{*}$ & $50.8 \pm 9.1$ & $51.8 \pm 5.9$ & $56.6 \pm 7.6$ & $56.3 \pm 5.4$
\end{tabular}

Vascular resistance

$\begin{array}{lrcrrrr}\text { Nonplacental } & 140 \pm 28 & 120 \pm 24 & 135 \pm 25 & 135 \pm 13 & 149 \pm 18 & 162 \pm 18 \\ \text { placental } & 37 \pm 16 & 22 \pm 7^{*} & 29 \pm 14 & 29 \pm 7 & 33 \pm 6 & 40 \pm 12\end{array}$

$\mathrm{O}_{2}$ Illows

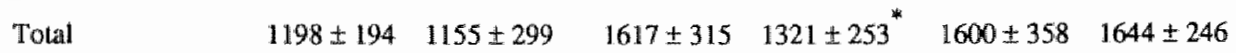

$\begin{array}{lrrrrrr}\text { Organs } & & & & & \\ \text { Myocardium } & 1836 \pm 378 & 1915 \pm 600 & 1960 \pm 651 & 2040 \pm 433 & 1993 \pm 519 & 1936 \pm 466 \\ \text { Brain } & 701 \pm 183 & 641 \pm 191 & 771 \pm 182 & 788 \pm 157 & 751 \pm 232 & 731 \pm 183 \\ \text { Kidneys } & 1709 \pm 337 & 1825 \pm 568 & 2527 \pm 692 & 2014 \pm 219^{*} & 2838 \pm 834 & 2475 \pm 483 \\ \text { Gastrointestinal tract } & 893 \pm 281 & 842 \pm 365 & 1001 \pm 198 & 906 \pm 82 & 1035 \pm 315 & 961 \pm 1.16 \\ \text { Skin } & 57 \pm 23 & 57 \pm 27 & 81 \pm 23 & 83 \pm 19 & 77 \pm 25 & 72 \pm 13 \\ \text { Carcass } & 134 \pm 48 & 109 \pm 25 & 164 \pm 37 & 153 \pm 35 & 185 \pm 55 & 163 \pm 48 \\ \text { Placenta } & 558 \pm 117 & 831 \pm 325^{*} & 838 \pm 244 & 772 \pm 153 & 775 \pm 270 & 1033 \pm 233^{*}\end{array}$

* Placental vasular resistance per g fetal mass; nonplacental vascular resistance per $\mathrm{g}$ maternal minus fetoplacental weight.

* p 0.05 (Wilcoxons' rank sum test).

H.H Expressed per $\mathrm{kg}$ of fetal weight. 
The guinea pig is a polytocous species which allows intralitter comparisons. The weight difference between the smallest and largest littermate was about $20 \%$. The median increase in placental blood flow after hemodilution and hemoconcentration in the largest littermate was 37 and $25 \%$, respectively, as compared to 68 and $20 \%$, respectively, in the smallest littermate. After hemodilution, the oxygen flow to the placenta of both the largest and smallest littermate did not change consistently. Hemoconcentration increased the oxygen flow to the largest littermate with $61 \%$ and to the smallest littermate with $42 \%$. The relative change in blood and oxygen flow observed in the largest littermate did not differ significantly from the corresponding values determined for the smallest littermate.

\section{Discussion}

The Hct values observed in this study ranged from 26 to 42 vol\%. It was thought that inducing Hct changes in this interval would not trigger complex unphysiologic responses. In the late-pregnant guinea pig, Hct values below 26 vol\% are often associated with an increased lactate output by the pregnant uterus (11). Such low Hct values did not occur in the present study. On the other hand, Hct values after hemoconcentration never exceeded the spontaneously occurring Het of 42 vol\%, a value that may still be considered physiologic (15). The effects of isovolemic hemodilution and hemoconcentration on maternal hemodynamics may be caused by the change in whole blood oxygen capacity or the change in whole blood viscosity; both variables were closely linked to one another in our experimental design. Hemodynamic changes after exchange transfusion not observed spontaneously in relation to Hct are caused by factors other than the induced Hct change, such as changes in vascullar tone hormone levels, plasma osmolality, non-Het related viscosity, blood volume etc. In the present study, the Hct was measured in the abdominal aorta. At the tissue level, this Hct can differ markedly from this central Hct (16). Therefore, differences in the relationship between spontaneous arterial Hct and hemodynamics, and those after hemodilution or hemoconcentration may result from differences created in the Hct at the tissue level. Whether the injection of microspheres could have caused the observed non-Hct-related changes in the maternal circulation is highly unlikely since the microspheres circulate only briefly after intraventricular injection while the interval between the two experiments was relatively long. 
Cardiac output did not correlate with the spontaneous. Hct or change in response to exchange transfusion. The approximately $6 \%$ lower cardiac output after the sham procedure is most likely related to the $\pm 7 \%$ reduction in blood volume caused by blood sampling on the 1 st day of experimentation. In contrast with the exchanged animals, the autotransfusion in the sham procedure did not compensate for the blood removed during the control experiment. In order to avoid more or less unpredictable changes related to (donor) blood transfusion in this group, we accepted the potential effects of slight hypovolemia: reduction in cardiac output and a shift of fluid from the interstitium into the intravascular compartment. Placental blood flow was found to vary in proportion to cardiac output. Therefore, the observed fall in cardiac output might have induced a fall in placental blood flow or might have limited a possible increase in placental blood flow after the sham procedure. In most animal species, cardiac output increases after isovolemic hemodilution (17-19). This increase in thought to be caused by a reduction in red cell aggregability which lowers the venous resistance and thus increases cardiac preload $(20,21)$. Cardiac output in guinea pig pregnancy increases only little, if any $(10,22)$. In this respect it is interesting that the fall in peripheral resistance induced with hemodilution is only associated with a fall in blood pressure without any increase in cardiac output. The following two characteristics of guinea pig pregnancy may explain this response. 1) In the last 2 wk of pregnancy the guinea pig appears to develop a state of relative hypovolemia because of a gradually developing gap between the rate of plasma volume expansion and the growth rate of the uteroplacental vascular bed. Support for this comes from recent experiments in our laboratory were hypervolemic hemodilution was found to induce a significant rise in cardiac output and a suppression of the normal redistribution of cardiac output in late pregnancy (10).2) We found that red cell aggregability in the guinea pig also measured with a Myrenne MA1 apparatus was about one-third the value reported for the human (4). In addition, shear rate is likely to be several fold higher in the guinea pig than for example in the human because of its relatively high cardiac output $(10,21)$. Because of these two factors, changes in low shear viscosity play a negligible role in the guinea pig. Therefore, hemodilution will only decrease high-shear viscosity which implies no reduction in venous resistance and thus no increase in cardiac preload.

It is noteworthy that in the present study placental blood flow increased approximately 45 and $25 \%$ after isovolemic hemodilution and hemoconcentration respectively. Assuming normal fetal growth and placental blood flow increasing in proportion to fetal size $(10,22), \pm 7 \%$ of this increase in both groups can be accounted for by the advancement of the pregnancy between the 
two experiments. This increase was probably blunted in the sham drop due to the reduction in blood volume. Overnight systemic shunting did not correlate with any of the hemodynamic variables measured. Therefore, it is likely that this shunting is similar in the three experimental groups. Assuming also comparable overnight leakage of microspheres from the placentas in the three groups, most of the increase in placental fraction of cardiac output in the sham group (median $=16 \%$ ) may be considered a result of shunting. Subtraction of both "flow-increasing" factors $(20-25 \%)$ would result in a net procedure-related increase in placental blood flow after hemodilution of $\pm 20 \%$. The observed increase in placental blood flow after hemoconcentration would be completely caused by advancing gestation and selectively shunting. The flow rise in the placentas in combination with the fall in peripheral vascular resistance after hemodilution may result from a reduction in whole blood viscosity. Since placental vascular resistance is not lower in anemia (Table 4), the placental circulatory reponse to hemodilution is caused by the hemodilution procedure itself rather that by the change in Hct. Isotonic plasma does not influence red cell deformability in vitro (3). Thus, it is unlikely that the administration of $8 \mathrm{ml}$ of isotonic donor plasma increases red cell deformability (3). It has already been mentioned that the role of changes in red cell aggregability is probably negligible in the guinea pig. Therefore, it seems that the increase in placental perfusion after hemodilution cannot be attributed to a change in these viscosity variables. In the present study blood volume was not determined. Therefore, it cannot be excluded that the increase in placental perfusion is somehow related to an increase in circulating blood volume, e.g. due to a transfusion-related change in plasma osmolality. The absence of a rise in cardiac output makes any important change in blood volume unlikely. The hemochorial placenta has a unique microarchitecture consisting of a porous structure instead of a capillary bed (23). In a capillary bed a rise in pressure gradient increases shear rate which in turn, reduces apparent viscosity (24). In contrast, a rise in pressure gradient and thus shear rate across a porous structure, is known to cause an increase in apparent viscosity (25).

To explain the selective, non-Hct-related rise in placental perfusion the following hypothesis is proposed. The fall in Hct after hemodilution decreases high-shear viscosity and thus peripheral vascular resistance. The associated lower blood pressure and thus perfusing pressure across the systemic circulation has a favorable mechanical effect selectively on the placental microcirculation. Blood rheology in the intervillous space improves in response to the lower shear rate giving rise to a decrease of the apparent viscosity across the placentas relative to the other capillary beds. The flow rise in the placentas, however, lasts only for the period during which the blood pressure is reduced. It is likely that 
baroreceptor and chemoreceptor responses will gradually normalize blood pressure and thus indirectly normalize the elevated placental blood flow. Placental oxygen flow is to decrease gradualiy to reduced value observed in anemic animals (Table 4). It should be stressed that this hypothesis is not based on experimental data. In fact, it is yet unknown how the pressure-flow relationship across a hemochorial placenta exists in an intact animal, where the simultaneously determined pressure-flow relationship of other organs can serve as a reference. The guinea pig placenta extracts about $60 \%$ of the supplied oxygen due to its unique countercurrent vascular arrangement $(9,29)$. Therefore it is unlikely that improvement of rheologic properties of blood within the intervillous space, associated with a fall in oxygen capacity, will improve transplacental oxygen transport. This is evidenced by the fact that a Hct of less than $27 \mathrm{vol} \%$ is associated with an increased risk for indadequate oxygenation of the conceptus in this species (11).

Taking into account the contributions of advancing gestation and ovemight shunting, hemoconcentration was not followed by a significant change in placental perfusion. However, the lack of a real increase in placental perfusion after hemoconcentration further supports the absence of a relationship between placental blood flow and Hct.

Our observations of a lack of a relationship between Hct and placental blood flow are in contrast with reports on the inverse relationship between newborn weight and maternal $\mathrm{Hb}$ concentration $(26,27)$. Placental blood flow correlates closely with cardiac output which, in turn varies as a function of blood volume (19). However, in these studies no information was available on total maternal blood volume. Therefore, it is possible that the reported relationship reflects the well-known correlation between newborn weight and total plasma compartment (28). It should also be kept in mind that the animals in the present study were healthy and had normal placentas, which may not be so in women with impaired fetal growth.

A relationship between the perfusion of brain, heart, kidneys and Hct, was seen spontaneously as well as after exchange transfusion. Consequently these changes are related to the Hct change. Hct-related changes in the perfusion of the brain and heart may reflect the relationship between flow and arterial oxygen content, as it is well known for these organs (30-32). The higher blood flows to brain and heart, both after hemodilution and in a state of anemia, allow for a maintained oxygen flow to these tissues. The lower renal blood flow at reduced Hct is probably a reflex-mediated effect due to the reduced blood oxygen capacity in a state of anemia and after hemodilution. Mild anemic hypoxia enhances sympathetic activity $(31,33,34)$ which is associated with renal vasoconstriction. Hemoconcentration tended to change the cardiac output 
fractions to heart, brain, and kidneys in the opposite direction to what was observed after hemodilution (Table 2). In the upper range of the Hct, changes in flow are probably smaller in response to a certain change in Hot or oxygen content due to the reciprocal relationship between flow and oxygen $(30,32)$. This may explain why flow changes to brain and heart were insignificant after hemoconcentration. Hemoconcentration induces only minor changes in the maternal circulation. Nevertheless, $\mathrm{O}_{2}$ capacity of blood has increased with as much as $20 \%$, the extra oxygen being evenly distributed over the peripheral tissues. This apparently favorable effect of isovolemic hemoconcentration is probably species related since the guinea pig with its low red cell aggregability and its high blood velocity will not respond to the Hct rise with a higher venous resistance and associated lower cardiac output. Skin flow varies independently from the Hct. Therefore, the correlation between the skin oxygen supply and spontaneous $\mathrm{Hct}$ seems to reflect entirely the relationship between arterial oxygen capacity and Hct.

The observations on the intralitter comparison are interesting. As with Myers et al. (35), we observed in our animals about $20 \%$ lower weight-specific uteroplacental blood flow to the smallest fetus in the litter compared to the largest. In order to completely compensate for the relative underperfusion, the oxygen extraction should be as high as $\pm 72 \%$. The smallest fetus is particularly prone to asphyxia because its probably marginal $\mathrm{O}_{2}$ supply relies heavily on extraction. This growth-retarded fetus will be particularly vulnerable in shortterm reductions in placental blood flow; e.g. as may occur during stress. Short-term episodes of mild hypoxia will also interfere with fetal growth. It follows that the smallest littermate benefits most from any rise in $\mathrm{O}_{2}$ supply because it diminishes its dependence on $\mathrm{O}_{2}$ extraction out of the danger zone. 


\section{References}

1. Hytten FE, Paintin DB 1965 Increase in plasma volume during normal pregnancy. J Obstet gynaecol Br Commonwealth 70;402-207

2. Buchan P 1982 Pre-eclampsia. A hyperviscosity syndrome. Am J Obstet Gynecol $1.42: 111-112$

3. Chieri 1975 Biophysical behavior of the red cell in suspension. In:Surgenor D (ed) The red blood cell. Academic Press, New York, pp 1031-1033

4. Schmid-Schónbein H 1976 Microrheology of erythrocytes, blood viscosity and the distribution of blood flow in the microcirculation. In Guyton AC, Cowley AW (eds) International review of physiology II, vol 9. University Park Press, Baltimore, pp 1-62

5. Groenendijk R, Trimbos JBMJ, Wallenburg HCS 1984 Hemodynamic measurements in pre-eclampsia:Preliminary observations. Am J Obstet Gynecol 150:232-236

6. Kaar K, Jouppila J, Luotola H, Toivanene J, Rekonen A 1980 Intervillous blood flow in normal and complicated late pregnancy measured by means of an intervillous ${ }^{133} \mathrm{Xe}$ method. Acta Obstet Gynecol Scand 59:7-10

7. Fumia FD, Edelstone DI, Holzman IR 1984. Blood flow and oxygen delivery to fetal organs as a function of fetal hematocrit. Am J Obstet Gynecol 150:274-282

8. Kiyohara Y, Masatoshhi F, Takao I, Tamaki K, Seizo S, Teruo O 1985 Effects of hematocrit on brain metabolism in experimentally induced cerebral ischemia in spontaneously hypertensive rats (SHR). Stroke 16:835-840

9. Peeters LLH, Mårtensson L, van Kreel BK, Wallenburg HCS 1984 Uterine arterial and venous concentration of glucose, lactate ketones, free fatty acids, and oxygen in the awake pregnant guinea pig. Pediatr Res 18:1172-1175

1.0. Peeters LLH, Grutters G, Martin CB 1980 The distribution of cardiac output in the unstressed pregnant guinea pig. Am J Obstet Gynecol 138:1177-1184

11. Peeters LLH, Mărtensson L, v Kreel BK, Saxena PR, Wallenburg HCS 1986 Movement of oxygen, glucose and lactate across the uterus of the awake near-term guinea pig. Pediatr Res 20:7307-734

12. Saxena PR, Schamhardt HC, Forsyth RP, Loeve J 1980 Computer programs for the radioactive microsphere technique. Determination of regional blood flows and other hemodynamic variables in different experimental conditions. Comp Prog Biomed $12: 63-84$

13. Widmann FK 1985 Technico manual of the american assocation of blood banks, 9 th ed. Karger, Basel, Switzerland

14. Saxena PR, Verdouw PD 1982 Redistribution of 5-hydroxytryptamine of carotid arterial blood at the expense of arteriovenous anastomotic blood flow. J Physiol (Lond) $332: 501-520$

15. Baumann R, Bauer C, Bartels H 1971 Influence of chronic and acute hypoxia on oxygen affinity and RBC 2,3-diphosphoglycerate of rats and guinea pigs. Respir Plyysiol 11:135-144 
16. Gaehtgens P 1980 Flow of blood through narrow capillaries: Rheological mechanisms determining capillary hematocrit and apparent viscosity. Biorheology 17:183-189

17. Sunder-Plasmann L, Kessler M, Jesch F, Dieterle $R$, Messmer K 1975 Acute normovolemic hemodilution. In:Messmer $\mathrm{K}$, Schmid-Schönbein $\mathrm{H}$ (eds) Internationall hemodilution Biblthca Haemat 41. Karger, Basel Switzerland, pp $44-53$

18. Messmer K 1981 Compensatory mechanism for acute dilutional anemia. Bibl Haematologica $47: 31-42$

19. Guyton $\mathrm{AC}_{\mathrm{y}}$ Jones $\mathrm{CE}$, Colemon TG 1985 Circulatory Physiology:Cardiac output and its regulation. WB Saunders, Philadelphia

20. Schmid-Schönbein H 1981 Factors promoting and preventing the fluidity of blood. In: Effros RM, Schmid-Schönbein H, Ditzel J (eds) Microcirculation. Academic Press, New York, pp 249-266

21. Messmer K, Sunder-Plassmann L, Klovekorn WP, Holper k 1972 Circulatory significance of hemodilution: rheological changes and limitations. In: Advances in microcirculation. vol 4. Karger, Basel, Switzerland, pp 1-73

22. Myers SA, Hsui-Yu Tseng MS 1985 A longitudinal study of cardiac output in unstressed pregnant guinea pigs. Am J physiol 248:R698-R701

23. Ramsey EM, Donner MW 1980 Placental vasculature and circulation. WB Saunders, Philadelphia

24. Geahtgens $\mathbf{P} 1981$ Distribution of flow and red cell flux in the microcirculation. Scand J Clin Invest 41 (suppl 156):83-87

25. Dullien FAL 1979 Porous media, fluid transport and pore structure. Academic press, New York

26. Mau G 1977 Hemoglobin changes during pregnancy and growth disturbances in the neonate. J. Perinatol Med 5:172-177

27. Sagen N, Nilsen ST, Kim HC, Bergsjo P, Koller O 1984 Maternal hemoglobin concentration is closely related to birth weight in normal pregnancies. Acta Obstet Gynecol Scan 63:245-248

28. Goodlin RC, Quaife MA, Dirksen JW 1981 The significance, diagnosis and treatment of matemal hypovolemia associated with fetal/maternal il ness. Semin Perinatol 5:163. 174

29. Meschia G 1983 Circulation to female reproductive organs. In:Geiger SR (ed) Handbook of Physiology, The cardiovascular system III. American Physiology Society, Bethesda, MD, pp 241-269

30. Guyton AC 1976 Textbook of Medical Physiology. WB Saunders, Philadelphia

31. Fan Foung-Chung, Chen RYZ, Schuessler GB, Chien S 1980 Effects of hematocrit variation on regional hemodynamics and oxygen transport in the dog. Am J Physiol 238:H545-522

32. Brown MM, Marshall J 1985 Regulation of cerebral blood flow in response to changes in blood viscosity. Lancet 1:604-609 
33. Glick $\mathrm{G}_{3}$, Plauth WH Jr, Braunwald E 1964 Role of autonomic nervous system in the circulatory response to acutely induced anemia in unanesthetized dogs. I. Clin. Invest $43: 2112-2124$

34. McDonald KM 1974 Effect of hematocrit and colloid-induced changes in blood viscosity on renal hemodynamics and renin release in the dog. Circ Res 34:112-122

35. Myers SA, Sparks JW, Makowski EL, Meschia G, Battaglia FC 1982 Relationship between placental blood flow and placental and fetal size in guinea pig. Am J Physiol 243:H404 H409. 


\section{Nondeformable red blood cells do not interfere with uteroplacental blood flow in awake late-pregnant guinea pig}

Carla M Verkeste, Peter F Boekkooi, Pramod R Saxena and Louis LH Peeters

Accepted for publication in Pediatric Research

\section{Abstract}

The fractional entrapment of rigidified -relative to control (labeled) red cells-following the intravascular bolus injection of a cocktail of these cells, and the concomitantly induced changes in cardiac output and its distribution (microspheres) were studied in 14 awake late-pregnant guinea pigs. In a preceding validation study in 8 nonpregnant guinea pigs, it was demonstrated that with this technique reproducible data could be generated on the fractional entrapment of rigidified red cells in all organs in this species except for lungs, liver and spleen.

In response to a bolus injection with rigidified and control red cells, only the brain showed preferential entrapment of rigidified red cells, together with a small but consistant increase in blood flow. In other organs (lungs, liver and spleen excluded) neither preferential entrapment of rigidified red blood cells, nor a consistent change in blood flow could be demonstrated.

The results of this study suggest that circulating nondeformable red cells have no measurable adverse effect on the perfusion of the nondiseased hemo- 
chorial placenta in the awake late-pregnant guinea pig. This does not exclude that rigidified red cells may increase the resistance to flow in a microcirculation which has been pathologically changed by some underlying disease.

\begin{tabular}{|l} 
Abbreviations \\
BV $=$ Blood volume $(\mathrm{ml})$ \\
$\mathrm{CO}=$ Cardiac output $\left(\mathrm{ml} \cdot \mathrm{min}^{-1}\right)$ \\
$\mathrm{Hct}=$ Hematocrit $(\mathrm{vol} \%)$ \\
$\mathrm{HR}=$ Heart rate $(\mathrm{bpm})$ \\
IUGR $=$ Intra uterine growth retardation \\
MAP $=$ Mean arterial pressure (mmHg) \\
RBC $=$ Red blood cell \\
RES $=$ Reticuloendothelial system \\
UBF $=$ Uteroplacental blood flow $\left(\mathrm{ml}^{\left.-\mathrm{min}^{-1}\right)}\right.$
\end{tabular}

\section{Introduction}

The $\mathrm{RBC}$ membrane is a complex structure able to mold into a kaleidoscope of shapes in response to shear forces exerted on its surface. This property is referred to as RBC deformability and depends on the ratio between surface area and cell volume, the composition of the cell membrane, and the cytoplasmatic viscosity of the RBC. The deformability of the RBC serves the following functional purposes: 1) It reduces the resistance of $\mathbb{R B C s}$ while they travel across both the macro and microcirculation, 2) It improves the cell-to-wall contact in the capillaries thus favoring gas exchange with the surrounding tissue. 3. It reduces friction among RBCs in flowing blood. The overall effect of these characteristics is a lower blood viscosity, particularly in high shear conditions.

The question as to how (human) pregnancy affects erythrocyte deformability is still unsettled, as indicated by reports claiming an unchanged $(2,3)$, an increased $(4-8)$, or a decreased RBC deformability $(9,10)$ in the course of pregnancy. The controversy with respect to RBC deformability in normal pregnancy may be purely technical, being associated with its complex measurement and modest reproducibility. In pregnancies complicated by preeclampsia 
or intra-uterine growth retardation (IUGR), RBC deformability is diminished, thus contributing to the elevated whole blood viscosity in these conditions ( 6 , $11,12)$. However, these studies do not elucidate whether the lower RBC deformability is a cause or an effect of the pregnancy complication for the following two reasons: 1) It is unknown whether RBC deformability decreases before, or in concert with the development of fetal growth retardation/preeclampsia. 2) The experimental data in the studies mentioned above are based on measurements in blood ex vivo and thus, do not take into account the interaction between $\mathrm{RBCs}$ deformability and pathologically changed placental microcirculation.

Assuming a cause/effect relationship, one could speculate that rigid erythrocytes encounter more resistance during their passage through the pores of the intervillous microarchitecture, thus giving rise to a higher overall resistance to flow. This phenomenon would be reflected in a higher placental entrapment of stiff $\mathrm{RBCs}$ relative to normal $\mathrm{RBCs}$, together with a reduced UBF.

The objective of the present study was to determine in the awake late-preg nant guinea pig: 1) the ease of rigid relative to control RBCs, to pass across the nonuterine capillary microcirculation, and the effects of a bolus injection with rigidified and control $\mathrm{RBCs}$ on $\mathrm{CO}$ and its distribution; 2) the smoothness by which rigidified relative to control RBCs travel across the porous placental microcirculation, and the effect of a bolus injection with rigidified and control RBCs on UBF. Prior to this study the methodology to measure fractional entrapment of differently labeled manipulated $\mathrm{RBCs}$ was validated in a group of nonpregnant guinea pigs.

\section{Materials and methods}

The study was performed in 8 nonpregnant and 14 late-pregnant albino guinea pigs with known postconceptional dates, supplied by a commercial. breeder (Winkelman, Borchen, West Germany). Under general anesthesia and using aseptic techniques, polyethylene catheters $(\mathrm{OD} / \mathrm{ID}=0.96 / 0.58 \mathrm{~mm})$ were inserted into the left ventricle, external jugular vein, and abdominal aorta as described in a previous report (13). In pregnant animals the cannulation was performed around the $48^{\text {th }}$ day of gestation (term $=68$ days). All animals were allowed to recover from surgery for at least 6 days.

Evaluation of label suitability. Eight nonpregnant guinea pigs were used to evaluate whether the injection of ${ }^{51} \mathrm{Cr}$ and ${ }^{59} \mathrm{Fe}$ labeled $\mathrm{RBCs}$ would result in a 
comparable fractional entrapment in the microcirculation. Such an observation would rule out methodologic error associated with type of radioactive label. The experiment was started by continuous monitoring of MAP and HR in the abdominal aorta (Statham pressure transducer) and measuring the arterial Hct (microcapillary method). After at least 15 minutes steady state in MAP and HR, $\mathrm{CO}, \mathrm{CO}$ distribution and the regional blood flows were determined with $15 \mu \mathrm{m}$ radioactive microspheres as follows (14): Microspheres, labeled with either ${ }^{141} \mathrm{Ce}$ or ${ }^{103} \mathrm{Ru}$, were injected into the left ventricle over a period of $20 \mathrm{~s}$, while a reference sample was withdrawn from the abdominal aorta at a rate of 0.6 $\mathrm{ml} \cdot \mathrm{min}^{-1}$, from $10 \mathrm{~s}$ before injection until $30 \mathrm{~s}$ after flushing ( $1 \mathrm{ml}$ saline). Immediately after flushing, a $10 \mathrm{ml} \mathrm{RBC}$ suspension with an Hct adjusted to that of the recipient animal, and prepared with blood from a nonpregnant donor guinea pig, was administered intravenously over a period of $5 \mathrm{~min}$. The RBC suspension was prepared as follows: Ten $\mathrm{ml}$ blood from a donor guinea pig, were centrifugated ( $3000 \mathrm{rpm}, 10 \mathrm{~min}$ ), the supernatant removed and the RBCs resuspended in phosphate buffer for $30 \mathrm{~min}(15)$. After recovery of the $\approx 3.5 \mathrm{ml}$ RBCs (recentrifugation) they were divided into 2 equal batches which were subsequently labeled with either ${ }^{51} \mathrm{Cr}\left(2.5 \mu \mathrm{Ci} . \mathrm{ml}^{-1}\right)$ or ${ }^{59} \mathrm{Fe}\left(2.0 \mu \mathrm{Ci} . \mathrm{ml}^{-1}\right)$ as detailed in the same report (15). Then the suspension was recentrifugated, the supernatant removed and diluted in plasma to obtain the Hct of the recipient guinea pig. Three blood samples of $3 \mathrm{ml}$ each were withdrawn from the abdominal aorta at 5, 10 and 15 min after the injection of the cocktail, in order to determine the ${ }^{51} \mathrm{Cr} /{ }^{59} \mathrm{Fe}$ ratio in the circulating blood. Twenty minutes after the administration of the $\mathrm{RBC}$ suspension, $\mathrm{CO}$ and its distribution were remeasured using the microsphere with the other label.

Finally, the animals were sacrificed by an overdose of pentobarbital, all organs dissected and the accumulated gamma radiation determined with a sodium crystal scintillation counter (Packard, Delft, The Netherlands). CO, CO distribution and regional blood flows before and after the injection of the suspension were calculated as described previously (16). The fractional accumulation of ${ }^{51} \mathrm{Cr}$ labeled cells relative to that of ${ }^{59} \mathrm{Fe}$ labeled cells ( $\mathrm{R}_{\mathrm{rel}}$ ) was calculated for each tissue using the following equation:

$$
R_{\text {rel }}=\frac{\text { tissue activity }{ }^{51} \mathrm{Cr} / \text { activity }{ }^{51} \mathrm{Cr} \text { in blood sample }}{\text { tissue activity }{ }^{59} \mathrm{Fe}^{+} / \text {activity }{ }^{59} \mathrm{Fe} \text { in blood sample }}
$$

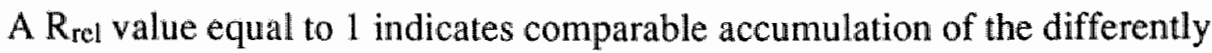
labeled control RBCs, whereas a value higher or lower than 1 indicates preferential trapping of ${ }^{51} \mathrm{Cr}$ or ${ }^{59} \mathrm{Fe}$-labeled cells, respectively. 
In each animal the blood volume $(\mathrm{BV}, \mathrm{ml})$ was estimated according to the equation:

$$
B V+9=\frac{\text { Total injected activity }{ }^{51} \mathrm{Cr} \times \text { weight blood sample }}{\text { activity }{ }^{51} \mathrm{Cr} \text { in blood sample }}
$$

$\mathrm{RBC}$ trapping may be affected by the sacrifice procedure. To verify that our procedure involving the intraventricular injection of barbiturates did not invalidate the fractional entrapment of $\mathrm{RBCs}$, the intravascular space in each organ $\left(\mathrm{ml} .100 \mathrm{~g}^{-1}\right)$ was estimated by using the information provided by the ${ }^{5 \mathrm{l}} \mathrm{Cr}$ labeled control RBCs and the estimated BV:

$$
\text { Tissue intravascular space }=\frac{\text { tissue activity }{ }^{51} \mathrm{Cr} \times \mathrm{BV} \times 100}{\text { total injected activity }{ }^{51} \mathrm{Cr} \times \text { organ weight }}
$$

Deformability study. The subsequent study was performed in fourteen 55-57 days pregnant guinea pigs (table 1). The study protocol was identical to the one described above with the only exception that the RBC suspension was treated differently: Half of the $\approx 3.5 \mathrm{ml}$ donor RBCs in the suspension were incubated in $0.025 \%$ glutaraldehyde diluted with phosphate buffer (rigidified) at $37^{\circ} \mathrm{C}$ for 30 min as described previously (15). The other half (control) was incubated in the phosphate buffer as described above. After incubation, both rigidified and control cells were labeled, centrifugated and resuspended in plasma as described above. Details about the rigidification procedure are described elsewhere (15). The subsequent labeling was randomized: Seven animals received a cocktail with ${ }^{51} \mathrm{Cr}$ labeled rigidified cells and ${ }^{59} \mathrm{Fe}$ control cells, whereas in the other seven guinea pigs the labels were reversed. The trapping of rigidified cells as fraction of control cells $\left(\mathrm{T}_{\mathrm{rel}}\right)$ for these animals was calculated by the following equation:

$$
T_{\text {rel }}=\frac{\text { tissue activity hardened cells/activity hardened cells in blood sample }}{\text { tissue activity control cells/ activity control cells in blood sample }}
$$

Statistics. Paired observations were analyzed with the Wilcoxon Rank Sign Test. BV and intravascular space for each tissue in the nonpregnant group were compared with those in the late-pregnant group using the Mann-Whitney test. A p-value less than 5\% was considered significant. Results are expressed as mean \pm standard deviation (SD) throughout the text. 


\section{Results}

Evaluation of label suitability. In 8 nonpregnant guinea pigs we studied the comparability of RBC trapping in the microcirculation when these cells differed only by type of label: ${ }^{59} \mathrm{Fe}$ or ${ }^{51} \mathrm{Cr}$. The relative distribution of ${ }^{51} \mathrm{Cr}$ and ${ }^{59} \mathrm{Fe}$-labeled cells $\left(\mathrm{R}_{\mathrm{rel}}\right)$, calculated for each tissue, are shown in figure 1 . The

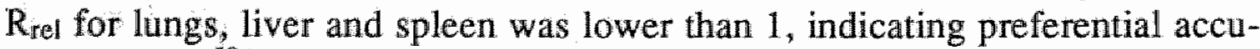
mulation of ${ }^{59} \mathrm{Fe}$ in these organs. It follows that the use of a RBC cocktail containing both ${ }^{59} \mathrm{Fe}$ and ${ }^{51} \mathrm{Cr}$ labeled $\mathrm{RBCs}$ is associated with preferential accumulation of the ${ }^{59} \mathrm{Fe}$ labeled $\mathrm{RBCs}$ in these 3 organs. This resulted in a time-dependent increase in the ratio between ${ }^{51} \mathrm{Cr}$ and ${ }^{59} \mathrm{Fe}$ in the circulating blood, according to a complex nonlinear function. Therefore, no information on $\mathrm{RBC}$ trapping in the lungs, liver and spleen can be generated, when ${ }^{51} \mathrm{Cr}$ and ${ }^{59} \mathrm{Fe}$ are used simultaneously. For all other organs, the type of label did not affect the trapping characteristics of the erythrocyte.

In order to determine whether the sacrifice procedure had affected the fractional distribution of $\mathrm{RBCs}, \mathrm{BV}$ and tissue intravascular space were calculated for later comparision with reported data. The results of these calculations are listed in table 2 and 3 . The values obtained were compared with those reported in literature $(17,18)$. Although $\mathrm{BV}$ was higher in pregnancy, weightspecific BV did not differ between nonpregnant and late-pregnant guinea pigs. Also the intravascular space in each tissue did not differ between pregnant and nonpregnant guinea pigs.

Deformability study. Incubation of guinea pig RBCs in glutaraldehyde completely rigidified the RBC membrane, as confirmed in vitro by ektacytometry (Technicon Instruments B.V., Gorinchem, The Netherlands) for shear rates between $255 \mathrm{~s}^{-1}$ and $10 \mathrm{~s}^{-1}$ (fig.2). After resuspension in plasma, the control and rigidified $\mathrm{RBCs}$ were examined microscopically. All cells were intact and had a normal biconcave discoid shape. Macroscopic hemolysis was never observed. The ratio between hardened cells and controll cells in the blood remained nearly constant throughout the experiments, when the hardened cells were labeled with ${ }^{51} \mathrm{Cr}$ and the control cells with ${ }^{59} \mathrm{Fe}$. This indicated that both types of cells were removed from the systemic circulation, at the same rate. In contrast, the latter ratio showed a time dependent decrease when the hardened and control cells were labeled with ${ }^{59} \mathrm{Fe}$ and ${ }^{51} \mathrm{Cr}$, respectively.

The mean values for $T_{\text {rel }}$ calculated for all pregnant guinea pigs are illustrated in figure 3. A value significantly higher than $\mathbb{1}$ for a certain tissue indicates that rigidified $\mathrm{RBCs}$ are preferentially entrapped in the microcircula- 


\section{Table 1}

Gestational age, maternal weight; hiter size, total fetal weight and toral placental weight in the 14 late pregnant guinea pigs.

Mean $\pm S D$

Gestational age (d)

Maternal weight $(\mathrm{g})$

Litter size (\#)

Total fetal weight $(\mathrm{g})$

Total placentall weight (g)
$56 \pm 4$

$992 \pm 155$

$3.7 \pm 1.3$

$217 \pm 76$

$13.1 \pm \quad 3.6$

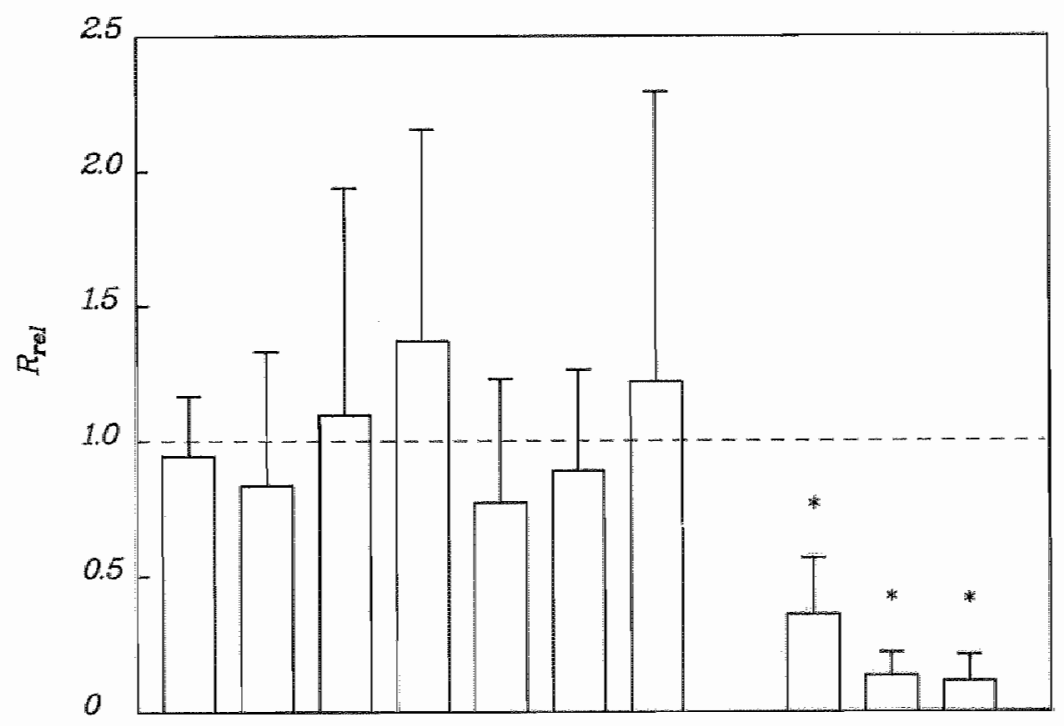

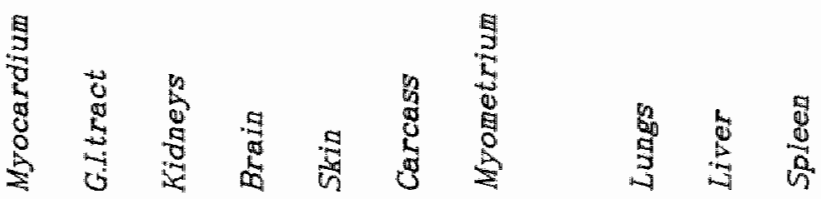

Figure I

Relative distribution of ${ }^{5 \rrbracket} \mathrm{Cr}$ and ${ }^{59} \mathrm{Fe}$ labeled red cells $\left(R_{\mathrm{rel}}\right)$ for each tissue in nompregnant guinea pigs $(n=8)$. Statistical differences $(p<0.05)$ are indicated by an asterisk 
Table 2

Body and organ welght, baseline cardiac output and cardiac output distribution, ${ }^{51} \mathrm{Cr}$ distribution and intravasicular volume in each organ in the nonpregnant animals $(n=8)$

\begin{tabular}{|c|c|c|c|c|}
\hline & $\begin{array}{l}\text { Weight } \\
\text { (grams) }\end{array}$ & $\begin{array}{l}\mathrm{CO} \\
\left(\mathrm{mil} \cdot \mathrm{min}^{-1}\right)\end{array}$ & $\begin{array}{l}\text { Blood } \\
\text { wolume } \\
\text { (mi) }\end{array}$ & $\begin{array}{l}\text { Weight-specific } \\
\text { blood volume } \\
\left(\mathrm{ml.kg}{ }^{-1}\right)\end{array}$ \\
\hline \multirow[t]{2}{*}{ Total body } & $544 \pm 163$ & $215 \pm 15$ & $39 \pm 4$ & $70 \pm 14$ \\
\hline & $\begin{array}{l}\text { Weight } \\
\text { (grams) }\end{array}$ & $\begin{array}{l}\mathrm{CO} \\
\text { distribution } \\
(\%)\end{array}$ & $\begin{array}{l}{ }^{51} \mathrm{Cr} \\
\text { distribution } \\
(\%)\end{array}$ & $\begin{array}{l}\text { Tissue intra- } \\
\text { vascular space } \\
\text { (\%) }\end{array}$ \\
\hline Myocardium & $2.1 \pm 0.3$ & $4.1 \pm 1.3$ & $0.4 \pm 0.2$ & $6.7 \pm 2.5$ \\
\hline G.I.tract & $45.1 \pm 9.5$ & $19.0 \pm 6.8$ & $2.9 \pm 2.1$ & $2.4 \pm 1.6$ \\
\hline Kidneys & $6.1 \pm 1.0$ & $12.0 \pm 4.8$ & $1.6 \pm 1.1$ & $10.7 \pm 4.3$ \\
\hline Brain & $3.8 \pm 0.3$ & $2.2 \pm 0.7$ & $0.1 \pm 0.1$ & $1.2 \pm 0.7$ \\
\hline Skin & $117 \pm 36$ & $7.3 \pm 2.0$ & $2.3 \pm 1.4$ & $0.9 \pm 0.8$ \\
\hline Carcass & $334 \pm 115$ & $43.8 \pm 11.4$ & $15.5 \pm 6.8$ & $2.1 \pm 1.3$ \\
\hline Myometrium & $1.3 \pm 0.5$ & $0.5 \pm 0.5$ & $0.2 \pm 0.1$ & $4.1 \pm 2.7$ \\
\hline Lungs & $5.2 \pm 1.7$ & $100 \%$ & $2.3 \pm 2.3$ & $14.6 \pm 10.6$ \\
\hline Liver & $25.8 \pm 5.4$ & $22.4 \pm 3.0$ & $6.7 \pm 4.9$ & $10.8 \pm 8.2$ \\
\hline Spleen & $1.3 \pm 0.6$ & $2.9 \pm 0.9$ & $0.9 \pm 0.7$ & $28.3 \pm 12.0$ \\
\hline
\end{tabular}

Pulmonary perfusion is assumed to be equal to the cardiac output.

** Hepatic perfusion is assumed to be equal to the sum of arterial hepatic and total splanchnic blood flow. 


\section{Table 3}

Body and organ weigh, baseline cardiac owtput and cardiac output distribution, ${ }^{51} \mathrm{Cr}$ distribution and intravascular volume in each organ in those pregnam animals which re. ceived ${ }^{51} \mathrm{Cr}$ labeled control red cells and ${ }^{59} \mathrm{Fe}$ labeled hardened red cells $(n=7)$.

\begin{tabular}{|c|c|c|c|c|}
\hline & $\begin{array}{l}\text { Weight } \\
\text { (grams) }\end{array}$ & $\begin{array}{l}\mathrm{co} \\
\left(\mathrm{ml} \cdot \mathrm{min}^{-1}\right)\end{array}$ & $\begin{array}{l}\text { Blood } \\
\text { volume } \\
\text { (ml) }\end{array}$ & $\begin{array}{l}\text { Weight-specific } \\
\text { blood volume } \\
\left(\mathrm{ml.kg}{ }^{-1}\right)\end{array}$ \\
\hline \multirow[t]{2}{*}{ Total body } & $1119 \pm 90$ & $212 \pm 49$ & $56 \pm 5$ & $75 \pm 8$ \\
\hline & $\begin{array}{l}\text { Weight } \\
\text { (grams) }\end{array}$ & $\begin{array}{l}\mathrm{CO} \\
\text { distribution } \\
(\%)\end{array}$ & $\begin{array}{l}{ }^{51} \mathrm{Cr} \\
\text { distribution } \\
(\%)\end{array}$ & $\begin{array}{l}\text { Tissue intra- } \\
\text { vascular space } \\
(\%)\end{array}$ \\
\hline Myocardium & $2.5 \pm 0.2$ & $1.8 \pm 1.1$ & $0.8 \pm 0.5$ & $17.1 \pm 11.1$ \\
\hline G.I.tract & $55.2 \pm 4.3$ & $20.3 \pm 4.6$ & $3.4 \pm 1.7$ & $3.5 \pm 1.8$ \\
\hline Kidneys & $7.2 \pm 0.5$ & $11.3 \pm 2.8$ & $1.5 \pm 0.7$ & $11.5 \pm 5.5$ \\
\hline Brain & $3.9 \pm 0.2$ & $1.5 \pm 0.5$ & $0.2 \pm 0.1$ & $2.7 \pm 1.7$ \\
\hline Skin & $143 \pm 11$ & $5.9 \pm 1.8$ & $3.0 \pm 1.8$ & $1.2 \pm 0.6$ \\
\hline Carcass & $411 \pm 24$ & $22.2 \pm 4.4$ & $11.1 \pm 1.4$ & $1.5 \pm 0.2$ \\
\hline Myometrium & $20.6 \pm 2.6$ & $2.0 \pm 0.8$ & $1.2 \pm 0.5$ & $3.8 \pm 0.7$ \\
\hline Placentas & $15.3 \pm 2.1$ & $13.0 \pm 6.3$ & $3.1 \pm 1.1$ & $11.7 \pm 5.1$ \\
\hline Lungs** & $7.2 \pm 2.4$ & $100 \%$ & $5.6 \pm 2.9$ & $39.8 \mathbb{E} 14.9$ \\
\hline Liver & $31.1 \pm 2.8$ & $22.5 \pm 4.0$ & $3.5 \pm 0.3$ & $6.4 \pm 1.2$ \\
\hline Spleen & $1.4 \pm 0.2$ & $1.9 \pm 0.5$ & $1.2 \pm 0.3$ & $46.7 \pm 9.3$ \\
\hline
\end{tabular}

\footnotetext{
Weight-specific blood volume is calculated as blood volume per unit non-uterine weight. ** Pulmonary perfusion is assumed to be equal to the cardiac output.

Hepatic perfusion is assumed to be equal to the sum of arterial hepatic and total splanchnic blood flow.
} 


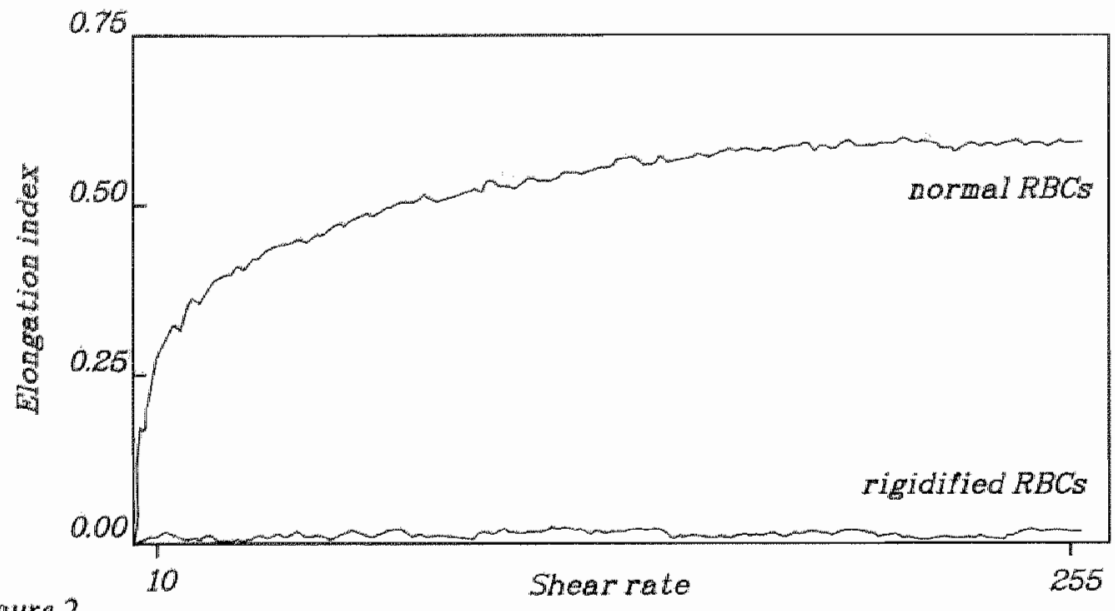

Figure 2

Shear rate

Ektacytograms of control and rigidified guinea pig red cells at different shear rates $\left(s^{-1}\right)$, depicted into 1 graph. The ektacytograms were obtained prior to injection of the cells into a recipient animal.

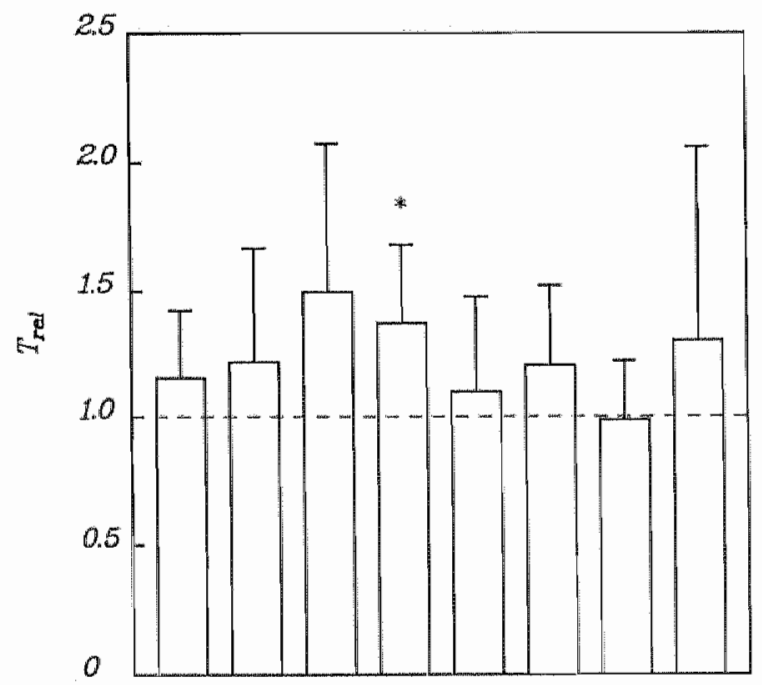

Figure 3

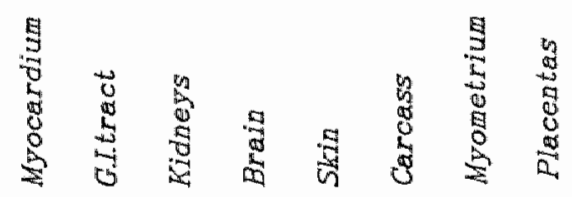

Relative distribution of rigidified and control red cells $\left(T_{\text {rell }}\right)$ for each tissue in pregnant guinea pigs $(n=14)$. Statistical differences $(p<0.05)$ are indicated by an asterisk. 


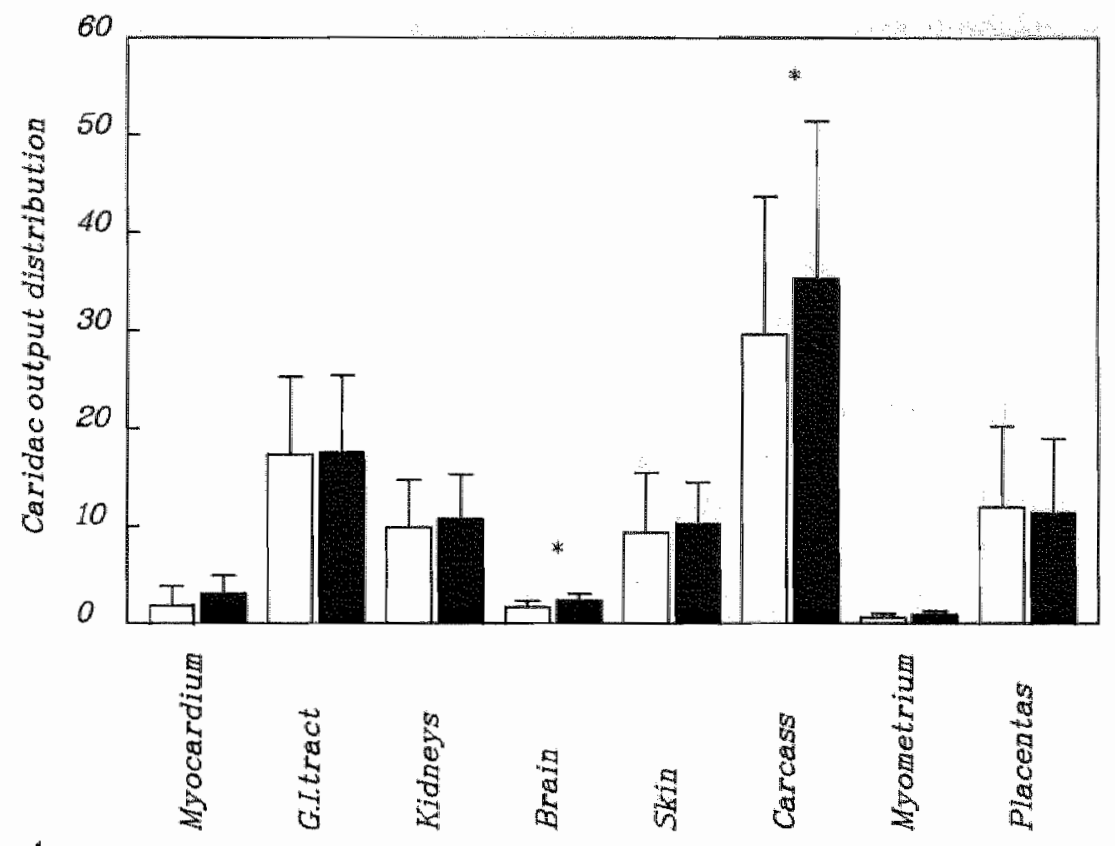

Figure 4

Cardiac output distribution (\%) to each tissue before (white bars) and 20 min. after (black bars) injection of the red cell suspension in pregnant guinea pigs $(n=12)$. Statistical differences $(p<0.05)$ are indicated by an asterisk.

tion of that tissue. This was only observed in the brain $\left(\mathrm{T}_{\mathrm{rel}}=1.34 \pm 0.31\right)$. None of the other organs (excl. lungs, liver, spleen) including the placenta, showed preferential accumulation of rigidified erythrocytes.

Reliable values for $\mathrm{CO}$ and organ flows could only be obtained in 4 animals due to problems with reference sampling. In these animals, values of $\mathrm{CO}$ before and 20 min after the bolus injection were almost identical $(210 \pm 37$ and $196 \pm$ $19 \mathrm{ml}$.min-1, respectively) and comparable with values reported previously (14). The lack of a consistent change in HR (254 \pm 35 and $245 \pm 44 \mathrm{bpm}$, respectively) at stable MAP ( $61 \pm 10$ and $61 \pm 9$, respectively) in all 14 guinea pigs, also supports the concept that $\mathrm{CO}$ did not change consistently after the cocktail injection. Therefore, $\mathrm{CO}$ fractions rather than organ flows were compared. Figure 4 illustrates the distribution of $\mathrm{CO}$ in the pregnant animals, before and 20 minutes after the injection of the blood suspension. The fraction of $\mathrm{CO}$ to brain (1.88 \pm 0.61$)$ and that to the carcass $(29.41 \pm 13.88)$ had increased after the injection ( $2.34 \pm 0.69$ and $35.14 \pm 15.82$, respectively). On the other hand, no consistent change was noted in the CO fractions to any other organ including that to the placenta. 


\section{Discussion}

The present study was designed to determine whether diminished RBC deformability interferes with the hemodynamic function in pregnancy in general and the perfusion of a hemochorial placenta in particular. The interest in the hemodynamic role of reduced $\mathrm{RBC}$ deformability was raised by clinical observations in UUGR and preeclampsia, where compromized UBF and diminished RBC deformability coincide. However, appropriate information on the role of RBC deformability in the microcirculation can only be obtained when the behavior of rigidified or otherwise manipulated $\mathrm{RBCs}$ is studied in vivo in their normal rheologic interaction with the microcirculation. Theoretically, one would expect that in IUGR and/or preeclampsia all erythrocytes have a slightly reduced deformability. However, recently it has been reported that in preeclampsia only a small fraction of RBCs has lost its potency to deform (19). Therefore, the effect of RBC deformability on UBF and other flows was studied by evaluating the effects of a bolus injection with differently labeled rigidified and controll RBCs. Since the limitations of this technique are not well documented, we performed a validity study prior to the actual study. In doing so, it was observed that ${ }^{59} \mathrm{Fe}$ labeled, nonmanipulated RBCs, as planned to be used in the actual study, became disproportionately entrapped in lungs, liver and spleen. Appearantly the metabolism of ${ }^{59} \mathrm{Fe}$ complicates the utilization of this label as a RBC marker. For this reason the technique as performed in this set-up was considered unreliable for the determination of RBC trapping in these three organs. This particular observation raises doubt about the physiologic meaning of the preferential trapping of hardened RBCs in liver, spleen and lungs previously reported, using the same technique (15). One could speculated that accumulation of ${ }^{59} \mathrm{Fe}$-labeled $\mathrm{RBCs}$, as well as rigidified $\mathrm{RBCs}$ in lungs, liver and spleen, may be a result of selective removal of these cells by macrophages of the reticuloendothelial system (RES) (20). Although we did not test the interchangeability of labels in pregnancy, we assumed that ${ }^{59} \mathrm{Fe}$-labeled RBCs were not preferentially accumulated in the placenta since 1) The accumulation of ${ }^{59} \mathrm{Fe}$-labeled RBCs appeared to be confined to RES organs. 2) In the two groups of 7 pregnant animals, rigidified and control RBCs did not show disproportional accumulation of ${ }^{59} \mathrm{Fe}$-labeled RBCs in the placentas.

$\mathrm{RBC}$ trapping data generated by this technique were used to estimate total $B V$ and tissue intravascular space. Our values corresponded with those reported on BV and tissue intravascular space in the guinea pig (17), and were slightly higher and had a higher coefficient of variation than those found in the anesthe- 
tized mongrol dog (18). However, the relative distribution was almost identical. The latter indicates that our sacrifice procedure did not distort the fractional distribution of RBCs in the systemic microcirculation.

Total BV per unit weight was comparable in nonpregnant and pregnant animals. Also the intravascular space of the peripheral organs did not differ between the nonpregnant and pregnant groups, although the lack of difference in this variable was partly related to the relatively large measurement error.

In the present study RBCs were rigidified by incubating them in glutaraldehyde, rather than in SH-reagents. Glutaraldehyd has been claimed to avoid not only the functional damage as induced by SH-reagents (20), but also osmotic swelling. The latter would have given rise to "physiological reactance" $(21)$ by its associated method-related entrapment. The validation of our methodology did not include the evaluation of possible changes in erythrocyte function induced by the labeling procedure. This information was considered irrelevant in the present study as we were only interested in the local rheological aspects associated with $\mathrm{RBC}$ rigidification.

In the pregnant guinea pigs, a $\mathrm{T}_{\mathrm{rel}}$ of slightly higher than 1 was found for the brain, suggesting that rigidified RBCs become selectively entrapped in the cerebral microcirculation. In spite of the presumably small biological significance of this observation, one could speculate that the microcirculation of the brain with its end arterioles and lack of anastomoses is particular prone to this type of embolisation. It seems unlikely that the concomitant increase in cerebral blood flow is related to a diminished $\mathrm{O}_{2}$-carrying capacity as $\mathrm{O}_{2}$ and glutaraldehyde have different binding sites within the hemoglobin molecule (22). However, the increase in cerebral blood flow may reflect impeded $\mathrm{O}_{2}$ diffusion due to diminished direct contact between RBC and endothelium. This would support the importance of the so-called "tank treading" of the deformable RBC in the release of $\mathrm{O}_{2}$ while travelling through the capillary bed. A lower diffusion of $\mathrm{O}_{2}$ to the tissue might have induced a secondary rise in cerebral blood flow.

In all other organs besides brain (lungs, liver and spleen excl.), the $\mathrm{T}_{\text {rel }}$ did not differ significantly from 1 , supporting the concept that a diminished RBC deformability does not increase their resistance to flow while travelling across the microcirculation.

Also for the uteroplacental wascular bed a $T_{\text {rel }}$ of about 1 was found, while the uteroplacental fraction of $\mathrm{CO}$ after injection of the blood suspension had not changed. Apparently, the ability of RBCs to change their shape while squeezing themselves through the smallest pores in the microvasculature of the labyrinthine hemochorial placenta has little impact on the overall flowing properties in this tissue. Whether the human placental perfusion is also inert to a decrease in RBC deformability is obscure since 1) the microarchitecture of the hemochorial 
human placenta differs from that in the guinea pig and 2) the simultaneous occurrence of impaired RBC deformability and compromized UBF coincides with pathological changes in both the placenta and warious other rheologically important variables such as Hct and fibrinogen.

We conclude from these results that in the awake late-pregnant guinea pig, RBC deformability in this particular experimental set-up does neither influence placental perfusion nor other organ flows, except for that of the brain. 


\section{References}

1. Canham PB 1970 The minimum energy of bending and shear stabilizing the shape of the red blood cell. J Theor Biol 26:61-81.

2. Inglis TCM, Stuart J, George AJ, Davies AJ 1982 Haemostatic and theological changes in normal pregnancy and pre-eclampsia. Br J Haematol 50:461-465.

3. Rodgers BD, Hreshchyshyn MM, Lee RV, Rodgers D, Ambrus CM 1988 Erythrocyte filterability in normal and high-risk pregnancy, Obstet Gynecol 71 (2):192-197.

4. Buchan PC, MacDonald HN 1981 Rheological studies in obstetrics and gynaecology. In: Buchan PC (ed) Clinical aspects of blood viscosity and cell deformability. Heidelberg Press, New York, pp 175-190.

5. Buchan PC 1980 Evaluation and modification of whole blood filtration in the measurement of erythrocyte deformability in pregnancy and the new born. Br J Haematol 45:97-105.

6. Thornburn J, Drummond MM, Whigham KA, Lowe GDO, Forbes CD, Prentice CRM, Whitfield CR 1982 Blood viscosity and haemostatic factors in late pregnancy, preeclampsia and fetal growth retardation. Br J Obstet Gynaecol 89:117-122.

7. Buchan PC 1984 Maternal and fetal blood viscosity throughout normal pregnancy. J Obstet Gynaecol 4:143-150.

8. Mandelli B, Polatti F, Bolis PF 1985 Study of erythrocyte deformability in physiological pregnancy. Clin Exp Obstet Gynecol 12:16-20.

9. Durocher JR, Weir MS, Lundblad EG, Patow WE, Conrad ME 1975 Effect of oral contraceptives and pregnancy on erythrocyte deformability and surface charge. Proc Soc Exp Biol Med 150:368-371.

10. Kaibara M, Marumoto Y, Taniguchi I, Kigasawa K, Kobayashi T 1985 Erythrocyte filterability and adenosine triphosphate levels in normal pregnancy and puerperium. Int J Microcirc Clin Exp 4:55-62.

11. Buchan PC 1982. Preeclampsia a hyperviscosity syndrome. Am J Obstet Gynecol 142:111-112.

12. Gresele $P$, Guerciolini R, Nenci GG 1982 Erythrocyte deformability changes in normal pregnancy and pre-eclampsia. Br J Haematol 52:340-342.

13. Peeters LLH, Mărtensson $\mathrm{L}$, van Kreel BK, Wallenburg HCS 1984 Uterine arterial and wenous concentration of glucose, lactate, ketones, free fatty acids and oxygen in the awake late pregnant guinea pig. Pediatr Res 18:1172-1175.

14. Peeters LLH, Grutters G, Martin CB 1980 The distribution of cardiac output in the unstressed guineal pig. Am J Obstet Gynecol 138:1177-1184.

15. Simchon $S$, Jan $\mathbb{K M}$, Chien $S 1987$ Influence of reduced red cell deformability on regional blood fllow. Am J Physiol 253:H898-H903. 
16. Saxena PR, Schamhardt HC, Forsyth RP, Loeve \1980 Computer programs for the radioactive microsphere technique. Determination of regional blood flow and other hemodynamic variables in different experimental conditions. Comp Prog Biomed 12:63-84.

17. Sisk BD 1976 Physiology. In: Wagner JE, Manning PJ (eds) Biology of the guinea pig. Academic Press, New York, pp 63-98.

18. Crystal Gi, Salem MR 1989 Blood volume and hematocrit in regional circulations during 1 *sovolemic hemodilution in dogs. Microvasc Res 37:237-240.

19. Cunningham FG, Lowe T, Guss S, Mason R 1985 Erythrocyte morphology in women with severe preeclampsia and eclampsia. Am J Obstet Gynecol 153:358-363.

20. Haest WM, Driessen GK, Kamp D, Heidtmann H, Fischer TM, Stöhr-Liesen M 1980 Is "deformability" a parameter for the rate of elimination of erythrocytes from the circulation?. Pfligers Archiv 388:69-73.

21. Vatner SF, Braunwald E 1975 Cardiovascular control mechanisms in the conscious state. N Engl J Med 293:970-971.

22. Corry WD, Meiselman HJ 1978 Modification of erythrocyte physicochemical properties by millimolar concentrations of glutaraldehyd. Blood Cells $4: 465-480$. 


\section{Increased red cell aggregability does not reduce uteroplacental blood flow in the awake hemoconcentrated late-pregnant guinea pig}

Carla M Verkeste, Peter F Boekkooi Pramod R Saxena and Louis LH Peeters

Accepted for publication in Pediatric Research

\section{Abstract}

The effect of increased red blood cell aggregability on uteroplacental blood flow was studied in 11 awake late-pregnant guinea pigs. The aggregability of the red cells was increased by administering high molecular weight dextran (HMWD) to the previously hemoconcentrated animal. The purpose of the hemoconcentration prior to HMWD was a) to use a preeclampsia model in which the hemorheology may be impaired due to the combined effect of polycythemia, an increased red cell aggregation and an increased plasma viscosity and b) to potentiate the aggregability-increasing effect of HMWD.

Relative to the pre-HMWD condition, arterial blood pressure and systemic vascular resistance had increased by $10 \%$ and $26 \%$, respectively. The cardiac output fraction shunted across the systemic circulation and the arterial hematocrit decreased by $30 \%$ and $4 \%$, respectively. Neither cardiac output nor the weighted organ flows, including those to the placentas changed in response to the rise in red cell aggregability.

We concluded that an imposed increase in red cell aggregability has no appreciable effect on uteroplacental bllood flow in the awake and healthy 
late-pregnant guinea pig. These data do not exclude the possibility that increased red blood cell aggregation potentiates the negative effects on uteroplacental blood flow, in e.g. pregnancy-induced hypertension or preeclampsia, where the placenta is not only marginally perfused but may also histologically damaged.
Abbreviations
$\mathrm{CO}=$ Cardiac output $\left(\mathrm{ml} \cdot \mathrm{min}^{-1}\right)$
Hct $=$ Hematocrit (vol\%)
$\mathrm{HC}=$ Hemoconcentration
HMWD $=$ High molecular weight dextran
HR = Heart rate $(\mathrm{bpm})$
MAP $=$ Mean arterial pressure $(\mathrm{mmHg})$
RBC $=$ Red blood cell
$\mathrm{RBC}_{\text {agg }}=\mathrm{RBC}$ aggregability
SVR = Systemic vascular resistance $\left(\mathrm{mmHg} \cdot \mathrm{min} \cdot \mathrm{ml}^{-1}\right)$
UBF = Uteroplacental blood flow $\left(\mathrm{ml} \cdot \mathrm{min}^{-1}\right)$

\section{Introduction}

Under normal macrocirculatory conditions, the local shear forces are always such that whole blood viscosity is of minor importance for blood flow. However, the role of whole blood viscosity upon local blood flow is likely to become more important, when the shear forces exerted upon the blood in the microcirculation are not optimized by vasomotor control or when the "Fahraeus-Lindquist phenomenon" is not operative $(1,2)$. The Fåhraeus-Lindqvist phenomenon is defined as the apparent fall in local hematocrit (Hct), and with it in viscosity, with a decrease in arterial/arteriolar diameter from 100 to $\approx 15 \mu \mathrm{m}$ (3). The pattern of streamlines of the flowing blood assumed to prevail in the porous (hemochorial) placental microvasculature makes it unlikely that the perfusion of the intervillous space benefits from the Fâhraeus-Lindquist phenomenon (4). This implies that the negative effects on perfusion of an elevated whole blood viscosity, could be larger in the hemochorial placenta than in capillary microcirculations. 
In pregnancies complicated by preeclampsia and/or impaired fetal growth, uteroplacental blood flow (UBF) appears to be chronically compromised by the combined effect of inadequate spiral artery growth/dilatation (5-7) and increased whole blood viscosity (8). In these pregnancies the increased whole blood viscosity is a result of the concerted action of elevated Hct (9-12), decreased red blood cell (RBC) deformability (10-14), increased RBC aggregability $\left(\mathrm{RBC}_{\mathrm{agg}}\right)(10,15,16)$, and to a lesser degree increased plasma viscosity $(8,11,17,18)$.

In recent studies Hct and red cell deformability were found to contribute little to the variation in UBF $(19,20)$. Inasmuch as Hct and red cell deformability affect primarily the high-shear viscosity, these findings were not surprising since the shear rate in the intervillous space is likely to be extremely low $(4,21)$. This fact raises the possibility that particularly a rise in $R B C_{\text {agg }}$ could have a more important (negative) effect on UBF than factors which primarily affect high-shear viscosity, such as Hct.

The objective of the present study was to evaluate whether an imposed increase in $R B C_{a g g}$ reduces $U B F$ in the awake, healthy late-pregnant guinea pig. The concomitant response of other maternal hemodynamic variables was used to evaluate the efficacy of the methodology which was employed to raise low-shear viscosity. To this end, the cardiac output (CO), heart rate (HR), mean arterial pressure (MAP), systemic vascular resistance (SVR) and regional blood flows were determined in awake, previously hemoconcentrated late-pregnant guinea pigs, before and 30 minutes after increasing the $\mathrm{RBC}_{\mathrm{agg}}$ fivefold by a bolus injection of high molecular weight dextran (HMWD). The hemoconcentration (HC) prior to HMWD was performed a) to use a preeclampsia model in which the hemorheology may be impaired due to the combined effect of polycythemia, an increased red cell aggregation and an increased plasma viscosity and b) to amplify the increasing effect of HMWD on $\mathrm{RBC}_{\mathrm{agg}}$ (22).

\section{Materials and methods}

The study was performed in 11 pregnant albino guinea pigs with known post-conceptional pregnancy length, supplied by a commercial breeder (Charles River, Sulzfeld, Germany). Using aseptic techniques (23), polyethylene catheters (outer diameter/inner diameter $=0.96 / 0.58 \mathrm{~mm}$ ) were inserted into the left ventricle and abdominal aorta around the $48^{\text {th }}$ day of gestation. After complete recovery ( \pm 6 days) and as soon as steady state was established (stable MAP and 
HR for at least $20 \mathrm{~min}$ ) the experiments were started. The first experiment (measurement 1: BASELINE) involved the measurement of $\mathrm{CO}$ and organ flows with $15 \mu$ m labeled microspheres $\left({ }^{95} \mathrm{Nb},{ }^{103} \mathrm{Ru},{ }^{113} \mathrm{Sn}\right.$ or $\left.{ }^{141} \mathrm{Ce}\right)(24)$, the measurement of arterial Hct (in duplicate, microcapillary method) and the quantitation of the $\mathrm{RBC}_{\mathrm{agg}}$ (MA1, Myrenne Gmbh, Roetgen, Germany). The aggregometer has two options for measuring the extent of aggregation: at stasis ( $\mathrm{SR}_{0}$ ) and at a low shear rate ( $\left.\mathrm{SR}_{10}\right)$. For both options the blood is rotated at a shear rate of $600 \mathrm{~s}^{-1}$ for $10 \mathrm{~s}$, whereafter the aggregation is determined during $15 \mathrm{~s}$, either at zero shear rate $\left(\mathrm{SR}_{0}\right)$ or at a shear rate of $10 \mathrm{~s}^{-1}\left(\mathrm{SR}_{10}\right)$. The quantity of transmitted infrared light, measured with photosensors, is proportional to the degree of aggregation and is digitally displayed in arbitrary units. After reference sampling (sample rate $0.65 \mathrm{ml} . \mathrm{min}^{-1}$, from $10 \mathrm{~s}$ before the intra-ventricular bolus injection of the microspheres until $30 \mathrm{sec}$ after its completion) the animals were gradually hemoconcentrated in 6 steps by consecutive isovolemic exchange transfusions. Each transfusion involved the substitution of $5 \mathrm{ml}$ blood of the recipient animal by an equal amount of packed red cells from a nonpregnant donor guinea pig. Twenty $h$ after the administration of packed cells, BP, HR, $\mathrm{CO}$, organ flows, Hct and $\mathrm{RBC}_{\text {agg }}$ were remeasured (measurement 2: PRE-AGGREGATION). Subsequently, $400 \mathrm{mg}$ of HMWD $\left(500,000 \mathrm{~g} \cdot \mathrm{mol}^{-1}\right)$ dissolved in $2 \mathrm{ml}$ of saline were injected into the left ventricle. It can be estimated (25) that this quantity will result in a HMWD plasma concentration of $1 \% \mathrm{w} / \mathrm{v}$. Thirty minutes after the bolus injection, all variables were remeasured (measurement 3: POST-AGGREGATION).

Finally, the animals were sacrificed with an overdose of pentobarbital. All organs were dissected, weighted and placed in counting vials. The accumulated radioactivity was determined in a sodium crystal scintillation counter (Packard, Delft, The Netherlands). The microsphere data obtained in BASELINE, PRE-AGGREGATION and POST-AGGREGATION were analyzed as described previously (26). Data from different experimental conditions were compared with each other using the Wilcoxon Rank Sign Test. A probability of less than 5\% (two-sided) was considered significant. The results are expressed as means $\pm S D$ throughout the text. 


\section{Results}

The average maternal weight at the day of the first experiment was $721 \pm 108$ $\mathrm{g}$, including $137 \pm 64 \mathrm{~g}$ fetal mass. The litter size ranged from 1 to 4 fetuses. The gestational age ranged from 52 to 63 days.

The hemodynamic changes in response to the HC procedure can be deduced by comparing the results listed in column 2 with those in column 1 of table 1 .

\section{Table 1}

Cardiac output (ml.min ${ }^{-1}$ ) Heart rate (bpm), Mean arterial pressure (mmHg), Systemic vascular resistance ( $\mathrm{mmHg}$.min.m $\mathrm{m}^{-1}$ ), Hematocrit (vol\%) and weighted organ flows $\left(\right.$ ml.min $\left.^{-1} .100 \mathrm{~g}^{-1}\right)(n=8)$ before (BASELINE), 20h after packed cell transfusion (PREAGGREGATION) and 30 min after increasing RBCagg (POST:AGGREGATION)

\begin{tabular}{|c|c|c|c|}
\hline & BASELINE & $\begin{array}{l}\text { PRE- } \\
\text { AGGREGATION }\end{array}$ & $\begin{array}{l}\text { POST- } \\
\text { AGGREGATION }\end{array}$ \\
\hline RBCagg at $\mathrm{SR}_{0}$ & $0.2 \pm 0.6$ & $0.9 \pm 1.3$ & $5.1 \pm 2.3^{\text {样 }}$ \\
\hline RBCagg at $S_{10}$ & $2.6 \pm 0.7$ & $2.2 \pm 1.5$ & $12.5 \pm 1.6^{\#+}$ \\
\hline Cardiac output & $188 \pm 49$ & $219 \pm 79$ & $191 \pm 55$ \\
\hline Heart rate & $256 \pm 8$ & $254 \pm 25$ & $272 \pm 43$ \\
\hline Mean arterial pressure & $52 \pm 9$ & $60 \pm 11^{*}$ & $66 \pm 12^{\#}$ \\
\hline Systemic vascular resistance & $6.1 \pm 1.9$ & $6.1 \pm 2.5$ & $7.7 \pm 2.6^{\text {殀 }}$ \\
\hline Hematocrit & $37 \pm 3$ & $56 \pm 4^{*}$ & $54 \pm 4^{\#+}$ \\
\hline Systemic shunting & $12 \pm 3$ & $10 \pm 3$ & $7 \pm 3^{H}$ \\
\hline
\end{tabular}

Weighted organ flows

$\begin{array}{lrrr}\text { Myocardium } & 324 \pm 66 & 326 \pm 96 & 298 \pm 73 \\ \text { Brain } & 94 \pm 28 & 72 \pm 33 & 72 \pm 22 \\ \text { Kidneys } & 326 \pm 111 & 480 \pm 144^{*} & 479 \pm 64 \\ \text { Gl tract } & 116 \pm 44 & 122 \pm 47 & 104 \pm 24 \\ \text { Skin } & 13 \pm 5 & 13 \pm 4 & 12 \pm 4 \\ \text { Carcass } & 15 \pm 6 & 15 \pm 4 & 15 \pm 5 \\ \text { Myometrium } & 11 \pm 6 & 19 \pm 10 & 18 \pm 7 \\ \text { Placentas } & 124 \pm 59 & 144 \pm 82 & 139 \pm 43\end{array}$

$p<0.05$ PRE-AGGREGATION different from BASELINE

\# $p<0.05$ POST-AGGREGATION different from PRE-AGGREGATION 
$\mathrm{CO}$ and thus also organ blood flows could only be determined succesfully in 8 out of 11 animals due to failure to obtain a reliable reference sample in 3 animals. HC had no effect on CO, HR, systemic shunting of the microspheres (i.e. lung fraction), or any weight-specific organ flows except for renal flow which increased consistently. Besides the obvious rise in Hct, the MAP had also increased markedly. The increase in blood pressure was, however, not paralleled by an increase in systemic vascular resistance.

The cardiovascular effects associated with the rise in $\mathrm{RBC}_{\text {agg }}$ emerge when the results listed in column 3 of table 1 (POST-AGGREGATION) are compared with those in column 2 (PRE-AGCREGATION). The administration of HMWD raised $\mathrm{RBC}_{\text {agg }}$ fivefold in both $\mathrm{SR}_{0}$ and $\mathrm{SR}_{10}$. An increase in both MAP and SVR was paralleled by a decrease in both arterial $\mathrm{Hct}$ and the $\mathrm{CO}$ fraction, distributed to shunts in the systemic circulation. Neither $\mathrm{CO}$ nor any weight-specific organ flow, including UBF, changed in response to the increase in $\mathrm{RBC}_{\text {agg. }}$.

\section{Discussion}

In order to study the effects of $\mathrm{RBC}_{\mathrm{agg}}$ on the systemic circulation it was felt necessary to adopt a procedure which would have a clear impact on red cell aggregability. By combining the aggregability-increasing effects associated with a high Hct with those induced by administering HMWD we managed to increase the $\mathrm{RBC}_{\mathrm{agg}}$ fivefold, a rise expected to be adequate to discern specific hemodynamic effects caused by an elevated $\mathrm{RBC}_{\mathrm{agg}}$. Before the $\mathrm{RBC}_{\mathrm{agg}}$ was raised, the Hct was increased by isovolemic HC to a much higher level than had been reached in a previous study from our laboratory (56 vol\% vs. 38 vol\%; (19)). The marked rise in BP which was observed after the more intensive HC in the present study seems to indicate that the effects of increased high shear viscosity on the circulation become manifest only when the Hct is raised above a certain threshold. Theoretically, it seems unlikely that the induced "hypertension" will interfere with the subsequently induced rise in $\mathrm{RBC}_{\mathrm{agg}}$, since changes in thigh-shear viscosity have their largest impact on the arterial side of the circulation, where shear rates are highest (small arteries and arterioles), as opposed to changes in $\mathrm{RBC}_{\mathrm{agg}}$, which influence primarily the viscosity of blood in vessels with a low shear rate (venules, small veins, intervillous space). The lack of increase in SVR in response to the HC procedure was the result of the increasing trend in $\mathrm{CO}$ with the rise in BP. In contrast, a rise in low-shear viscosity primarily increases venous resistance, imposing a negative effect on 
venous return (27). The increase in renal flow after the HC was also observed in our previous study (19). The underlying mechanism appears to be maintenance of renal plasma flow (28). Neither the SVR, nor the CO, HR and other regional flows changed in response to $\mathrm{HC}$, supporting that the post-aggregation condition represents a selective effect of the imposed increase in $\mathrm{RBC}_{\mathrm{agg}}$.

The observed changes in response to the rise in $\mathrm{RBC}_{\mathrm{agg}}$ were an increase in both MAP and SVR by $10 \%$ and $26 \%$, respectively, together with a fall in systemic shunting and arterial Hot by $30 \%$ and $4 \%$, respectively. $\mathrm{CO}$ and all organ flows did not change consistently. The increasing trend in $\mathrm{CO}$ after $\mathrm{HC}$, followed by a decreasing trend after HMWD, suggests that HMWD affects primarily the venous compartment, i.e. venous return. Assuming that the rise in $\mathrm{RBC}_{\mathrm{agg}}$ caused an increase in venous resistance, the modest increase in MAP could be a compensation serving the purpose of maintaining the perfusion pressure across the systemic microcirculation. The marked decline in fractional systemic shunting could represent an additional compensation for the apparent fall in intra-arterial volume (29). That is to say, an induced rise in venous resistance would lead to pooling of blood in the venous compartment, thus interference with venous return. The associated negative impact on $\mathrm{CO}$ can be expected to activate the baroreceptor and sympathetic nervous system resulting in a decrease in the $\mathrm{CO}$ fraction shunted across the microcirculation. The arterial Hct may be reduced in the POST-AGGREGATION state partly as a result of reference sampling. However, theoretically increased formation of aggregates in the venous compartment will increase the venous $\mathrm{Hct}$ at the cost of the arterial Hct.

Interestingly, UBF was not compromized by the marked rise in $\mathrm{RBC}_{\text {agg. }}$. The lack of change in UBF in response to both moderate (19) and severe isovolemic $\mathrm{HC}$ (present study) supports the concept that high-shear viscosity has a negligible effect on the perfusion of the intervillous space. Meanwhile, the results of the present study support the concept that also a rise in low-shear viscosity fails to have a measurable effect on the perfusion of the hemochorial placenta in this particular model. One could speculate that such an effect is prevented by the action of some form of vasomotion or autoregulation operative in the supplying arteries.

From these data we conclude that an imposed increase in red cell aggregability has no appreciable effect on UBF in the awake and healthy late-pregnant guinea pig. These data do not exclude the possibility that $\mathrm{RBC}$ aggregation potentiates the negative effects on UBF, in e.g. pregnancy-induced hypertension or preeclampsia where the placenta is not only marginally perfused but might also histologically damaged. 


\section{References}

1. Merrill EW 1969 Rheology of blood. Physiol Rey 49(4):863-888.

2. Schmid-Schönbein H 1981 Interaction of vasomotion and blood rheology. In Lowe $\mathrm{GDO}$, Barbenel JC, Forbes $\mathrm{CD}$ (eds) Clinical aspects of blood viscosity and cell deformability. Berlin Springer pp 49-66.

3. Gaehtgens P 1980 Flow of blood through narrow capillaries: Rheological mechanisms determining capillary hematocrit and apparent viscosity. Biorheology 17:183-189.

4. Schmid-Schönbein H 1988 Conceptional proposition for a specific microcirculatory problem: maternal blood flow in hemochorial multiwillous placentae as percolation of a "porous medium". In: Kaufmann P, Miller RK (eds), Trophoblast Research vol3. Plenum Publishing Corporation, pp 17-38.

5. Brosens IA 1977 Morphological changes in the utero-placental vascular bed in pregnancy hypertension. Clin Obstet Gynecol 4(3):573-593.

6. Fox H 1981 Placental malfunction as a factor in intra-uterine growth retardation. In: van Assche FA, Robertson WB (eds), Fetal growth retardation. Chirchill Livingstone, Edinburgh, London, Melbourne, New York, pp 117-125.

7. Gerretsen G, Huisjes HJ, Elema JD 1981 Morphological changes of the spiral arteries in the placental bed in relation to pre-eclampsia and fetal growth retardation. $\mathrm{Br} I$ Obstet Gynatecol 88:876-881.

8. Heilmann L, Mattheck C, Kurz E 1977 Rheological changes in the blood in normal and pathological pregnancies. Arch Gynaekol 223:283-298.

9. Pickart LR, Greasy RK, Thaler MM 1976 Hyperfibrinogenemia and polycythemia with intrauterine growth retardation in fetal lambs. Am J Obstet Gynecol 124:268-271.

10. Heilmann L Siekmann U, Schmid-Schönbein H, Ludwig H 1981 Hemoconcentration and pre-ectampsia. Arch Gynecol 231:7-21.

11. Buchan PC 1982 Preeclampsia a hyperviscosity syndrome. Am J Obstet Gynecoll 142(1):111-1.12.

12. Lang GD, Lowe GDO, Walker JJ, Forbes CD, Prentice CRM, Calder AA 1984 Blood rheology in pre-eclampsia and intrauterine growth retardation: Effects of blood pressure reduction with labetolol. Br J Obstet Gynaecol 91:438-443.

13. Thornburn J, Drummond MM, Whigham KA, Lowe GDO, Forbes CD, Prentice CRM, Whitfield CR 1982 Blood viscosity and haemostatic factors in late pregnancy, preeclampsia and fetal growth retardation. Br J Obstet Gynaecol. 89:117-122.

14. Gresele P, Guerciolini R, Nenci GG 1982 Erythrocyte deformability changes in normal pregnancy and pre-eclampsia. $\mathrm{Br} \mathrm{J}$ Haematol 52:340-342.

15. Dunlop W, Furness C, Hill LH 1978 Maternal hemoglobin concentration haematocrit and renal handling of urate in pregnancies ending in the births of small-for-dates infants. Br J Obstet Gynaecol 85:938-940.

16. Hobbs JB, Oats JN, Palmer AA, Mitchell G, Lou A, McIver MA 1982 Whole blood viscosity in preeclampsia. Am J Obstet Gynecol 142:288-292. 
17. Matthews JD, Mason TW 1974 Plasma viscosity and pre-eclampsia. Lancet ii:409.

18. Eastham RD 1965 Plasma viscosity estimation in the improved haematological screening of antenatal patients. J Obstet Gynaecol Br Commonw 72:763-764.

19. Peeters LLH, Verkeste CM, Saxena PR, Wallenburg HCS 1987 Relationship between maternal hemodynamics and hematocrit and hemodynamic effects of isovolemic hemodilution and hemoconcentration in the awake late-pregnant guinea pig. Pediatr Res $21(6): 584-589$

20. Verkeste CM., Boekkooi PF, Saxena PR, Peeters LLH 1990 Nondeformable red cells do not interfere with uteroplacental blood flow in awake late pregnant guinea pig. Submitted for publication in Pediatr Res.

21. Peeters LLH, Buchan PC 1989 Blood viscosity in perinatology. Rev Perinat Med 6:53-89.

22. Rampling MW 1988 Red cell aggregarion and yield stress. In: Lowe GDO (ed), Clinical blood rheology. CRC Press, Buka Raton, pp 45-64.

23. Peeters $\mathrm{LLH}$, Mărtensson $\mathrm{L}$, van Kreel BK, Wallenburg HCS 1984 Uterine arterial and venous concentration of glucose, lactate, ketones, free fatty acids and oxygen in the awake late pregnant guinea pig. Pediatr Res 18:1172-1175.

24. Peeters LLH, Grutters G, Martin CB 1980 The distribution of cardiac output in the unstressed guinea pig. Am J Obstet Gynecol 138:1177-1184.

25. Metcalfe J, Stock MK, Barron DH 1988 Maternal physiology during gestation. In: Knobie E, Neill JD (eds), The physiology of reproduction vollI. Raven Press, New York, pp 2145-1276.

26. Saxena PR, Schamhardt HC, Forsyth RP, Loeve J 1980 Computer programs for the radioactive microsphere technique. Determination of regional blood flow and other hemodynamic variables in different experimental conditions. Comp Prog Biomed $12: 63-84$.

27. Goslinga H 1982 The viscosity of blood. An experimental study into the effect of alterations blood viscosity during shock. Thesis: State University Utrecht.

28. de Wardener HE 1985 The kidney. Churchill Livingstone. New York pp 118-119.

29. Rothe CF 1986 Physioloy of venous return. An unappreciated boost to the heart. Arch Intern Med 146(5):977-982. 


\title{
Uteroplacental blood flow appears to be autoregulated for hydrostatic pressure in the awake late-pregnant guinea pig
}

\author{
Carla M Verkeste and Louis LH Peeters \\ Submitted for publication in the American Journal of Obstetrics \\ and Gynecology
}

\section{Abstract}

The objective of the present study was to evaluate the relationship between uteroplacental blood flow and mean arterial pressure, in an animal with a hemochorial placenta. By isovolemic hemodilution, hemoconcentration or sham exchange transfusion, Hct changes were induced in 33 awake late-pregnant guinea pigs. These manipulations were paralleled by changes in blood pressure which covaried only slightly with those in Hct. The hemodynamic effects associated with the the changes in blood pressure were separated from those in Hct by multiple linear regression analysis.

Changes in weight-specific cerebral and renal flow correlated negatively and positively, respectively, with changes in hematocrit. These correlations suggest that in the brain, blood flow variations served to maintain cerebral oxygen delivery, and in the kidneys renal plasma flow. All changes in weight-specific regional blood flows, including uteroplacental blood flow, varied independently of observed alterations in mean arterial pressure. These data support the concept that the microcirculation of the hemochorial placenta possesses autoregulation for blood flow over the spectrum of arterial pressure changes observed in the 
present study. However, the larger variation in uteroplacental perfusion chariges, as compared to those observed in the myometrium, suggests that the autoregulatory response of the uteroplacental vascular bed is more fragile than that of capillary structures.

Abbreviations
CBF $=$ Cerebral blood flow $\left(\mathrm{ml}_{\mathrm{min}} \mathrm{mi}^{-1}\right)$
Hct $=$ Hematocrit $(\mathrm{vol} \%)$
$\mathrm{HR}=$ Heart rate (bpm)
MAP $=$ Mean arterial pressure $(\mathrm{mmHg})$
$\mathrm{RBF}=$ Renal blood flow $\left(\mathrm{ml} . \mathrm{min}^{-1}\right)$
UBF $=$ Uteroplacental blood flow $\left(\mathrm{ml} . \mathrm{min}^{-1}\right)$

\section{Introduction}

Autoregulation of tissue flow can be defined as a local mechanism to prevent undue blood flow changes with pressure alterations and to control transcapillary fluid exchange (1). The autoregulatory response is subject to positive (fall in tissue $\mathrm{pO}_{2}$; rise in certain metabolites) and negative feedback (catecholamines, angiotensin II) influences. The negative feedback appears to have a more systemic origin with the constricting effect predominantly being produced in arterioles larger than $25 \mu \mathrm{m}$. Meanwhile, the positive feedback is predominantly generated by locally released vasoactive substances leading to vasodilation mostly in the terminal arterioles $(\leq 25 \mu \mathrm{m})$ and precapillary sphincters (2). Theoretically, autoregulation is of vital importance for the protection of the microcirculation. So far, experimental prove has been produced for autoregulation in the kidney (3), brain (4), myocardium (5), skeletal muscle (6) and intestines (7).

Whether the hemochorial placenta is autoregulated is still obscure. It is generally assumed that autoregulation is absent since the placental exchange area is supplied directly by the spiral artery without interconnecting arterioles and precapillary sphincters (8). In addition, the uteroplacental bed is thought to be maximally dilated $(9,10)$ which precludes a basal vascular tone and thus also maintenance of the perfusion in case of a fall in hydrostatic pressure. Therefore, 
doubt has been raised about the structural feasibility of a myogenic pressurebuffering mechanism in the hemochorial placenta. Until now, studies designed to prove or disprove the existance of placental autoregulation have provided conflicting information (9-15). The inconsistency in experimental results are probably related to differences in experimental set-up (anesthetized or conscious animals) or inter-species differences in uteroplacental microarchitecture. Anesthesia and/or pharmacological agents may alter the responsiveness of various hemodynamic regulatory mechanisms, which may indirectly influence the normal uteroplacental blood flow (UBF)/mean arterial pressure (MAP) relationship (16). Furthermore, the pressure-flow relationship in hemochorial (villous or labyrinthine) placentas such as in the human, guinea pig, rat and rabbit may differ from that in the epitheliochorial placenta of the ewe which has a capillary microcirculation at the maternal side.

However, the unique microarchitecture of the (hemochorial) placenta without arterioles and precapillary sphincters between supplying arteries and microcirculatory exchange site, does not necessarily exclude autoregulation. In fact, a myogenic vascular response resembling the one of arterioles may be generated by the small radial arteries and proximal portion of the spiral artery. This concept is supported by the comparable intravascular pressure in the trumpet-shape outlet of the spiral artery and proximal portion of a capillary (17, 18) and the intermittant opening and closure of the pre-spiral uterine arteries (19). Therefore, we hypothesize that the hydrostatic capillary pressure in the intervillous space is controlled, the "resistance modulating response" being produced in the radial arteries and proximal portion of the spiral arteries instead of in precapillary resistence vessels.

The objective of the present study was to evaluate the relationship between UBF and MAP in an unanesthetized animal model with a hemochorial placenta. The UBF/MAP relation was studied in 33 awake late-pregnant guinea pigs in which MAP had changed after either isovolemic hemodilution, hemoconcentration or a sham exchange transfusion. The primarily endogeneous origin of the changes in MAP observed after these manipulations were assumed to be paralleled by less hemodynamic side effects than if they would have been induced by pharmacological intervention. The response to MAP changes of the weightspecific blood flows to non-placental autoregulated organs served as a reference. 


\section{Materials and methods}

In this study the relationship was determined between the change in weightspecific organ flows and that in MAP using the experimental data from previous studies, in a total of 33 awake late-pregnant albino guinea pigs. The objective of those previous studies was to determine the relationship between maternal hemodynamics and hematocrit ( $\mathrm{Hct}$ ), and involved the manipulation of the Hct by isovolemic exchange transfusion $(20,21)$. UBF changes were found to be largely independent of Hct changes. The procedures to manipulate the Hct were found to have an inconsistent effect on MAP. This was reflected in a less than $9 \%$ covariance between Hct and MAP (Spearman regression). The lack of consistency in the direction of the MAP change in response to the exchange transfusion appeared to be a direct consequence of the narrow range over which the Hct was changed and the inclusion of a sham group. Because of the unresponsiveness of UBF to Hct changes and the low dependence of MAP on Hct, it was considered appropriate to re-evaluate these flow data for the possible interdependence of UBF on MAP.

All animals included in this analysis had known conceptional dates and were supplied by a commercial breeder (Charles River, Sulzfeld, FRG). Details about breeding, housing and animal handling are described in a previous report (22). Under general anesthesia polyethylene catheters $(\mathrm{OD} / \mathrm{ID}=0.96 / 0.58 \mathrm{~mm}$ ) were inserted into the left ventricle and the abdominal aorta around the $48^{\text {th }}$ of pregnancy, as detailed elsewhere (22). The experiments were performed after complete recovery, approximately 6 days after surgery. MAP and heart rate (HR) were recorded continuously throughout the experiments. When MAP and HR had been stable for at least 15 minutes, an arterial blood sample was collected from the abdominal aorta for the measurement of Hct (microcapillary method). Subsequently, organ blood flows were determined with $15 \mu \mathrm{m}$ radioactive microspheres (23). After this blood flow measurement, the animals either received an exchange transfusion with red cells or plasma, or were subjected to a sham procedure. This resulted in the following 4 groups (table 1): 1) hemodilution $(n=6), 2)$ sham $(n=8), 3)$ mild hemoconcentration $(n=15)$ or 4$)$ extensive hemoconcentration $(n=4)$, respectively. In the sham group the animals' own blood was withdrawn and reinfused. In the other groups the change in Hct was induced through a variable number of consecutive exchange transfusions as detailed in table 1. For each transfusion, $10 \mathrm{ml}$ blood of the recipient animal was replaced by a similar amount of either plasma or packed red cells obtained from a nonpregnant donor guinea pig. After 20 hours all variables determined prior to the manipulation were remeasured using a microsphere with 


\section{Table I}

Experimental design in awake late-pregnan guinea pig subwitted to different theological manipulations used for retrospective evaluation of the uteroplacental flow-pressure talationship in awake late-pregnant guinea pig.

Experimental design

Number of

Blood substitute

transfusions

1. Isovolemic hemodilution $(n=6)$

2. Sham $(n=8)$

1

Donor plasma

3. Mild hemoconcentration $(n=15)$

1

Homologue blood

4. Extensive hemoconcentration $(n=4)$

Donor packed cells

3

Donor packed cells

a different radioactive label. Finally, the animals in all groups were sacrificed with an overdose of pentobarbital. All organs were dissected and radioactivity was determined with a sodium crystal scintillation counter (Packard, Delft, Holland). The microspheres data were analyzed as described by Saxena and coworkers (24).

The correlation between the change in HR, cardiac output (CO), and regional flows on the one hand, and the change in MAP on the other, was analyzed by multiple linear regression. With this approach the MAP-induced effects could be separated from those associated with the change in Hct. In most animals, MAP had changed only mildly in response to the transfusion/sham procedure. Consequently, the relatively low number of data at the extremes of the spectrum of MAP changes could have a disproportional large effect on the regression. In order to reduce the influence of this source of error, the 33 animals were divided into 3 groups on the basis of the magnitude of the MAP change in response to the manipulation imposed:

a group $1(M A P / D O W N, n=4)$ : MAP had decreased by more than $10 \%$. The decrease ranged between 15 and $21 \%$ (mean $18 \pm 2 \%$ ).

b group 2 (MAP/NOCHANGE, $\mathrm{n}=19$ ): MAP changed by less than $10 \%$ (mean $-1 \pm$ $6 \%$ ).

c group 3 (MAP/UP, $\mathrm{n}=10$ ): MAP had increased by more than 10\%. The rise varied between $11 \%$ and $60 \%$ (mean $22 \pm 15 \%$ ).

Only the animals in which the MAP had changed by more than $10 \%$ (groups 1 and $3, n=14$ ) were subjected to further analysis. In these animals, the correlation between the change in all hemodynamic parameters and that in MAP was 
evaluated by Spearman Nonparametric Regression Analysis. A probability of less than 5\% (two-sided) was considered significant. Data are presented as

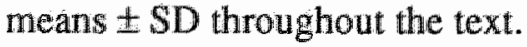

\section{Results}

Maternal hemodynamics, before and after the imposed manipulation in the 3 MAP groups, are listed in table 2. In the MAP/DOWN and MAP/UP groups, Hot had decreased and increased, respectively. In addition the weight-specific cerebral perfusion had increased and decreased, respectively, in the latter 2

\section{Table 2}

Cardiac output ( $\mathrm{ml}_{\mathrm{min}}{ }^{-}$heart rate (bpm), hematocrit (vol\%) and weight-specific organ blood flows ( $\mathrm{ml}^{\mathrm{min}}{ }^{-1} .100 \mathrm{~g}^{-1}$ ) in baseline condition and after rheological manipulation (Experimental), allocated in three different groups of blood pressure changes (MAP/DOWN $(n=4)$, MAPINOCHANGE $(n=19)$ AND MAP/UP $(n=10))$.

\begin{tabular}{|c|c|c|c|c|c|c|}
\hline & \multicolumn{2}{|c|}{ MAP/DOWN } & \multicolumn{2}{|c|}{ MAP/NOCHANGE } & \multicolumn{2}{|l|}{ MAP/UP } \\
\hline & Baseline & Experimental & Baseline & Experimental & Baseline & Experimental \\
\hline Cardiac output & $221 \pm 33$ & $217 \pm 24$ & $220 \pm 44$ & $213 \pm 43$ & $221 \pm 38$ & $222 \pm 42$ \\
\hline Heart rate & $308 \pm 30$ & $289 \pm 33$ & $260 \pm 45$ & $251 \pm 37$ & $244 \pm 16$ & $273 \pm 37$ \\
\hline Hemalocril & $33 \pm 3$ & $30 \pm 4^{*}$ & $33 \pm 5$ & $35 \pm 8$ & $34 \pm 4$ & $41 \pm 9^{*}$ \\
\hline \multicolumn{7}{|c|}{ Organ blood flows } \\
\hline Myocardium & $338 \pm 103$ & $375 \pm 84$ & $276 \pm 81$ & $275 \pm 66$ & $322 \pm 121$ & $270 \pm 93$ \\
\hline Liver & $3 \pm 3$ & $3 \pm 2$ & $3 \pm 3$ & $5 \pm 7$ & $2 \pm 1$ & $2 \pm \quad 2$ \\
\hline Gr tract & $148 \pm 42$ & $170 \pm 43$ & $141 \pm 38$ & $135 \pm 27$ & $148 \pm 62$ & $151 \pm 62$ \\
\hline Kidneys & $389 \pm 136$ & $363 \pm 122$ & $367 \pm 125$ & $359 \pm 98$ & $362 \pm 140$ & $434 \pm 155$ \\
\hline Brain & $121 \pm 18$ & $137 \pm 21^{*}$ & $109 \pm 27$ & $104 \pm 24$ & $102 \pm 23$ & $82 \pm 21^{*}$ \\
\hline Skin & $11 \pm 3$ & $14 \pm 4$ & $11 \pm 4$ & $11 \pm 3$ & $11 \pm 2$ & $11 \pm 4$ \\
\hline Carcass & $28 \pm 8$ & $22 \pm 5$ & $23 \pm 7$ & $22 \pm 7$ & $24 \pm 8$ & $23 \pm 9$ \\
\hline Placentas & $168 \pm 33$ & $229 \pm 95$ & $150 \pm 66$ & $162 \pm 47$ & $160 \pm 59$ & $173 \pm 56$ \\
\hline Myometrium & $23 \pm 11$ & $26 \pm 9$ & $17 \pm 10$ & $16 \pm 9$ & $18 \pm 11$ & $15 \pm 4$ \\
\hline
\end{tabular}

$p<0.05$ Post-procedure value different from baseline (Wilcoxon Signed Rank Test) 
groups. None of the other hemodynamic variables had changed. The correlation between the observed hemodynamics on the one hand, and Hct and MAP on the other was tested for all animals by multiple regression. The change in cerebral blood flow $(\delta \mathrm{CBF})$ correlated negatively $(\delta \mathrm{CBF}=-2.24 \delta \mathrm{Hct} 2,25 ; \mathrm{r}=0.68$; $\mathrm{p}<0.01)$, and that in renal blood flow $(\delta \mathrm{RBF})$ positively with the change in $\mathrm{Hct}$ $(\delta \mathrm{RBF}=9,87 \delta \mathrm{Hct} 11,13 ; \mathrm{r}=0.62 ; \mathrm{p}<0.01)$. None of the other hemodynamic variables including the change in UBF showed a correlation with the change in Hct.

With respect to the change in MAP, only the changes in HR were found to correlate with the changes in MAP $(\delta B P=0.11 \delta \mathrm{HR}+0.82 ; \mathrm{r}=0.49, \mathrm{p}<0.05)$. None of the changes in weight-specific organ flows varied as a function of MAP, including those to the placenta and the myometrium (fig 1).

By separate analysis in the animals with at least $10 \%$ change in MAP, $\delta \mathrm{HR}$ $(r=0.70 ; p<0.05)$ and $\delta \mathrm{O}_{2}$ content $(r=0.65 ; p<0.05)$ were found to correlate positively, with the change in MAP. All weight-specific organ flows, as well as renal plasma flow and cerebral $\mathrm{O}_{2}$ delivery, varied independently of $\delta \mathrm{MAP}$.

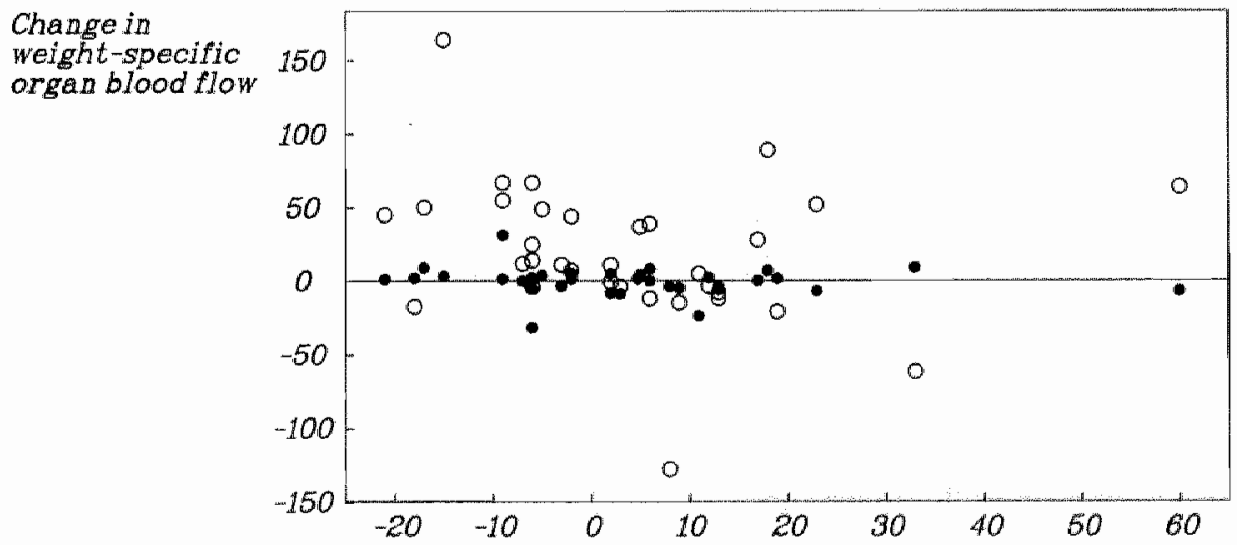

Figure I

Change in mean arterial pressure

Changes in weight-specific organ blood flow ( $\left.\mathrm{ml}^{\mathrm{min}} \mathrm{m}^{-t} .100 \mathrm{~g}^{-1}\right)$ to the uteroplacental vascular bed $(\bigcirc)$ and the myometrium ( ) at various changes in mean arterial pressure (\%) $(n=33)$. 


\section{Discussion}

The aim of this study was to evaluate the effect of changes in MAP on LBF, when MAP changes occurred without pharmacological intervention. It was expected that this approach would have a more selective effect on MAP, thus reducing the risk for interference of the methodology with the locally operative autoregulation. The limited covariance between MAP and Hct and the variable direction of the MAP change in response to isovolemic hemodilution, hemoconcentration and the sham procedure, suggested that the observed change in MAP was coincidental rather than related to the procedure. On the other hand HR increased with MAP, indicating that the changes in MAP may have been related to changes in sympathetic activity. Therefore, a superimposed influence of the sympathetic tone on UBF can not be excluded.

The negative correlation between $\delta \mathrm{CBF}$ and $\delta \mathrm{Hct}$, together with the absence of a relationship between the residual variation in $\delta$ CBF and $\delta \mathrm{MAP}$, supports the influence of cerebral $\mathrm{O}_{2}$ delivery on the cerebral autoregulatory response (25). Similarly, $\delta \mathrm{RBF}$ changed in the same direction as the Hct, with no additional contribution to this relationship of the concomitant changes in MAP. This observation supports that RBF appears to be influenced by the concomitantly autoregulated glomerular pressure and filtration $(3,26)$.

By the 2 statistical approaches employed, it was demonstrated that the observed changes in other organs, myometrium and placentas included, neither correlated with $\delta$ Hct nor $\delta$ MAP. This implies that the weight-specific blood flow to the labyrinthine placentas together with that to the myometrium and all other organs, vary independently of the MAP over the spectrum of MAP changes evaluated in the present study. Support for local control of placental blood flow comes from the "spontaneous" intermittent functional patency of the arteries supplying the intervillous space (19) which resembles the phenomenon of vasomotion in capillary microcirculations. However, the much larger fluctuations in UBF relative to those in myometrial flow (fig 1), could indicate that the autoregulatory response of the placental vascular bed is less tight and thus is more easily disturbed. This brings up an important aspect of autoregulation. A complete autoregulatory response not only controls the buffering of changes in hydrostatic and transorgan exchange pressure, but also alterations in volume flow and capillary fluid exchange (1). The latter 2 characteristics require adjustment of perfusion pressure and capillary recruitment. In capillary microcirculations, this is achieved by feedback mechanisms which are triggered both at the exchange site and in the venules, sorting their effects on precapillary sphincters and small arterioles. A rise in venous pressure activates the so-called venous- 
arteriolar reflex (6), causing arteriolar constriction and closure of some precapillary sphincters, to restore the balance of Starling forces. Complete autoregulation of UBF would require a functional communication between the precotelydonary resistance vessels on the one hand, and both intervillous space and placental venous outflow, on the other. Since the intervillous space and its venous drainage is located beyond the anatomic divide between maternal and fetal blood streams, activation of feedback mechanisms in these structures or in the distal portion of the spiral artery appears highly unlikely. Therefore, it is more plausible that the placental autoregulatory response consists only of a myogenic response induced in the radial arteries and proximal portion of the spiral artery, which may be more refined by its coil-shape. The presumed lack of feedback that originates from downstream the spiral artery, would imply that UBF is particularly vulnerable to changes in venous pressure. This is also suggested by recent observations in awake near-term rat where an artificial increase in venous pressure (27) led to massive selective intralabyrinthine congestion and villous compression. 


\section{References}

1. Lundvall 1989 Myogenic mechanisms in the control of systemic resistance and transcapillary fluid exchange. J Hypertension 7 (suppl 4):S85-S91.

2. Mellander $\mathbf{S} 1989$ Functional aspects of myogenic vascular control. J Hypertension. 7 (Suppl 4):\$21-\$30.

3. Aukland $\mathrm{K}$, Oein AH 1987 Renal autoregulation:models combining tubuloglomerular feedback and myogenic response. Am J Physiol 252:F768-F783.

4. Faraci FM, Baumbach GL, Heistad DD 1989 Myogenic mechnaisms in the cerebral circulation. J Hypertension 7 (suppl 4):S61-S64.

5. Feigl EO 1989 Coronary autoregulation. J Hypertension 7 (suppl 4): S55-S58.

6. Johnson PC 1986 Autoregulation of blood flow. Circ Res 59: 483-495.

7. Lundgren O 1989 Autoregulation of intestinal blood flow: Physiology and pathophysfology. JHypertension 7 (suppl 4):S79-\$84.

8. Ramsey EM, Donner MW 1980 Placental vasculature and circulation. Stuttgart: Georg Thieme Publishers, 1980.

9. Meschia G 1973 Circulation to female reproductive organs. In: Hamilton WF Dow $\mathrm{P}$ (eds), Handbook of physiology The cardiovascular system 1II. Whasington DC: American Physiological Society 1973:241-269.

10. Greiss jr F 1966 Pressure-flow relationship in the gravid uterine vascular bed. Am J Obst Gynecol $96: 41-47$.

11. Bruce NW, Abdul-Karim RW 1974 Mechanisms controlling maternal placental circulation. Clin Obstet Gynecol 17(3):135-151.

12. Venuto RC, Cox JW, Stein JH, Ferris TF 1976 The effect of changes in perfusion pressure on uteroplacental blood flow in the pregnant rabbit. J Clin Invest 57:938-944.

13. Ladner C, Brinkman III CR, Weston P, Assali NS 1970 Dynamics of uterine circulation in pregnant and nompregnant sheep. Am J Physiol 218(1):257-263.

14. Berman W, Goodlin RC, Heymann MA, Rudolph AM 1976 Relationships between pressure and flow in the umbilical and uterine circulations of the sheep. Circ Res $38(4)$ "262-266"

15. Herberger $\mathrm{J}$, Moll $\mathrm{W} 1976$ The flow resistance of the maternal placental vascular bed of anesthetized guinea pigs. Z Geburtsh Perinatol 180:61-66.

16. Assali NS 1989 Dynamics of the uteroplacental circulation in health and disease. Am J Perinatol 6(2): 105-109.

17. Moll W, Künzel W 1973 The blood pressure in arteries entering the placentae of guinea pigs, rats, rabbits and sheep. Pflügers Arch 388:125-131.

18. Moll W, Künzel W, Stolte LAM, Kleinhout J, de Jong PA, Veth AFL 1974 The blood pressure in the decidual part of the uteroplacental arteries (spiral arteries) of the rhesus monkey. Pflügers Arch 346:291-297.

19. Martin CB, McGaughey HS, Kaiser IH, Donner MW, Ramsey EM 1964 Intermittent functioning of the uteroplacental arteries. Am J Obstet Gynecol 90:819-823. 


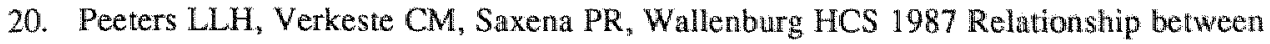
matemal hemodynamics and hematocrit and hemodynamic effects of isowolemic hemodilution and hemoconcentration in the awake late pregnant guinea pig. Pediatr Res $21(6): 584-589$.

21. Verkeste CM, Boekkooi PF, Saxena PR, Peeters LLH 1990 Increased red cell aggregability does not reduce uteroplacental blood flow in the awake hemoconcentrated late-pregnant guinea pig. Submitted for publication in Pediatr Res.

22. Peeters LLH, Mårtensson L, van Kreel BK, Wallenburg HCS 1984 Uterine arterial and venous concentration of glucose, Lactate, ketones, free fatty acids and oxygen in the awake late pregnant guinea pig. Pediatr Res 18:1172-1175.

23. Peeters LLH, Grutters $\mathrm{G}$, Martin CB 1980 The distribution of cardiac output in the unstressed guinea pig. Am J Obstet Gynecol 138:1177-1184.

24. Saxena PR, Schamhardt HC, Forsyth RP, Loeve $J 1980$ Computer programs for the radioactive microsphere technique. Determination of regional blood flow and other hemodynamic variables in different experimental conditions. Comp Prog Biomed 12:63-84.

25. Kontos HA, Wei EP, Raper AJ, Rosenblum WI, Navari RM, Patterson JL 1978 Role of tissue hypoxia in local regulation of cerebral microcirculation. Am J Physiol 234: H582-H591.

26. de Wardener HE. The kidney. New York: Churchill Livingstone 1985:118-119.

27. Boekkooi PF, Verkeste CM, Saxena PR, Kaufman P, Peeters LLH 1990 The effects of steady-state hypervolemia on regional blood flows in awake late-pregnant and nonpregnant rats. Submitted for publication in Pediatr Res. 


\section{Summary and conclusions}

\section{Samenvatting en conclusies}

\section{Summary and conclusions}

The fluidity (rheology) of blood (hemorheology) is primarily determined by hematocrit, red cell deformability and red cell aggregation. Rheological factors are thought to play an important role in tissue perfusion, particularly in organs with a relatively "slow flow" and impaired or absent vasomotor control (autoregulation). It is generally assumed that the maternal side of the (hemochorial) placenta (uteroplacenta) lacks autoregulation and that the arterial supply to the intervillous space is maximally dilated. Theoretically, this would imply that the uteroplacental circulation may be vulnerable to disturbances in rheological parameters such as hematocrit, red cell deformability and red cell aggregability. This in turn could have important clinical implications when the placenta is only marginally perfused. In these conditions, improvement of the bloods' fluidity may increase intervillous perfusion and with it contribute to fetal well-being.

Several investigators studied the relationship between hemorheological parameters and fetal well-being and/or outcome. However, their observations were always based on ex vivo blood measurements, which can not be extrapolated to local tissue perfusion. In addition, the ex vivo observations were conflicting, and the impact of those parameters on uteroplacental blood flow was never determined.

In the present studies we hypothesized that an unfavorable rheological environment such as an augmented maternal hematocrit, a reduced red blood cell deformability and an elevated red blood cell aggregability interferes with uteroplacental perfusion, and vice versa (figure 1). To this end, hematocrit, red cell deformability and red cell aggregability were manipulated selectively in vivo in order to study their independent impact on uteroplacental blood flow in awake late-pregnant guinea pigs. The guinea pig was chosen because of its 


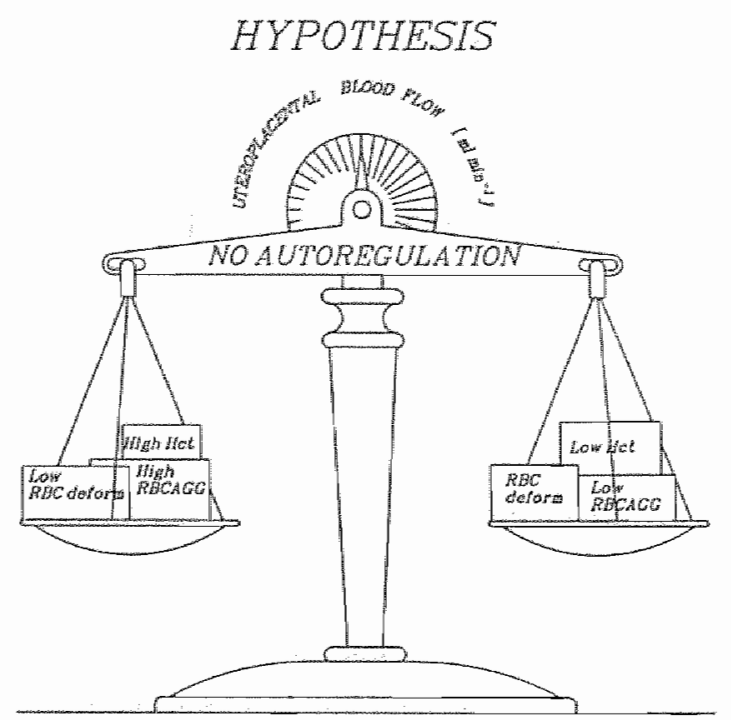

Figure 1

hemochorial lacuneous labyrinthine uteroplacental microarchitecture, resembling that of men. The perfusion of the uteroplacenta, and other organs, was determined with $15 \mu \mathrm{m}$ radioactive microspheres before and after manipulating either maternal Hct, red cell deformability or red cell aggregation. The systemic leakage of radioactive microspheres over the period of study did not invalidate the derived blood flow measurements obtained with this technique (Chapter 2).

When hematocrit was varied isovolemically between 26 and 42 vol\%, no correlation between hematocrit and uteroplacental blood flow could be demonstrated (Chapter 3). Subsequently, the impact of red blood cell deformability on uteroplacental perfusion was evaluated. To this end, preferential entrapment of artificially hardened red blood cells in the trophoblastic lacunae, and the concomitant effect on uteroplacental blood flow was investigated (Chapter 4).

Rigidified red blood cells, did not become preferentially entrapped in the uteroplacental microcirculation, as compared to normal deformable red cells. Neither did their injection into the systemic circulation interfere with the uteroplacental perfusion.

Finally, the effect of an increased red cell aggregability on uteroplacental perfusion was evaluated (Chapter 5). Increasing the tendency of red blood cells to aggregate, with high molecular-weight dextran, did not reduce uteroplacental perfusion. 
The absence of a measurable effect of rheological manipulation on uteroplacental blood flow raised doubt about the still commenly accepted lack in uteroplacental autoregulation. Therefore, the uteroplacental flow-pressure relationship was evaluated in a separate study, using the unresponsiveness of uteroplacental blood flow to variation in hematocrit and the small covariance between hematocrit and mean arterial pressure (Chapter 6). Uteroplacental blood flow was found to vary independently of increases and decreases in blood pressure ( $\pm 20 \%$ from baseline), supporting the concept that uteroplacental microcirculation is autoregulated in awake late-pregnant guinea pigs. The previously observed lack of change in uteroplacental blood flow in response to rheological manipulation provides additional support for uteroplacental autoregulation (figure 2 ). However, these data do not exclude an effect of rheological parameters on uteroplacental blood flow in a pathologically changed placenta where uteroplacental autoregulation may be either impaired, overruled or even absent. Therefore, whether rheological factors influence placental perfusion when the placenta is hypoperfused and/or histologically damaged remains to be determined.

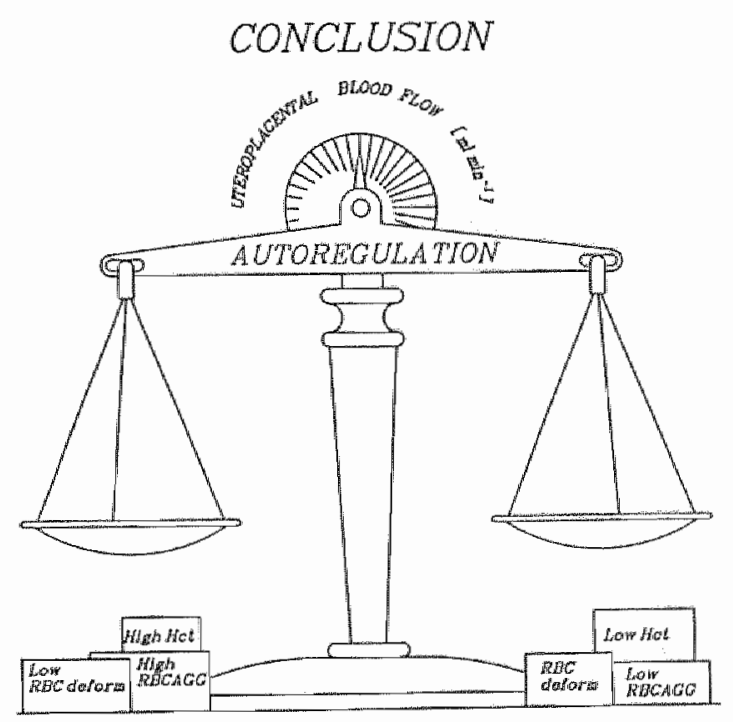

Figure 2 


\section{Samenvatting en conclusies}

De rode cel concentratie (hematocriet) alsmede de vervormbaarheid en de neiging tot aggregatie van deze cellen bepalen voor een belangrijk deel het stroomgedrag (rheologie) van het bloed (hemorheologie). Met name in organen waar de stroomsnelheid van het bloed laag is, en de drukgradient over het orgaan niet constant gehouden wordt d.m.v. autoregulatie is beschreven dat bovengenoemde rheologische factoren de doorstroming van het orgaan kunnen beinvloeden. Aan de moederlijke zijde van de placenta (uteroplacenta) wordt verondersteld dat autoregulatie afwezig is, en de aanvoerende vaten naar de placenta maximaal verwijd zijn. Theoretisch zou tengevolge hiervan de uteroplacentaire doorstroming gevoelig zijn voor veranderingen in hematocriet, rode cel vervormbaarheid en rode cel aggregatie. Dit zou belangrijke klinische gevolgen kunnen hebben wanneer de placenta een slechte doorstroming heeft. Verbetering van de rheologische omstandigheden zouden dan leiden tot een verbeterde placenta doorstroming en mogelijk tot een betere conditie van de foetus.

In het verleden zijn reeds diverse studies uitgevoerd waarbij de relatie tussen rheologische factoren en de conditie van de foetus en/of geboortegewicht werd onderzocht. De resultaten van deze studies waren echter gebaseerd op ex vivo metingen, en vertoonden onderling vele tegenstrijdigheden.

De hypothese van de in dit proefschrift beschreven studies is dat hematocriet, rode cel vervormbaarheid en rode cel aggregatie de placenta doorstroming beinvloeden door de afwezigheid van autoregulatie in dit vaatbed (figuur 1). Dientengevolge werden hematocriet, rode cel vervormbaarheid en rode cel aggregatie selectief in vivo gemanipuleerd in diverse groepen drachtige cavia's. De cavia werd voor dit onderzoek het meest geschikte proefdier geacht vanwege de gelijkenis in placenta structuur met de mens (hemomonochoriaal). De doorstroming van de placenta, alsmede die van overige organen, werd gemeten met $15 \mu \mathrm{m}$ radioactieve microspheren vò̀r- en na manipulatie van de rheologische factoren. De lekkage van radioactieve deeltjes uit de placenta gedurende de experimenten werd verondersteld de bioeddoorstromings metingen niet te beinvloeden (Hoofdstuk 2).

Isovolemische veranderingen in hematocriet tussen 26 en 42 vol\%, leidden niet tot veranderingen in uteroplacentaire doorstroming (Hoofdstuk 3). Vervol- 
gens werd het effect van rode cel vervormbaarheid op de uteroplacentaire doorstroming bekeken. Hiertoe werd een mengsel van kunstmatig geharde cellen en normaal vervormbare cellen in de bloedstroom ingespoten, en gekeken of de geharde rode cellen selectief in het uteroplacentaire vaatbed vastliepen. De geharde cellen bleken niet in het uteroplacentaire vaatbed te blijven steken en veroorzaakten daardoor geen verlaging van de placenta doorstroming (Hoofdstuk 4). Tenslotte werd het effect van een verhoogde rode cel aggregatie op de uteroplacentaire doorstroming bekeken. Een verhoogde aggregatie neiging van de cellen, teweeg gebracht door injectie van dextraan met een hoog molecuul gewicht, leidde niet tot een verlaging van de placenta doorstroming (Hoofdstuk 5).

Daar geen van de rheologische manipulaties de uteroplacentaire doorstroming leek te beinvloeden, werd getwijfeld aan de afwezigheid van autoregulatie in de placenta en werd de druk-doorstromings relatie in een aparte studie bekeken. Hierbij werd gebruik gemaakt van de onafhankelijkheid tussen placenta doorstroming en hematocriet veranderingen, en de kleine covariantie tussen hematocriet en bloeddruk (Hoofdstuk 6). Over het traject van de bloeddruk, $20 \%$ beneden tot $20 \%$ boven het gemiddelde, waren veranderingen in de bloeddruk niet gerelateerd aan verandering in de uteroplacentaire doorstroming. Het is daarom waarschijnlijk dat de uteroplacentaire doorstroming in dit onderzochte bloeddruk interval geautoreguleerd is. De aanwezigheid van autoregulatie in het uteroplacentaire vaatbed wordt benadrukt door de afwezigheid van veranderingen in de doorstroming van dit vaatbed na rheologische manipulatie (figuur 2). Het kan echter niet uitgesloten worden dat rheologische factoren wel een rol spelen bij de doorstroming van de placenta indien deze autoregulatie door een pathologische oorzaak verstoord of zelfs afwezig is. Of rheologische factoren de doorstroming van de placenta beinvloeden, indien placenta doorstroming laag is en/of de placenta histologisch beschadigd dient dan ook nader onderzocht te worden. 


\section{Ter afsluiting}

De meeste bijdrage aan het tot standkomen van dit proefschrift heeft wellicht mijn co-promoter Dr L.L.H. Peeters geleverd.

Louis, om mij naar Maastricht te krijgen heb je iedereen daar ervan moeten overtuigen hoe "goed" ik wel niet was, ik hoop dan ook dat ik je naam hoog gehouden heb. Het enthousiasme en de inzet voor je werk die jij op anderen weet over te brengen, zijn vaak mijn grootste drijfveer geweest.

Prof.Dr J. de Haan heb ik vaak betiteld als "Pa", niet alleen omdat hij op sommige vlakken gelijkenis vertoont met de karaktertrekken van mijn eigen vader, maar tevens omdat hij ons onderzoekers als een vader achter de vodden kon zitten en ons op zijn tijd, terecht of niet, een "draai om de oren" of een "aai over de bol" wist te geven.

Mijn collegae Hans van Huisseling, Guido Muysers en Focco Boekkooi hebben mij tijdens mijn promotieonderzoek morele ondersteuning verleend door altijd te zeggen "Ja, dat heb ik ook", zij wisten immers waar zij over praatten.

De ontwerper van de omslag en de illustraties is mijn ex-buur en vriend Raymond Ritzen. Ik waardeer het dat hij hier veel van zijn vrije tijd in heeft gestoken.

Iemand die ik zeker niet wil vergeten in dit dankwoord is mijn pendel-genoot Ineke Klöpping-Ketelaars. Ien, het gekwebbel in de trein en tijdens onze lunch als meiden onder elkaar, waarbij we elkaar vaak door een research-depressie heen moesten slepen, is altijd een enorme steun voor me geweest.

Mijn ouders, Freek en Bep, wil ik graag bedanken voor hun geëmancipeerde opvoeding en hun vriendschap. Altijd hebben zij geprobeerd om daar te zijn waar ik, en later ook René, hen nodig had. Hun motto's "Waar je aan begint maak je af" en "Zorg goed voor je zelf, want een ander doet het niet voor je" hebben zeker geleid tot het resultaat was thans voor u ligt.

Helaas mocht ik mijn "dikste" vriend niet bedanken. 


\section{Curriculum Vitae}

Carla Verkeste werd geboren op 6 december 1960 te Rotterdam. Na voltooiing van de middelbare school in Spijkenisse, Openbaar scholengemeenschap de Ring van Putten (MAVO, HAVO), werd in 1978 aangevangen met de Hogere Beroepsopleiding-a in de biochemische studierichting aan het van Leeuwenhoek instituut te Delft. De vereiste stage periode werd volbracht in het Medisch Biologisch Laboratorium van TNO te Rijswijk, o.l.v. Dr J.L.F. Gerbrandy. Vanaf 1981 werd in de avonduren aangevangen met een chemie studie aan de Hogere Technische School, van 't Hoff instituut te Rotterdam. Overdag was zij werkzaam als biochemisch analiste bij de afdeling Experimentele Cardiologie van de Erasmus Universiteit Rotterdam, o.l.v. Prof.Dr P.D. Verdouw. In 1984 werd deze aanstelling voortgezet op de afdeling Gynaecologie en Obstetrie van de Erasmus Universiteit Rotterdam, o.l.v. Prof.Dr H.C.S. Wallenburg. De chemie studie aan de Hogere Technische School werd in 1986 met goed gevolg beeindigd. Vanaf 1987 is de schrijfster als onderzoeksmedewerkster in dienst van de afdeling Gynaecologie en Obstetrie aan de Rijksuniversiteit Limburg, o.l.v. Prof.Dr J. de Haan. 